DALE W. JORGENSON

Harvard University

KEVIN J. STIROH

Federal Reserve Bank of New York

\title{
Raising the Speed Limit: U.S. Economic Growth in the Information Age
}

THE CONTINUED STRENGTH and vitality of the U.S. economy continue to astonish economic forecasters. ${ }^{1}$ A consensus is now emerging that something fundamental has changed, with "new economy" proponents pointing to information technology (IT) as the causal factor behind the strong performance. In this view, technology is profoundly altering the nature of business, leading to permanently higher productivity growth throughout the economy. Skeptics remain, however, arguing that the recent success reflects a series of favorable, but temporary, shocks. This argument is buttressed by the view that the U.S. econ-

We are indebted to Mun Ho for his comments and assistance with the industry and labor data. We are also grateful to Robert Arnold of the Congressional Budget Office for helpful comments and discussions of that agency's results and methods, and to Bruce Grimm and David Wasshausen of the Bureau of Economic Analysis for details on their agency's investment data and prices. Our thanks are due also to Erwin Diewert, Robert Gordon, Stephen Oliner, Daniel Sichel, and Kun-Young Yun, as well as to seminar participants at the Brookings Panel, the Federal Reserve Bank of New York, and the Federal Reserve Board for helpful comments and advice. David Fiore provided excellent research assistance. The views expressed in this paper are those of the authors only and do not necessarily reflect the views of the Federal Reserve Bank of New York or the Federal Reserve System.

1. Labor productivity growth for the business sector averaged 2.7 percent per year during 1995-99. These four years recorded the four fastest annual productivity growth rates in the 1990s, except for a temporary jump of 4.3 percent in 1992 as the economy exited the 1990-91 recession (Bureau of Labor Statistics, 2000). 
omy behaves rather differently than envisioned by the "new economy" advocates. $^{2}$

Productivity growth, capital accumulation, and the impact of technology were topics once reserved for academic debates, but the recent success of the U.S. economy has moved them into popular discussion. This paper employs well-tested and familiar methods to analyze important new information made available by the recent benchmark revision of the U.S. national income and product accounts (NIPAs). We document the case for raising the speed limit: for an upward revision of intermediate-term projections of future growth to reflect the latest data and trends.

The late 1990s were exceptional in comparison with the growth experience of the U.S. economy over the past quarter century as a whole. Although growth rates have not yet returned to those of the golden age of the U.S. economy in the 1960s, the data nonetheless clearly reveal a remarkable transformation. Rapid declines in the prices of computers and semiconductors are well known and carefully documented, and evidence is accumulating that similar declines are taking place in the prices of software and communications equipment. Unfortunately, the empirical record is seriously incomplete, and therefore much remains to be done before definitive quantitative assessments can be made about the complete role of these high-technology assets.

Despite the limitations of the available data, the mechanisms underlying the structural transformation of the U.S. economy are readily apparent. As an illustration, consider the increasing role that computer hardware plays as a source of economic growth. ${ }^{3}$ For the period 1959-73, computer inputs contributed less than 0.1 percentage point to annual U.S. economic growth. Since 1973, however, the price of computers has fallen at a historically unprecedented rate, and firms and households, following a basic principle of economics, have substituted toward these relatively cheaper

2. Stiroh (1999) critiques alternative views on the new economy, Triplett (1999) examines some data issues in the new economy debate, and Gordon (1999b) provides an often-cited rebuttal of the new economy thesis.

3. Our work on computers builds on the path-breaking research of Oliner and Sichel (1994, 2000) and Sichel $(1997,1999)$ and our own earlier results, reported in Jorgenson and Stiroh $(1995,1999,2000)$ and Stiroh (1998a). Other valuable work on computers includes that of Haimowitz (1998), Kiley (1999), and Whelan (2000). Gordon (1999a) provides a historical perspective on the sources of U.S. economic growth, and Brynjolfsson and Yang (1996) review the microeconomic evidence on computers and productivity. 
inputs. Since 1995 the price decline for computers has accelerated, reaching nearly 28 percent per year from 1995 to 1998. In response, investment in computers has exploded, and the growth contribution of computer hardware has increased more than fivefold, to 0.46 percentage point per year in the late 1990s. ${ }^{4}$ Software and communications equipment, two other types of IT assets, contributed an additional 0.30 percentage point per year for 1995-98. Preliminary estimates through 1999 reveal further increases in these contributions for all three high-technology assets.

Next, consider the acceleration of average labor productivity (ALP) growth in the 1990s. After a twenty-year slowdown dating from the early 1970s, ALP grew 2.4 percent per year during 1995-98, more than a percentage point faster than during 1990-95..$^{5}$ A detailed decomposition shows that capital deepening, the direct consequence of price-induced substitution and rapid investment, added 0.49 percentage point to ALP growth. Faster total factor productivity (TFP) growth contributed an additional 0.63 percentage point, partly reflecting technical change in the production of computers and the resulting acceleration in their price decline. Meanwhile, slowing growth in labor quality retarded ALP growth by 0.12 percentage point relative to the early 1990s, as employers exhausted the pool of available workers.

TFP growth had been an anemic 0.34 percent per year for 1973-95 but accelerated to 0.99 percent for 1995-98. After more than twenty years of sluggish TFP growth, four of the five years ending in 1998 saw growth rates near 1 percent. It could be argued that this represents a new paradigm. In this view, the diffusion of IT improves business practices, generates spillover benefits, and raises productivity throughout the economy. If this trend is sustainable, it could revive the optimistic expectations of the 1960s and overcome the pessimism of the "Age of Diminished Expectations," as an influential book at the beginning of the 1990s called the era of the productivity slowdown. ${ }^{6}$

4. See Baily and Gordon (1988), Stiroh (1998a), Jorgenson and Stiroh (1999), and U.S. Department of Commerce (1999) for earlier discussions of relative price changes and input substitution in the high-technology areas.

5. The Bureau of Labor Statistics' (2000) estimates for the business sector show a similar increase, from 1.6 percent per year for 1990-95 to 2.6 percent for 1995-98. See Council of Economic Advisers (2000, p. 35) for a comparison of productivity growth at various points in the economic expansions of the 1960s, 1980s, and 1990s.

6. Krugman (1990). 
A closer look at the data, however, shows that gains in TFP growth can be traced in large part to IT industries, which produce computers, semiconductors, and other high-technology gear. The evidence is equally clear that computer-using industries such as finance, insurance, and real estate (FIRE) and other services have continued to lag in productivity growth. Reconciling the massive investment in high technology with the relatively slow productivity growth observed in service industries remains an important task for proponents of the "new economy" position. ${ }^{7}$

What does this imply for the future? The sustainability of growth in labor productivity is the key issue for future growth projections. For some purposes, the distinctions among capital accumulation and growth in labor quality and TFP may not matter, so long as ALP growth can be expected to continue. It is sustainable labor productivity gains, after all, that ultimately drive long-run growth and raise living standards.

In this respect, the recent experience provides grounds for caution, since much depends on productivity gains in high-technology industries. Ongoing technological advances in these industries have been a direct source of improvement in TFP growth, as well as an indirect source of more-rapid capital deepening. The sustainability of this growth, therefore, hinges critically on the future pace of technological progress in these industries. As measured by relative price changes, this progress has accelerated recently: the 28 percent per year decline in computer prices during 1995-98, mentioned above, compares with only a 15 percent per year decline in 1990-95. There is no guarantee, of course, of continued productivity gains and price declines of this magnitude. Nonetheless, as long as high-technology industries maintain the ability to innovate and improve their productivity at rates comparable even to their long-term averages, relative prices will fall, and the virtuous circle of an investment-led expansion will continue. ${ }^{8}$

Finally, we argue that the rewards from new technology accrue to the direct participants: first, to the innovating industries producing the high-

7. See Gullickson and Harper (1999), Jorgenson and Stiroh (2000), and below for industry-level analyses.

8. There is no consensus, however, that technical progress in computer and semiconductor production is slowing. According to Lawrence M. Fisher ("New Era Approaches: Gigabyte Chips." New York Times, February 7, 2000, p. C8), chip processing speed continues to increase rapidly. Moreover, the product cycle is accelerating as new processors are being brought to market more quickly. 
technology assets, and second, to the industries that restructure to implement the latest technology. There is little evidence of spillovers from production of IT to the industries that use this technology. Indeed, many of the industries that use IT most intensively, such as FIRE and other services, show high rates of substitution of IT for other inputs but relatively low rates of productivity growth. In part, this may reflect problems in measuring the output of these industries, but the empirical record provides little support for the "new economy" picture of spillovers cascading from IT producers onto users of this technology. ${ }^{9}$

This paper is organized as follows. The next section describes our methodology for quantifying the sources of U.S. economic growth. We present results for the period 1959-98 and focus on the period of the late 1990s. We then explore the implications of the recent experience for future growth, comparing our results with recent estimates by the Congressional Budget Office, the Council of Economic Advisers, and the Office of Management and Budget. Finally, we move beyond the aggregate data to quantify productivity growth at the industry level. Using methodology first introduced by Evsey Domar, we consider the impact of IT on aggregate productivity.

\section{The Recent U.S. Growth Experience}

The U.S. economy has undergone a remarkable transformation in recent years, with growth in output, labor productivity, and TFP all accelerating since the mid-1990s. This growth resurgence has led to a widening debate about the sources of this growth and whether profound changes are taking place in the structure of the economy. Proponents of the view that we are in a "new economy" trace the increased growth to developments in IT, especially the rapid commercialization of the Internet, which they claim are fundamentally changing economic activity. "Old economy" advocates focus on the lackluster performance during the first half of the 1990s, the increase in labor force participation and the rapid decline in unemployment since 1993, and the recent investment boom.

9. See Dean (1999) and Gullickson and Harper (1999) for the Bureau of Labor Statistics' perspective on measurement error; Triplett and Bosworth (2000) provide an overview of measuring output in the service industries. 
Our objective here is to quantify the sources of the recent surge in U.S. economic growth, using new information made available by the benchmark revision of the NIPAs released in October 1999 by the Bureau of Economic Analysis (BEA). ${ }^{10}$ We then consider the implications of our results for intermediate-term projections of U.S. economic growth. We give special attention to the rapid escalation in growth rates in the official projections, such as those by the Congressional Budget Office (CBO) and the Council of Economic Advisers (CEA). The CBO projections are particularly suitable for our purposes, since they are widely disseminated, are well documented, and represent best practice. We do not focus on the issue of inflation and do not comment on potential implications for monetary policy.

\section{Sources of Economic Growth}

Our methodology is based on the production possibilities frontier introduced by Dale Jorgenson and first employed by Jorgenson and Zvi Griliches. ${ }^{11}$ This captures substitutions among outputs of investment and consumption goods, as well as between inputs of capital and labor. We identify IT with investments in computers, software, and communications equipment, as well as consumption of computers and software as outputs. The service flows from these assets are also inputs. The aggregate production function employed by Robert Solow and, more recently, by Jeremy Greenwood, Zvi Hercowitz, and Per Krusell, is an alternative to our model. ${ }^{12}$ In their approach a single output is expressed as a function of capital and labor inputs. This implicitly assumes, however, that investments in IT are perfect substitutes for other outputs, so that relative prices do not change.

Our methodology is essential in order to capture two important facts about which there is general agreement. The first is that prices of computers have declined drastically relative to the prices of other investment goods. The second is that this rate of decline has recently accelerated. In addition, estimates of investment in software, now available in the NIPAs, are comparable to investment in hardware. The new data show that the price of software has fallen relative to the prices of other investment goods,

10. Data are available at www.bea.doc.gov.

11. Jorgenson (1966); Jorgenson and Griliches (1967).

12. Solow (1957, 1960); Greenwood, Hercowitz, and Krusell (1997). 
but more slowly than the price of hardware. We examine the estimates of software investment in some detail in order to assess the role of software in recent economic growth. Finally, we consider investment in communications equipment, which shares many of the technological features of computer hardware.

THE PRODUCTION POSSIBILITIES FRONTIER. Aggregate output $Y_{t}$ consists of investment goods $I_{t}$ and consumption goods $C_{t}$. These outputs are produced from aggregate input $X_{t}$, consisting of capital services $K_{t}$ and labor services $L_{t}$. We represent productivity as a Hicks-neutral augmentation $A_{t}$ of aggregate input: ${ }^{13}$

$$
Y\left(I_{t}, C_{t}\right)=A_{t} \cdot X\left(K_{t}, L_{t}\right) .
$$

The outputs of investment and consumption goods and the inputs of capital and labor services are themselves aggregates, each with many subcomponents.

Under the assumptions of competitive product and factor markets and constant returns to scale, growth accounting gives the share-weighted growth of outputs as the sum of the share-weighted growth of inputs and growth in TFP:

$$
\bar{w}_{l, t} \Delta \ln I_{t}+\bar{w}_{C, t} \Delta \ln C_{t}=\bar{v}_{K, t} \Delta \ln K_{t}+\bar{v}_{L, t} \Delta \ln L_{t}+\Delta \ln A_{t},
$$

where $\bar{w}_{I, t}$ is investment's average share of nominal output, $\bar{w}_{C, t}$ is consumption's average share of nominal output, $\bar{v}_{K, t}$ is capital's average share of nominal income, $\bar{v}_{L, t}$ is labor's average share of nominal income, $\bar{w}_{I, t}+\bar{w}_{C, t}=\bar{v}_{K, t}+\bar{v}_{L, t}=1$, and $\Delta$ refers to a first difference. Note that we reserve the term TFP for the augmentation factor in equation 1.

Equation 2 enables us to identify the contributions of outputs as well as of inputs to economic growth. For example, we can quantify the contributions of different investments, such as computers, software, and communications equipment, to the growth of output by decomposing the growth of investment among its subcomponents. Similarly, we can quantify the contributions of different types of consumption, such as services from computers and software, by decomposing the growth of consump-

13. It would be a straightforward change to make technology labor-augmenting, or Harrod-neutral, so that the production possibilities frontier could be written as $Y(I, C)=$ $X(K, A L)$. Also, there is no need to assume that inputs and outputs are separable, but this simplifies our notation. 
tion. As shown by Jorgenson and Kevin Stiroh, ${ }^{14}$ both computer investment and consumption of IT made important contributions to U.S. economic growth in the 1990s. We also consider the output contributions of software and communications equipment as distinct high-technology assets. Similarly, we decompose the contribution of capital input to isolate the impact of computers, software, and communications equipment on input growth.

Rearranging equation 2 enables us to present results in terms of growth in ALP, defined as $y_{t}=Y_{t} / H_{t}$, where $Y_{t}$ is output, defined as an aggregate of consumption and investment goods, and $k_{t}=K_{t} / H_{t}$ is the ratio of capital services to hours worked:

$$
\Delta \ln y_{t}=\bar{v}_{K, t} \Delta \ln k_{t}+\bar{v}_{L, t}\left(\Delta \ln L_{t}-\Delta \ln H_{t}\right)+\Delta \ln A_{t} .
$$

This gives the familiar allocation of ALP growth among three factors. The first is capital deepening, the growth in capital services per hour worked. Capital deepening makes workers more productive by providing more capital for each hour of work, and it raises the growth of ALP in proportion to the share of capital. The second term is the improvement in labor quality, defined as the difference between growth rates of labor input and hours worked. Reflecting the rising proportion of hours supplied by workers with higher marginal products, an improvement in labor quality raises ALP growth in proportion to labor's share. The third factor is TFP growth, which increases ALP growth on a point-for-point basis.

COMPUTERS, SOFTWARE, AND COMMUNICATIONS EQUIPMENT. We nOW consider the impact of investment in computers, software, and communications equipment on economic growth. For this purpose we must carefully distinguish the use of IT from the production of IT. ${ }^{15}$ For example, computers themselves are an output of one industry (commercial and industrial machinery), and computing services are inputs into other industries (computer-using industries such as trade, FIRE, and other services).

Massive increases in computing power, like those currently experienced by the U.S. economy, therefore have two effects on growth. First, as the production of computers improves and becomes more efficient, more computing power is being produced from the same inputs. This raises overall productivity in the computer-producing industry and contributes to

14. Jorgenson and Stiroh (1999); Gordon (1999b).

15. Baily and Gordon (1988), Griliches (1992), Stiroh (1998a), Jorgenson and Stiroh (1999), Whelan (2000), and Oliner and Sichel (2000) discuss the impact of investment in computers from these two perspectives. 
TFP growth for the economy as a whole. Labor productivity also grows at both the industry and the aggregate levels. ${ }^{16}$

Second, the rapid accumulation of computers leads to growth of computing power as an input in computer-using industries. Since labor is working with more and better computer equipment, this investment increases labor productivity. If the contributions to output are captured by the effect of capital deepening, TFP growth is unaffected. As Martin Baily and Robert Gordon remark, "there is no shift in the user firm's production function," ${ }^{17}$ and thus no gain in TFP. Increasing deployment of computers increases TFP only if there are spillovers from the production of computers to production in the computer-using industries, or if there are measurement problems associated with the new inputs.

We conclude that rapid growth in computing power affects aggregate output through both TFP growth and capital deepening. Progress in the technology of computer production contributes to growth in TFP and ALP at the aggregate level. The accumulation of computing power in computerusing industries reflects the substitution of computers for other inputs and leads to growth in ALP. In the absence of spillovers, this growth does not contribute to growth in TFP.

The remainder of this section provides empirical estimates of the variables in equations 1 through 3 . We then employ equations 2 and 3 to quantify the sources of growth of output and ALP for 1959-98 and various subperiods.

\section{Output}

Our output data are based on the most recent benchmark revision of the NIPAs. ${ }^{18}$ Real output $Y_{t}$ is measured in chained 1996 dollars, and $P_{Y, t}$ is the corresponding implicit deflator. Our output concept is similar, but not identical, to one used in the Bureau of Labor Statistics (BLS) productivity program. Like the BLS, we exclude the government sector, but

16. Triplett (1996) points out that much of the decline in computer prices reflects falling semiconductor prices. If all inputs are correctly measured for quality change, therefore, much of the TFP gain in computer production is rightly pushed back to TFP gains in semiconductor production, since semiconductors are a major intermediate input in the production of computers. See Flamm (1993) for early estimates on semiconductor prices. We address this issue further below.

17. Baily and Gordon (1988, p. 378).

18. See appendix A for details on our source data and methodology for output estimates. 
unlike the BLS we include imputations for the service flow from consumer durables and owner-occupied housing. These imputations are necessary to preserve comparability between durables and housing, and they enable us to capture the important impact of IT on households.

Our estimate of current dollar, private output in 1998 is $\$ 8.013$ trillion, including imputations of $\$ 740$ billion that primarily reflect services of consumer durables. ${ }^{19}$ Real output growth was 3.63 percent per year for the full period 1959-98, compared with 3.36 percent for the official GDP series. This difference reflects both our imputations and our exclusion of the government sectors in the NIPA data. Appendix table A1 presents the current dollar value and corresponding price index of total private output and of each major category of IT assets: investment in computers $I_{c}$, investment in software $I_{s}$, investment in communications equipment $I_{m}$, consumption of computers and software $C_{c}$, and the imputed service flow from consumers' computers and software $D_{c}$.

The most striking feature of these data is the enormous price decline for computer investment: 18 percent per year from 1960 to 1995 (figure 1). Since 1995 this decline has accelerated to 27.6 percent per year, as noted above. By contrast, the relative price of software investment has been flat for much of the period and only began to fall in the late 1980s. The price of communications equipment behaves in a manner similar to the software price, whereas the price of consumption of computers and software shows declines similar to that of computer investment. The top panel of table 1 summarizes the growth rates of prices and quantities for major output categories for 1990-95 and for 1995-98.

In terms of current dollar output, investment in software was the largest IT asset in 1998, followed by investment in computers, with investment in communications equipment a close third (figure 2). Although business investments in computers, software, and communications equipment are by far the largest categories, households have spent more than $\$ 20$ billion per year on computers and software since 1995, generating a service flow of comparable magnitude.

19. Current dollar GDP in the NIPAs in 1998 was $\$ 8.759 .9$ trillion. Our estimate differs because of total imputations ( $\$ 740$ billion), our exclusion of the general government and government enterprise sectors ( $\$ 972$ billion and $\$ 128$ billion, respectively), and our exclusion of certain retail taxes ( $\$ 376$ billion). 
Figure 1. Relative Prices of Information Technology Outputs, 1960-98

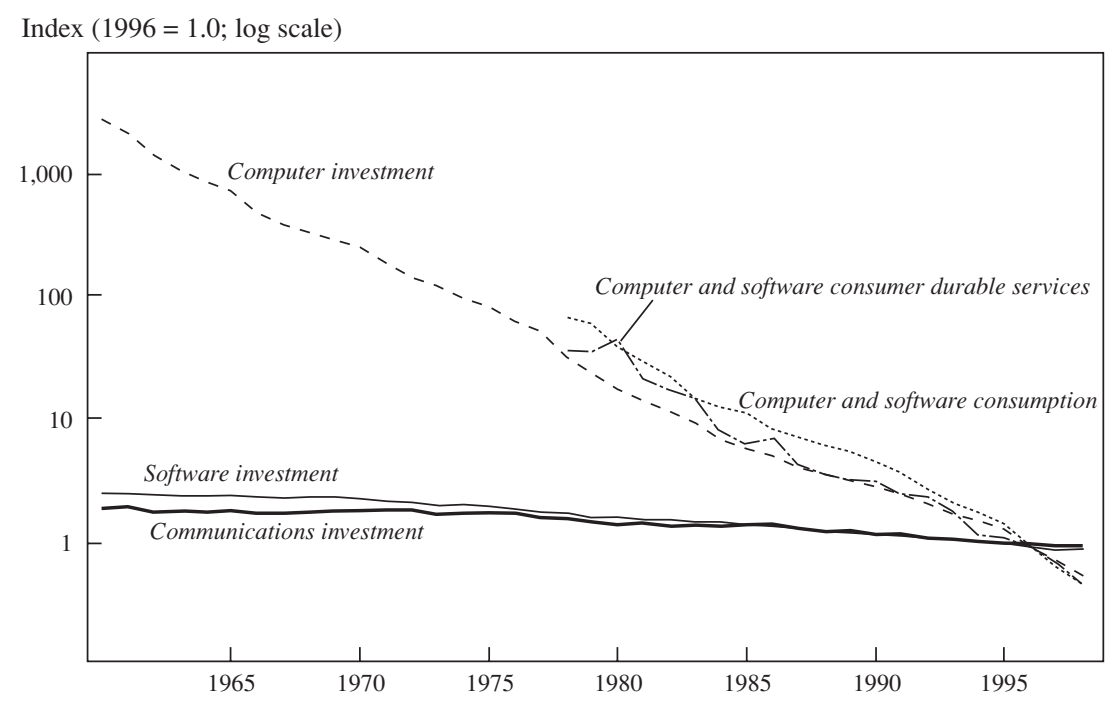

Source: Authors' calculations based on BEA, BLS, Census Bureau, and other data sources. a. All price indexes are relative to the output price index.

\section{Capital Stock and Capital Services}

Here we describe our capital estimates for the U.S. economy from 1959 to $1998 .^{20}$ We begin with investment data from the BEA, estimate capital stocks using the perpetual inventory method, and aggregate capital stocks using rental prices as weights. This approach, originated by Jorgenson and Griliches ${ }^{21}$ is based on the identification of rental prices with marginal products of different types of capital. Our estimates of these prices incorporate differences in asset prices, service lives and depreciation rates, and the tax treatment of capital incomes. ${ }^{22}$

20. See appendix B for details on the theory, source data, and methodology for our capital estimates.

21. Jorgenson and Griliches (1967).

22. Jorgenson (1996) provides a recent discussion of our model of capital as a factor of production. BLS (1983) describes the version of this model employed in the official productivity statistics. Hulten (2000) provides a review of the specific features of this methodology for measuring capital input and the link to economic theory. 
Table 1. Average Growth Rates of Prices and Quantities for Selected Outputs and Inputs, 1990-98

Percent

\begin{tabular}{|c|c|c|c|c|}
\hline \multirow[b]{2}{*}{ Type of output or input } & \multicolumn{2}{|c|}{ 1990-95 } & \multicolumn{2}{|c|}{$1995-98$} \\
\hline & Prices & Quantities & Prices & Quantities \\
\hline & \multicolumn{4}{|c|}{ Outputs } \\
\hline Private domestic output $(Y)$ & 1.70 & 2.74 & 1.37 & 4.73 \\
\hline Other $\left(Y_{n}\right)$ & 2.01 & 2.25 & 2.02 & 3.82 \\
\hline Computer and software consumption $\left(C_{c}\right)$ & -21.50 & 38.67 & -36.93 & 49.26 \\
\hline Computer investment $\left(I_{c}\right)$ & -14.59 & 24.89 & -27.58 & 38.08 \\
\hline Software investment $\left(I_{s}\right)$ & -1.41 & 11.59 & -2.16 & 15.18 \\
\hline Communications investment $\left(I_{m}\right)$ & -1.50 & 6.17 & -1.73 & 12.79 \\
\hline \multirow[t]{2}{*}{$\begin{array}{l}\text { Computer and software consumer durable } \\
\text { services }\left(D_{c}\right)\end{array}$} & -19.34 & 34.79 & -28.62 & 44.57 \\
\hline & \multicolumn{4}{|c|}{ Inputs } \\
\hline Total capital services $(K)$ & 0.60 & $2.83^{1}$ & 2.54 & 4.80 \\
\hline Other $\left(K_{n}\right)$ & 1.00 & 1.78 & 4.20 & 2.91 \\
\hline Computer capital $\left(K_{c}\right)$ & -10.59 & 18.16 & -20.09 & 34.10 \\
\hline Software capital $\left(K_{s}\right)$ & -2.07 & 13.22 & -0.87 & 13.00 \\
\hline Communications capital $\left(K_{m}\right)$ & 3.10 & 4.31 & -7.09 & 7.80 \\
\hline Total consumption services $(D)$ & 1.98 & 2.91 & -0.67 & 5.39 \\
\hline Other $\left(D_{n}\right)$ & 2.55 & 2.07 & 0.54 & 3.73 \\
\hline $\begin{array}{l}\text { Computer and software consumer durable } \\
\text { services }\left(D_{c}\right)\end{array}$ & -19.34 & 34.79 & -28.62 & 44.57 \\
\hline Labor $(L)$ & 2.92 & 2.01 & 2.80 & 2.81 \\
\hline
\end{tabular}

Source: Authors' calculations based on BEA, BLS, Census Bureau, and other data sources.

We refer to the difference between growth in capital services and growth in the capital stock as the growth in capital quality $q_{K, t}$; this represents substitution toward assets with higher marginal products. ${ }^{23}$ For example, the shift toward IT increases the quality of capital, since computers, software, and communications equipment are assets with relatively high marginal products. Capital stock estimates, like those originally employed by Solow, ${ }^{24}$ fail to account for this increase in quality.

We employ a broad definition of capital, including tangible assets such as equipment and structures, as well as consumer durables, land, and

23. More precisely, growth in capital quality is defined as the difference between the growth in capital services and the growth in the average of the current and lagged capital stock. Appendix B provides details. We use a geometric depreciation rate for all reproducible assets, so that our estimates are not identical to the wealth estimates published in BEA (1998b).

24. Solow (1957). 
Figure 2. Shares of Information Technology in Total Output, 1960-98

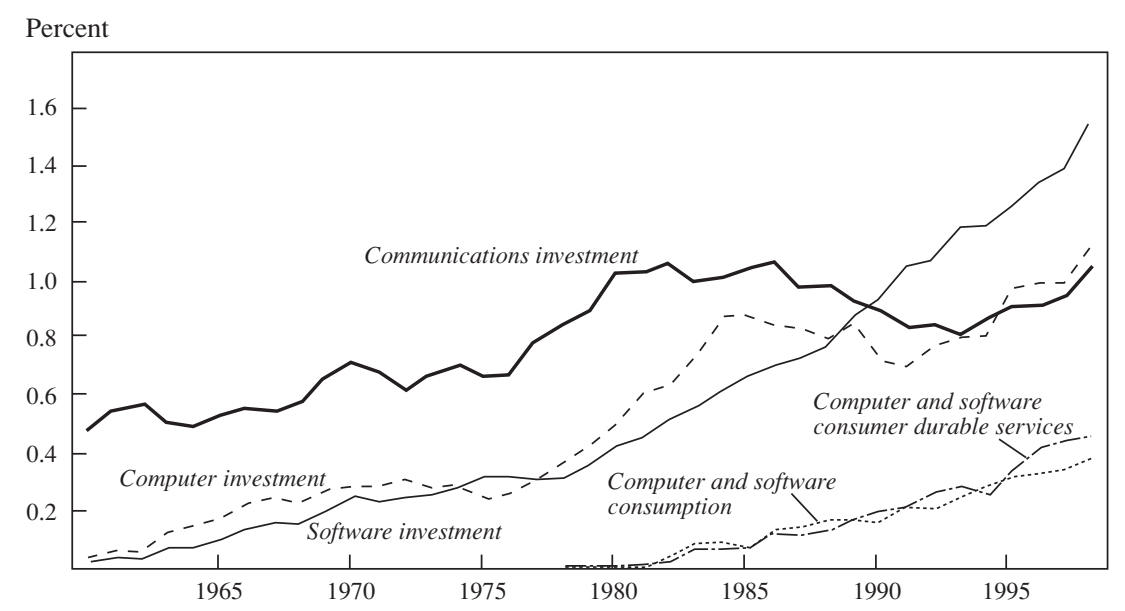

Source: Authors' calculations based on BEA, BLS, Census Bureau, and other data sources. a. Shares are of current dollar output.

inventories. We estimate a service flow from the installed stock of consumer durables, which enters our measures of both output and input. It is essential to include this service flow, since a steadily rising proportion is associated with purchases of IT by the household sector. In order to capture the impact of IT on U.S. economic growth, investments by the business and household sectors as well as the services of the resulting capital stocks must be included.

Our estimate of the capital stock is $\$ 26$ trillion in 1997, substantially larger than the $\$ 17.3$ trillion in fixed private capital estimated by the BEA. ${ }^{25}$ This difference reflects our inclusion of consumer durables, inventories, and land. Our estimates of the capital stock for comparable categories of assets are quite similar to those of the BEA. Our estimate of fixed private capital in 1997, for example, is $\$ 16.8$ trillion, almost the same as the BEA's. Similarly, our estimate of the stock of consumer durables is $\$ 2.9$ trillion, whereas the BEA's estimate is $\$ 2.5$ trillion. The remaining discrepancies reflect our inclusion of land and inventories. Appendix table B1 lists the component assets and 1998 investment and stock values; table B2 presents the value of the total capital stock and that of each IT asset 
category from 1959 to 1998 , as well as asset price indexes for total capital and IT assets.

The stocks of IT business assets (computers, software, and communications equipment), as well as consumers' purchases of computers and software, have grown dramatically in recent years but remain relatively small. In 1998, combined IT assets accounted for only 3.4 percent of tangible capital and 4.6 percent of reproducible private assets.

We now move to estimates of capital services flows, where the capital stocks of individual assets are aggregated using rental prices as weights. Appendix table B3 presents the current dollar service flows and corresponding price indexes for 1959-98, and the second panel of table 1 summarizes the growth rates for the prices and quantities of IT inputs for 1990-95 and 1995-98.

There is a clear acceleration in the growth of aggregate capital services, from 2.8 percent per year for 1990-95 to 4.8 percent for 1995-98. This is largely due to rapid growth in services from IT equipment and software, and it reverses the trend toward slower capital growth through 1995. IT assets account for only 11.2 percent of the total capital service flow, but a much larger share than the corresponding capital stock shares. In 1998 capital services were only 12.4 percent of the capital stock for tangible assets as a whole, but services were 40.0 percent of stocks for IT. This reflects the rapid price declines and high depreciation rates that enter into the rental prices for IT.

Figure 3 highlights the rapid increase in the importance of IT assets, reflecting the accelerating pace of relative price declines. In the 1990s the service price for computer hardware fell 14.2 percent per year, compared with an annual increase of 2.2 percent for non-IT capital. As a direct consequence of this relative price change, computer services grew 24.1 percent per year, compared with only 3.6 percent for the services of non-IT capital, in the 1990s. The current dollar share of services from computer hardware increased steadily, to reach nearly 3.5 percent of all capital services in 1998 (figure 3 ). ${ }^{26}$

The rapid accumulation of software, however, appears to have different origins. The price of software investment has declined much more

26. Tevlin and Whelan (2000) provide empirical support for this explanation, reporting that computer investment is particularly sensitive to the cost of capital, so that a rapid drop in service prices can be expected to lead to a large investment response. 
Figure 3. Shares of Information Technology in Total Capital and Consumer Durable Services, 1960-98

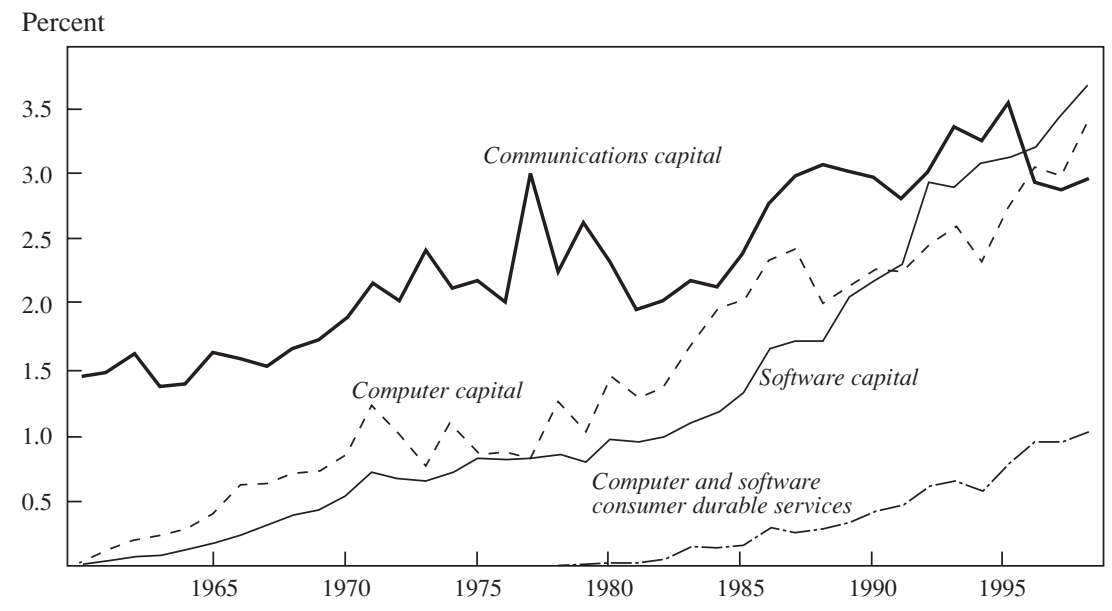

Source: Authors' calculations based on BEA, BLS, Census Bureau, and other data sources. a. Shares are of current dollar output.

slowly, by 1.7 percent per year versus 19.5 percent for computer hardware for 1990-98. These differences in investment prices have led to a much slower decline in service prices for software and computers, 1.6 percent per year for software versus 14.2 percent for hardware. Nonetheless, firms have been accumulating software quite rapidly: real capital services grew 13.1 percent per year in the 1990s. Although this is less than the 24.1 percent annual growth in computers, software growth has been much more rapid than growth in other forms of tangible capital. Complementarity between software and computers is one possible explanation: firms may respond to the decline in relative computer prices by accumulating computers and investing in complementary inputs such as software to put the computers into operation..$^{27}$

A competing explanation is that the official price indexes used to deflate software investment omit a large part of true quality improvements. This would lead to a substantial overstatement of price inflation and a corresponding understatement of real investment, capital services, and eco-

27. An econometric model of the responsiveness of different types of capital services to own- and cross-price effects could be used to test for complementarity, but this is beyond the scope of this paper. 
nomic growth. According to two recent reports from the BEA, ${ }^{28}$ only prices for prepackaged software are calculated from constant-quality price deflators based on hedonic methods. Prices for business own-account software are based on input cost indexes, which implicitly assume no change in the productivity of computer programmers. Custom software prices are a weighted average of prepackaged software and own-account software, with an arbitrary 75 percent weight for business own-account software prices. Thus the price deflators for nearly two-thirds of recent software investment are estimated under the maintained assumption of no gain in productivity. ${ }^{29}$ If the quality of own-account and custom software is improving at a pace even remotely close to that of packaged software, this implies a large understatement in investment in software.

Although the price decline for communications equipment during the 1990s is comparable to that for software, as officially measured in the NIPAs, investment has grown at a rate that is more in line with prices. However, there are also possible measurement biases in the pricing of communications equipment. The technology of switching equipment, for example, is similar to that of computer hardware; investment in this category is deflated by a constant-quality price index developed by the BEA. Conventional price deflators are employed for transmission gear, such as fiber-optic cables, which also appear to be declining rapidly in price. This could lead to an underestimate of the rate of growth in communications equipment investment, the capital stock, and capital services, as well as an overestimate of the rate of inflation. ${ }^{30}$ We return to this issue below.

\section{Measuring Labor Services}

Here we describe our estimates of labor input for the U.S. economy from 1959 to 1998. We begin with individual data from the Census of Population for 1970, 1980, and 1990, as well as the annual Current Population Surveys. We estimate constant-quality indexes for labor input and its

28. Moulton, Parker, and Seskin (1999); Parker and Grimm (2000).

29. According to Parker and Grimm (2000), total software investment of $\$ 123.4$ billion includes $\$ 35.7$ billion in prepackaged software, $\$ 42.3$ billion in custom software, and $\$ 45.4$ billion in own-account software in 1998. Applying the weighting conventions employed by the BEA, this implies that $\$ 46.3$ billion $=\$ 35.7$ billion $+0.25 \times \$ 42.3$ billion, or 38 percent of total software investment, is deflated with explicit quality adjustments.

30. Grimm (1997) presents hedonic estimates for digital telephone switches and reports average price declines of more than 10 percent per year from 1985 to 1996. 
price to account for heterogeneity of the work force across sex, employment class, age, and education levels. ${ }^{31}$

The distinction between labor input and labor hours is analogous to the distinction between capital services and the capital stock. Growth in labor input reflects the increase in labor hours, as well as changes in the composition of hours worked as firms substitute among heterogeneous types of labor. We define growth in labor quality as the difference between growth in labor input and growth in hours worked. Increases in labor quality reflect the substitution of workers with high marginal products for those with low marginal products; the growth in hours employed by Solow and others does not capture this substitution. ${ }^{32}$ Appendix table $\mathrm{C} 1$ presents our estimates of labor input, hours worked, and labor quality.

Our estimates show a value of labor expenditure of $\$ 4.546$ trillion in 1998 , or roughly 57 percent of the value of output. This share accurately includes private output and our imputations for capital services. If we exclude these imputations, labor's share rises to 62 percent, in line with conventional estimates. As shown in table 1, growth in the index of labor input $L_{t}$ appropriate for our model of production in equation 1 accelerated to 2.8 percent per year for $1995-98$, from 2.0 percent for 1990-95. This rise was primarily due to growth in hours worked, which rose from 1.4 percent per year for 1990-95 to 2.4 percent for 1995-98, as labor force participation increased and unemployment rates plummeted. ${ }^{33}$

Growth in labor quality decelerated in the late 1990 s, from 0.65 percent per year for 1990-95 to 0.43 percent for 1995-98. This slowdown reflects well-known underlying demographic trends in the composition of the work force, as well as exhaustion of the pool of available workers as unemployment rates steadily declined. Projections of future economic growth that omit labor quality, like those of the CBO (discussed below), implicitly incorporate changes in labor quality into measured TFP growth. This reduces the reliability of projections of future economic growth. Fortunately, this is easily remedied by extrapolating demographic changes in the

31. This follows the approach of Jorgenson, Gollop, and Fraumeni (1987), whose estimates have been revised and updated by Ho and Jorgenson (1999). Appendix C provides details on the source data and methodology.

32. Solow (1957).

33. By comparison, BLS (2000) reports growth in business hours of 1.2 percent per year for 1990-95 and 2.3 percent for 1995-98. The slight discrepancies reflect our methods for estimating hours worked by the self-employed, as well as minor differences in the scope of our output measure. 
work force in order to reflect foreseeable changes in composition by characteristics of workers such as age, sex, and educational attainment.

\section{Quantifying the Sources of Growth}

Table 2 presents results of our growth accounting decomposition based on an extension of equation 2 for the period 1959-98 and various subperiods, as well as preliminary estimates through 1999 . We decompose economic growth by both output and input categories in order to quantify the contribution of IT to investment and consumption outputs, as well as capital and consumer durable inputs. ${ }^{34}$ We extend our previous treatment of the outputs and inputs of computers by identifying software and communications equipment as distinct IT assets.

To quantify the sources of IT-related growth more explicitly, we employ an extended production possibilities frontier:

$$
Y\left(Y_{n}, C_{c}, I_{c}, I_{s}, I_{m}, D_{c}\right)=A \cdot X\left(K_{n}, K_{c}, K_{s}, K_{m}, D_{n}, D_{c}, L\right),
$$

where outputs include computer and software consumption $C_{c}$, computer investment $I_{c}$, software investment $I_{s}$, telecommunications investment $I_{m}$, the services of consumers' computers and software $D_{c}$, and other outputs $Y_{n}$. Inputs include the capital services of computers $K_{c}$, software $K_{s}$, telecommunications equipment $K_{m}$, other capital assets $K_{n}$, services of consumers' computers and software $D_{c}$, other durables $D_{n}$, and labor input $L .{ }^{35}$ As in equation 1 , TFP is denoted by $A$ and represents the ability to produce more output from the same inputs. Time subscripts have been dropped for convenience.

The corresponding extended growth accounting equation is

$$
\begin{aligned}
\bar{w}_{Y n} \Delta \ln Y_{n}+\bar{w}_{c c} \Delta \ln C_{c}+\bar{w}_{l c} \Delta \ln I_{c} & \\
+\bar{w}_{l s} \Delta \ln I_{s}+\bar{w}_{\operatorname{lm}} \Delta \ln I_{m}+\bar{w}_{D c} \Delta \ln D_{c}= & \bar{v}_{K n} \Delta \ln K_{n}+\bar{v}_{K c} \Delta \ln K_{c} \\
& +\bar{v}_{K s} \Delta \ln K_{s}+\bar{v}_{K m} \Delta \ln K_{m} \\
& +\bar{v}_{D n} \Delta \ln D_{n}+\bar{v}_{D c} \Delta \ln D_{c} \\
& +\bar{v}_{L} \Delta \ln L+\Delta \ln A,
\end{aligned}
$$

34. As in Jorgenson and Stiroh (1999).

35 . Note that we have broken broadly defined capital into tangible capital services $K$ and consumer durable services $D$. 


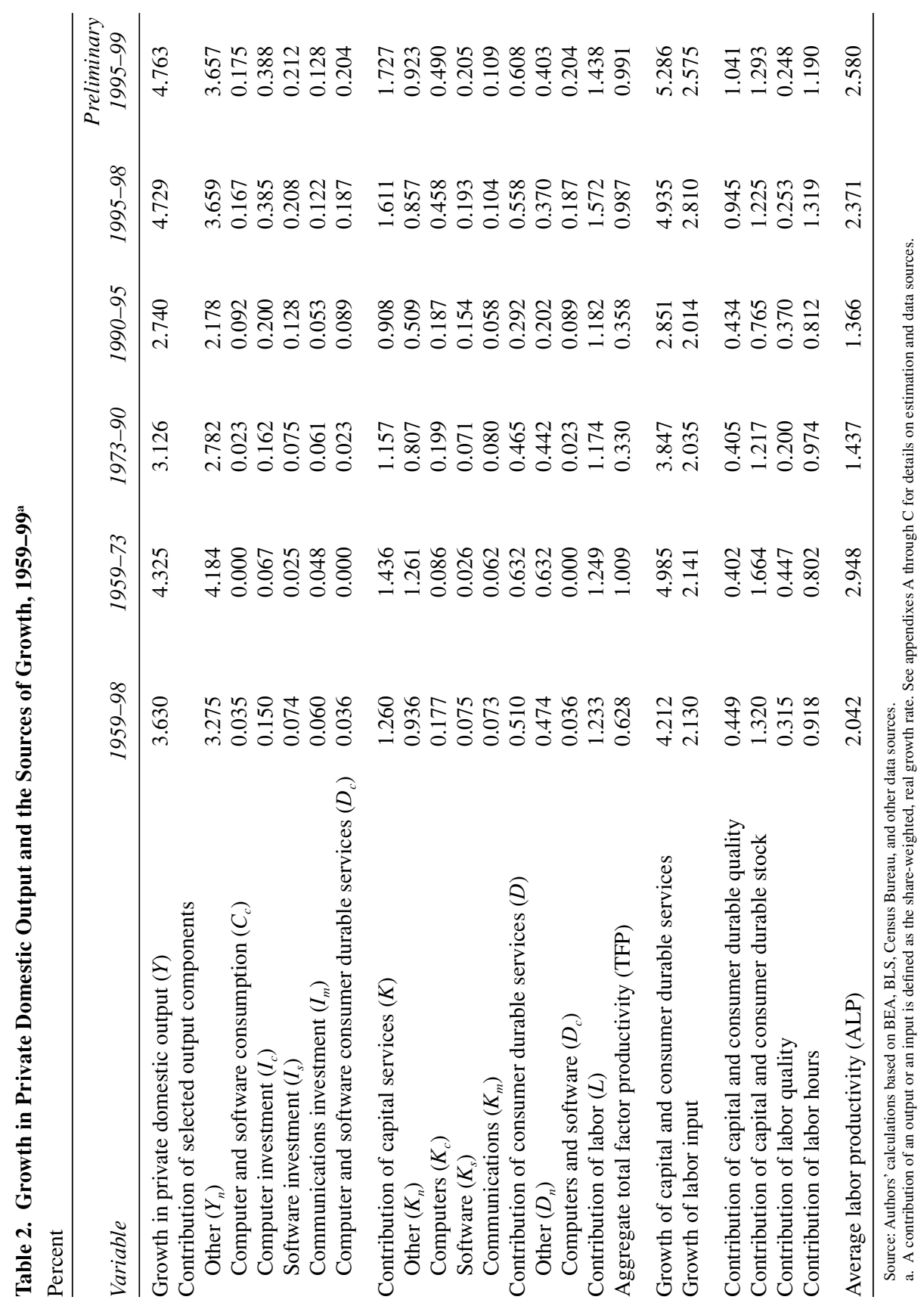


where $\bar{w}$ and $\bar{v}$ denote average shares in nominal income for the subscripted variable, $\bar{w}_{Y n}+\bar{w}_{C c}+\bar{w}_{I c}+\bar{w}_{I s}+\bar{w}_{I m}+\bar{w}_{D c}=\bar{v}_{K n}+\bar{v}_{K c}+\bar{v}_{K s}+\bar{v}_{K m}$ $+\bar{v}_{D n}+\bar{v}_{D c}+\bar{v}_{L}=1$, and we refer to a share-weighted growth rate as the contribution of an input or output.

OUTPUT GROWTH. We first consider the sources of output growth for the entire 1959-98 period. Broadly defined capital services make the largest growth contribution, 1.8 percentage points (1.3 percentage points from business capital and 0.5 percentage point from consumer durable assets); labor services contribute 1.2 percentage points; and TFP growth is responsible for only 0.6 percentage point. Input growth is the source of nearly 80 percent of U.S. growth over the past forty years, and TFP has accounted for approximately one-fifth. Figure 4 highlights this result by showing the relatively small growth contribution of the TFP residual in each subperiod.

More than three-quarters of the contribution of broadly defined capital reflects the accumulation of capital stock, whereas increased labor hours account for slightly less than three-quarters of labor's contribution. The quality of both capital and labor has made important contributions, 0.45 percentage point and 0.32 percentage point per year, respectively. Accounting for substitution among heterogeneous capital and labor inputs is therefore an important part of quantifying the sources of economic growth.

A look at the U.S. economy before and after 1973 reveals some familiar features of the historical record. After a period of strong output and TFP growth in the 1960s and early 1970s, the U.S. economy slowed markedly through 1990, with annual output growth falling from 4.3 percent for 1959-73 to 3.1 percent for 1973-90, and annual TFP growth falling almost two-thirds of a percentage point, from 1.0 percent to 0.3 percent. Growth in capital inputs also slowed, falling from 5.0 percent per year for 1959-73 to 3.8 percent for 1973-90, and this contributed to sluggish ALP growth, which fell from 2.9 percent per year for 1959-73 to 1.4 percent for 1973-90.

We now focus on the 1990s and highlight some recent changes. ${ }^{36}$ Relative to the early 1990s, annual output growth increased by nearly

36. Table 2 also presents preliminary results for the more recent period 1995-99, where the 1999 numbers are based on the estimation procedure described in appendix E rather than the detailed model described above. The results for 1995-98 and 1995-99 are quite similar; we focus our discussion on the period 1995-98. 
Figure 4. Sources of Growth, 1959-98

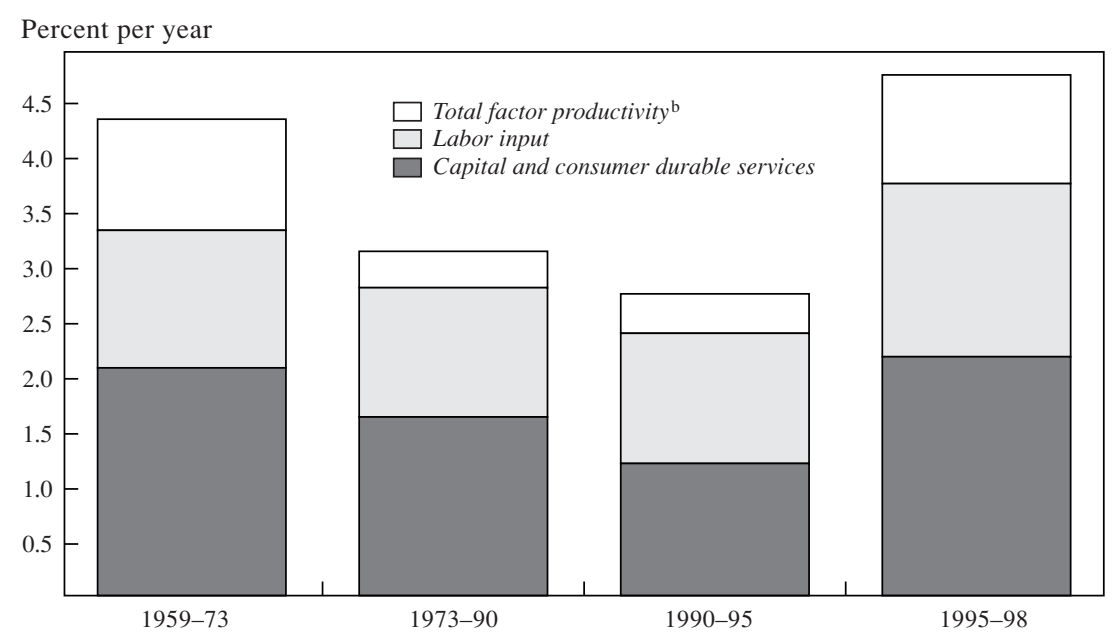

Source: Authors' calculations based on BEA, BLS, Census Bureau, and other data sources.

a. An input's contribution is its average, share-weighted, annual growth rate.

b. Defined in equation 2 .

2 percentage points for 1995-98. The contribution of capital and consumer durables jumped by 1.0 percentage point, that of labor rose by 0.4 percentage point, and TFP growth accelerated by 0.6 percentage point. ALP growth rose 1.0 percentage point. The rising contributions of labor and capital encompass several well-known trends in the late 1990s. Growth in hours worked accelerated as labor markets tightened, unemployment fell to a thirty-year low, and labor force participation rates increased. ${ }^{37}$ The contribution of capital reflects the investment boom of the late 1990s, as businesses poured resources into plant and equipment, especially computers, software, and communications equipment.

The acceleration in TFP growth is perhaps the most remarkable feature of the data. After averaging only 0.34 percent per year from 1973 to 1995, TFP accelerated to 0.99 percent per year for 1995-98, suggesting massive improvements in technology and increases in the efficiency of production. Although the resurgence in TFP growth in the 1990s has yet to

37. Katz and Krueger (1999) explain the strong performance of the U.S. labor market in terms of demographic shifts toward a more mature labor force, a rise in the prison population, improved efficiency in labor markets, and the "weak backbone" hypothesis of worker restraint. 
surpass that of the 1960s and early 1970s, more-rapid TFP growth is critical for sustained growth at higher rates.

Figures 5 and 6 highlight the rising contributions of IT outputs to U.S. economic growth. Figure 5 shows the breakdown between IT and non-IT outputs for the same subperiods as in figure 4, whereas figure 6 decomposes the contribution of IT outputs into the five components identified above, also for these four subperiods. Although the role of IT has steadily increased, figure 5 shows that the recent investment and consumption surge nearly doubled the output contribution of IT for 1995-98 relative to that of 1990-95. Figure 6 shows that computer investment was the largest single IT contributor in the late 1990s, and that consumption of computers and software is becoming increasingly important as a source of output growth.

Figures 7 and 8 present a similar decomposition of the role of IT assets as production inputs, where their contribution is rising even more dramatically. Figure 7 shows that the contribution of IT to growth in capital and consumer durables increased rapidly in the late 1990s, and these assets now account for more than two-fifths of the total growth contribution from broadly defined capital. Figure 8 shows that computer hardware is also the single largest IT contributor on the input side, reflecting the growing share and rapid growth rates of the late 1990s.

The contribution of computers, software, and communications equipment presents a different picture from that depicted in our previous research, for both data and methodological reasons. ${ }^{38}$ First, the BEA benchmark revision has classified software as an investment good. Although software is growing more slowly than computers, the substantial nominal share of software services has raised the overall contribution of IT. Second, we have added communications equipment, also a slowergrowing component of capital services, with similar effects. Third, we now incorporate asset-specific revaluation terms in all rental price estimates. Since the acquisition prices of computers are falling steadily, asset-specific revaluation terms have raised the estimated service price and increased the share of computer services. Finally, we have modified our timing convention and now assume that capital services from individual assets are proportional to the average of the current and the lagged stock. For assets with relatively short service lives like most IT, this is a more reasonable 
Figure 5. Contribution of Information Technology to Output, 1959-98

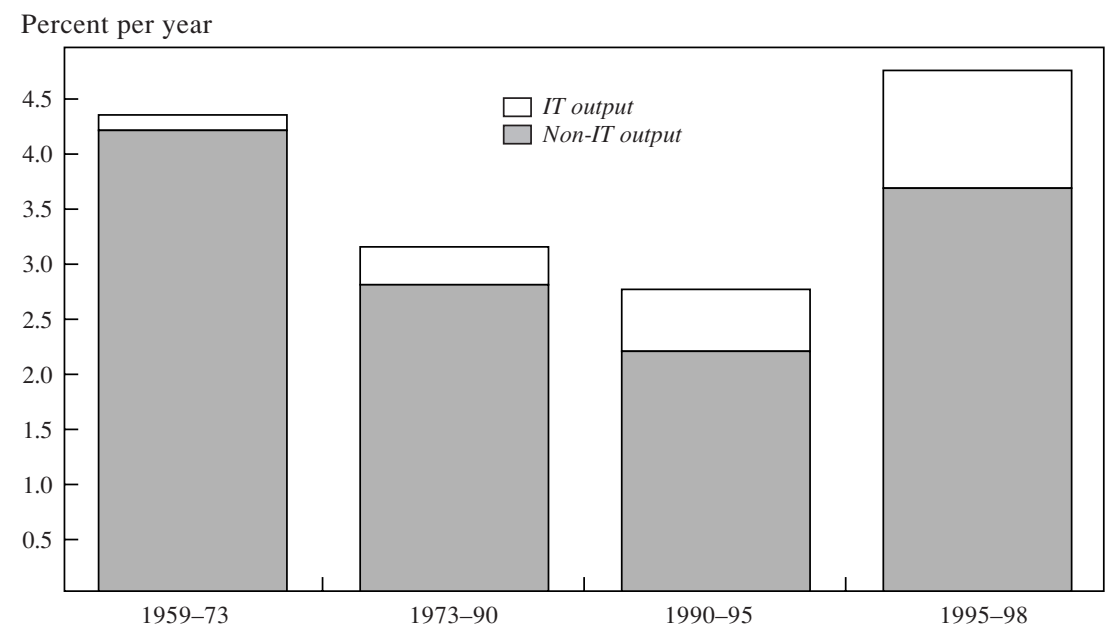

Source: Authors' calculations based on BEA, BLS, Census Bureau, and other data sources. a. An output's contribution is its average, share-weighted, annual growth rate.

Figure 6. Contribution of Information Technology to Output, by Type of Asset, 1959-98

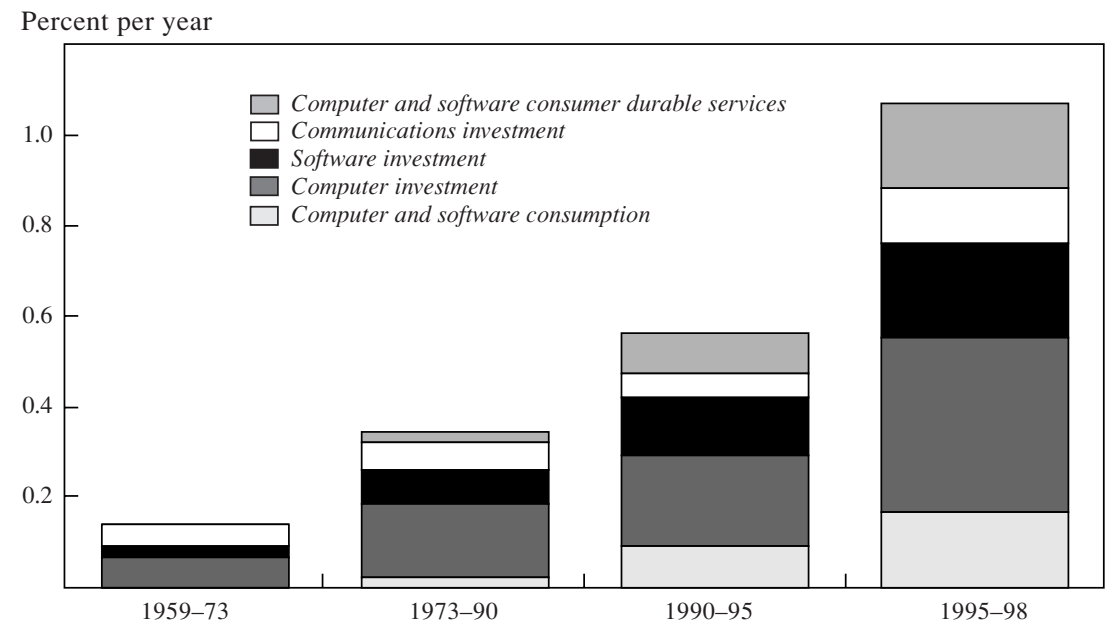

Source: Authors' calculations based on BEA, BLS, Census Bureau, and other data sources. a. An output's contribution is its average, share-weighted, annual growth rate. 
Figure 7. Contribution of Information Technology to Capital and Consumer Durable Input, 1959-98

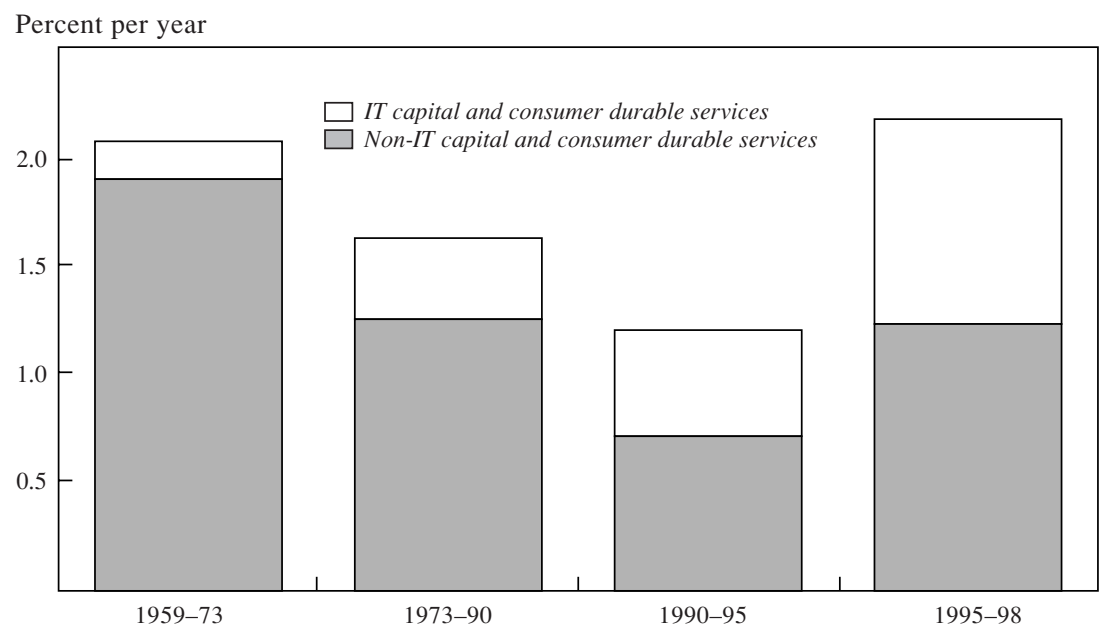

Source: Authors' calculations based on BEA, BLS, Census Bureau, and other data sources. a. An input's contribution is its average, share-weighted, annual growth rate.

assumption than in our earlier work, which assumed that it took a full year for new investment to become productive. ${ }^{39}$

This large increase in the growth contribution of computers and software is consistent with recent estimates by Stephen Oliner and Daniel Sichel, ${ }^{40}$ although their estimate of the contribution is somewhat larger. They report that computer hardware and software contributed 0.95 percentage point to growth for 1996-99, whereas communications contributed another 0.15 percentage point. The discrepancy between their estimates and ours primarily reflects our broader output concept, which lowers the input share of these high-technology assets, as well as minor differences in tax parameters and stock estimates. Karl Whelan also reports a larger growth contribution ( 0.82 percentage point) from computer hardware for 1996-98. ${ }^{41}$ The discrepancy again reflects our broader output

39. We are indebted to Daniel Sichel for very helpful discussions of this timing convention.

40. Oliner and Sichel (2000).

41. Whelan (2000). 
Figure 8. Contribution of Information Technology to Capital and Consumer Durable Input, by Type of Asset, 1959-98

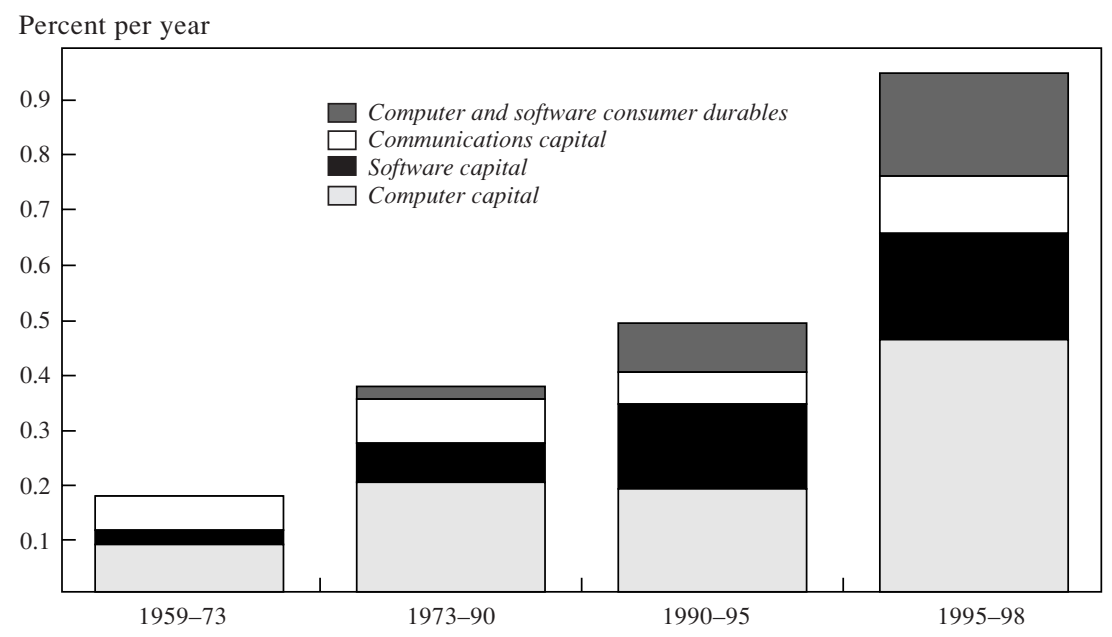

Source: Authors' calculations based on BEA, BLS, Census Bureau, and other data sources. a. An input's contribution is its average, share-weighted, annual growth rate.

concept. In addition, Whelan introduces a new methodology to account for retirement and support costs; this methodology generates a considerably larger capital stock and raises the input share and the growth contribution from computer capital.

Despite differences in methodology and data sources among studies, a consensus is building that computers are having a substantial impact on economic growth. ${ }^{42}$ What is driving the increase in the contributions of computers, software, and communications equipment? As we have argued elsewhere, ${ }^{43}$ price changes lead to substitution toward capital services with lower relative prices. Firms and consumers are responding to relative price changes.

Table 1 showed that the acquisition price of computer investment fell nearly 28 percent per year, the price of software fell 2.2 percent per year, and the price of communications equipment fell 1.7 percent per year during

42. Oliner and Sichel (2000) provide a detailed comparison of the results across several studies of computers and economic growth.

43. Jorgenson and Stiroh (1999). 
the period 1995-98, while other output prices rose 2.0 percent per year. In response to these price changes, firms accumulated computers, software, and communications equipment more rapidly than other forms of capital. Investment other than in IT actually declined as a proportion of private domestic product. The story of household substitution toward computers and software is similar. These substitutions suggest that the gains of the computer revolution accrue to firms and households that are adept at restructuring activities to respond to these relative price changes.

AVERAGE LABOR PRODUCTIVITY GROWTH. To provide a different perspective on the sources of economic growth, we focus next on ALP growth. By simple arithmetic, output growth equals the sum of growth in hours and growth in labor productivity. ${ }^{44}$ Table 3 shows the output breakdown between growth in hours and ALP for the same pre-1999 periods as in table 2. For the entire period 1959-98, ALP growth was the predominant determinant of output growth, increasing just over 2 percent per year, while hours increased about 1.6 percent per year. We then examine the changing importance of the factors determining ALP growth. As shown in equation 3, ALP growth depends on a capital deepening effect, a labor quality effect, and a TFP effect.

Figure 9 plots the importance of each factor, revealing the well-known productivity slowdown of the 1970s and 1980s and highlighting the acceleration of labor productivity growth in the late 1990s. The slowdown through 1990 reflects declines in all three components: less capital deepening, declining labor quality growth, and decelerating growth in TFP. The growth of ALP slipped further during the early 1990s, with the serious slump in capital deepening only partly offset by a revival in the growth of labor quality and an uptick in TFP growth. Slow growth in hours combined with slow ALP growth during 1990-95 to produce a further slide in the growth of output. This stands out from previous cyclical recoveries during the postwar period, when output growth accelerated during the recovery, powered by more rapid growth in hours and in ALP.

For the most recent period, 1995-98, strong output growth reflects growth in labor hours and in ALP almost equally. Comparing 1990-95 with $1995-98$, output growth accelerated by nearly 2 percentage points

44. See Krugman (1997) and Blinder (1997) for discussions of the usefulness of this relationship. 
Table 3. Sources of Growth in Average Labor Productivity, 1959-98

Percent

\begin{tabular}{lccccc}
\hline Variable & $1959-98$ & $1959-73$ & $1973-90$ & $1990-95$ & $1995-98$ \\
\hline Growth of private domestic output $(Y)$ & 3.630 & 4.325 & 3.126 & 2.740 & 4.729 \\
$\quad$ Growth in hours $(H)$ & 1.588 & 1.377 & 1.689 & 1.374 & 2.358 \\
$\quad \begin{array}{l}\text { Growth in ALP }(Y / H) \\
\quad \text { Contribution of capital deepening } \\
\quad \text { to ALP }\end{array}$ & 1.100 & 1.492 & 0.908 & 0.637 & 1.131 \\
$\quad \begin{array}{l}\text { Contribution of labor quality } \\
\quad \text { to ALP }\end{array}$ & 0.315 & 0.447 & 0.200 & 0.370 & 0.253 \\
$\quad$\begin{tabular}{l} 
Contribution of TFP to ALP \\
\hline
\end{tabular} & 0.628 & 1.009 & 0.330 & 0.358 & 0.987 \\
\hline
\end{tabular}

Source: Authors' calculations based on BEA, BLS, Census Bureau, and other data sources.

a. ALP contributions are defined in equation 3 .

Figure 9. Sources of Labor Productivity Growth, 1959-98

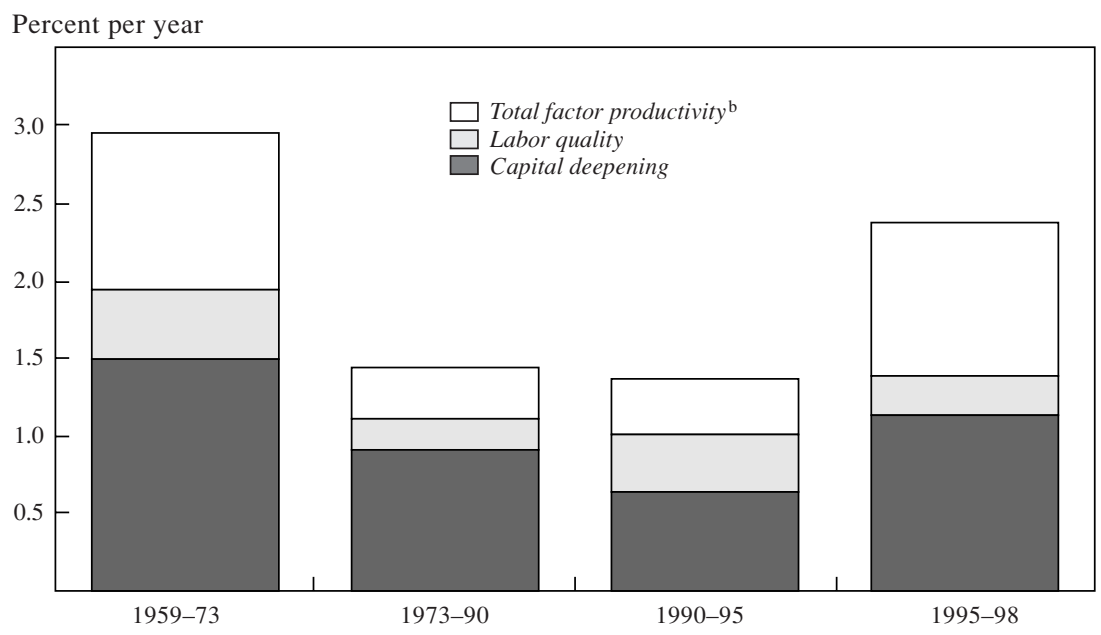

Source: Authors' calculations based on BEA, BLS, Census Bureau, and other data sources.

a. Contributions are defined in equation 3.

b. Defined in equation 2 .

as a result of a 1.0-percentage-point increase in hours worked and a 1.0-percentage-point increase in ALP growth. ${ }^{45}$ Figure 9 shows that the acceleration in ALP growth was due to rapid capital deepening from the investment boom, as well as faster TFP growth. Capital deepening contributed 0.49 percentage point to the acceleration in ALP growth, while

45. BLS data show similar trends for the business sector, with hours growth increasing from 1.2 percent per year during $1990-95$ to 2.3 percent per year during $1995-98$, while 
acceleration in TFP growth added 0.63 percentage point. Growth in labor quality slowed somewhat as growth in hours accelerated. This reflects the falling unemployment rate and tightening of labor markets, as more workers with relatively low marginal products were drawn into the work force. ${ }^{46}$

Our decomposition also throws some light on the hypothesis advanced by Gordon, who argues that the vast majority of recent ALP gains are due to the production of IT, particularly computers, rather than the use of IT. ${ }^{47}$ As we have already pointed out, more efficient IT production generates aggregate TFP growth as more computing power is produced from the same inputs, whereas IT use affects ALP growth through capital deepening. In recent years, acceleration of TFP growth has been a slightly more important factor in the acceleration of ALP growth than capital deepening. Efficiency gains in computer production are an important part of aggregate TFP growth, as Gordon's results on ALP suggest. We discuss this issue in greater detail below.

TOTAL FACTOR PRODUCTIVITY GROWTH. Finally, we consider the remarkable performance of U.S. TFP growth in recent years. After maintaining an average annual rate of 0.33 percent for the period 1973-90, TFP growth rose to 0.36 percent per year for $1990-95$ and then vaulted to 0.99 percent per year for 1995-98. This jump is a major source of growth in output and ALP for the U.S. economy (figures 4 and 9). Although TFP growth for the 1990s has yet to reattain its peaks of certain periods in the golden age of the 1960s and early 1970s, the recent acceleration suggests that the U.S. economy may be recuperating from the anemic productivity growth of the past two decades. Of course, caution is warranted until more historical experience is available.

Since Domar's 1961 article, economists have utilized a multi-industry model of the economy to trace aggregate TFP growth to its sources at the level of individual industries. Jorgenson and colleagues have employed this model to identify industry-level sources of growth. ${ }^{48}$ More recently, William Gullickson and Michael Harper, and Jorgenson and Stiroh, have

\footnotetext{
ALP increased from 1.6 percent per year to 2.6 percent per year. Data are available at www.bls.gov.

46. Oliner and Sichel (2000) also show a decline in the growth contribution of labor quality in the late 1990 s, from 0.44 percentage point during $1991-95$ to 0.31 percentage point during 1996-99.
}

47. Gordon (1999b).

48. Jorgenson, Gollop, and Fraumeni (1987); Jorgenson (1990). 
used the model for similar purposes ${ }^{49}$ We postpone more detailed consideration of the sources of TFP growth until we have examined the impact of alternative price deflators on our growth decomposition.

\section{Alternative Growth Accounting Estimates}

Tables 1 through 3 and figures 1 through 9 reported our primary results using the official data published in the NIPAs. As already noted, however, there is reason to believe that the rates of inflation in official price indexes for certain high-technology assets, notably software and telecommunications equipment, may be overstated. Two recent papers from the BEA, for example, report that only the prepackaged portion of software investment is deflated with a constant-quality deflator. ${ }^{50}$ Own-account software is deflated with an input cost index, and custom software is deflated with a weighted average of the prepackaged and own-account deflator. Similarly, the BEA reports that, in the communications equipment category, only telephone switching equipment is deflated with a constant-quality, hedonic deflator. ${ }^{51}$

Here we incorporate alternative price series for software and communications equipment and examine the impact on estimates of U.S. economic growth and its sources. Table 4 presents growth accounting results under three different scenarios. The "base case" repeats the estimates from table 2, which are based on official NIPA price data. Two additional cases incorporate price series for software and communications equipment that show faster price declines and correspondingly more rapid real investment growth. $^{52}$

The "moderate price decline" case assumes that prepackaged software prices are appropriate for all types of private software investment, including custom and business own-account software. Since the index for prepackaged software is based on explicit quality adjustments, it falls much faster than the prices of custom and own-account software: 10.1 percent per year versus 0.4 percent and 4.1 percent per year, respectively, for

49. Gullickson and Harper (1999); Jorgenson and Stiroh (2000).

50. Moulton, Parker, and Seskin (1999); Parker and Grimm (2000).

51. Bruce Grimm, Bureau of Economic Analysis, personal communication.

52.The notion that official price deflators for investment goods omit substantial quality improvements is hardly novel. The magisterial work of Gordon (1990) successfully quantified the overstatements of rates of inflation for the prices of a wide array of investment goods, covering all producer durable equipment in the NIPAs. 


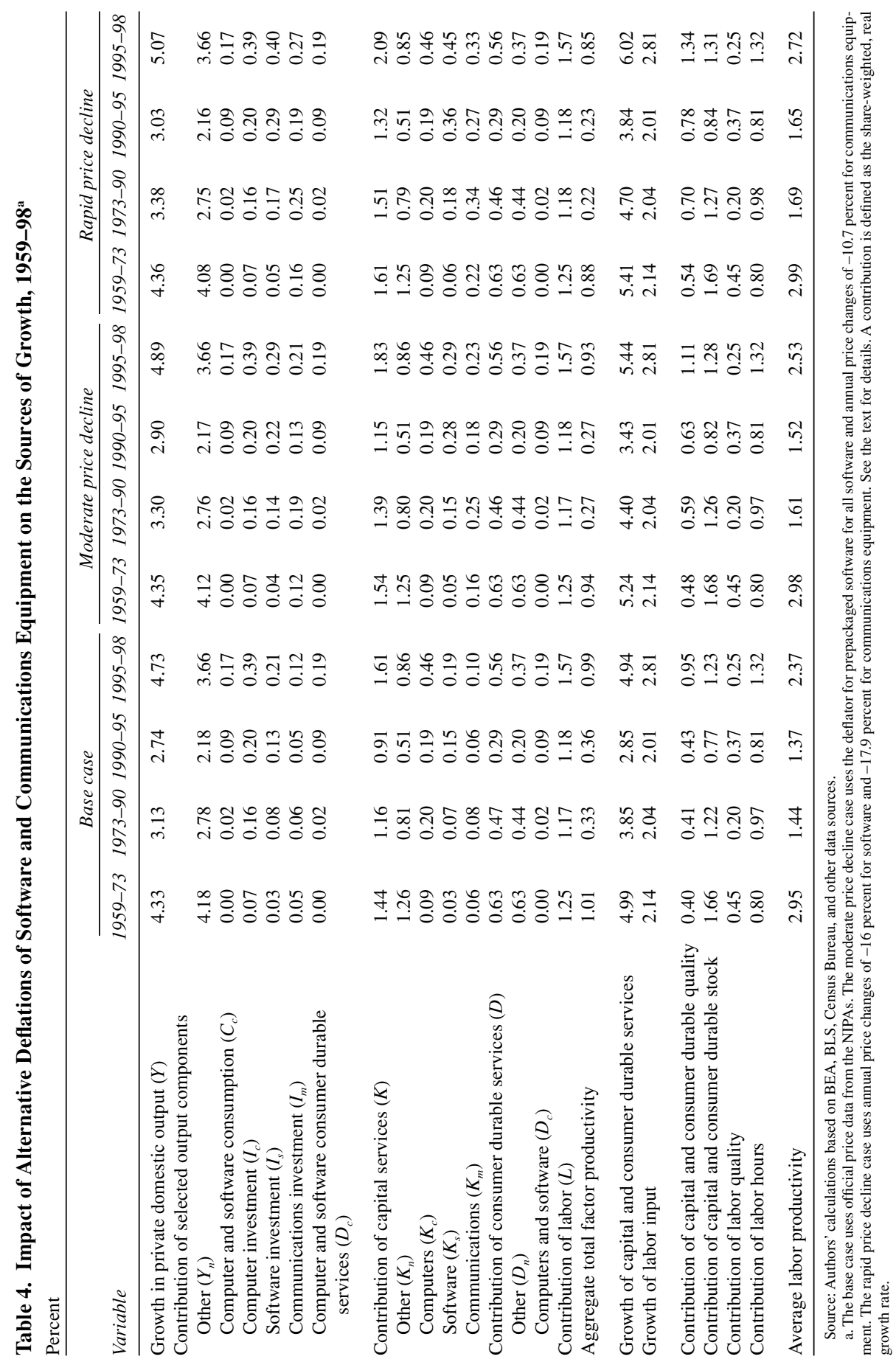


the full 1959-98 period. ${ }^{53}$ For communications equipment the data are more limited, and we assume that prices fell 10.7 percent per year throughout the entire period. This estimate is the average annual "smoothed" decline for digital switching equipment for 1985-96 reported by Bruce Grimm. ${ }^{54}$ Although this series may not be appropriate for all types of communications equipment, it exploits the best available information.

The "rapid price decline" case assumes that software prices fell 16 percent per year for 1959-98, the rate of quality-adjusted price decline reported by Erik Brynjolfsson and Chris Kemerer for microcomputer spreadsheets for 1987-92..$^{55}$ This is a slightly faster decline than the 15 percent annual rate for 1986-91 estimated by Neil Gandal, and considerably faster than the 3 percent annual decline for word processors, spreadsheets, and databases for 1987-93 reported by Oliner and Sichel. ${ }^{56}$ For communications equipment we used estimates from the most recent period from Grimm, ${ }^{57}$ who reports a decline of 17.9 percent per year for 1992-96.

Although this exercise necessarily involves some arbitrary choices, the estimates incorporate the limited data now available and provide a valuable perspective on the crucial importance of accounting for quality change in the prices of investment goods. Comparisons among the three cases are also useful in suggesting the range of uncertainty currently confronting analysts of U.S. economic growth.

Before discussing the empirical results, it is worthwhile to emphasize that a more rapid price decline for IT has two direct effects on the sources of growth and one indirect effect. The alternative investment deflators raise measured real output growth by reallocating nominal growth away from prices and toward quantities. This also increases the growth rate of the capital stock, since there are larger investment quantities in each year. More-rapid price declines also give greater weight to capital services from IT.

The counterbalancing effects of increased output growth and increased input growth lead to an indirect effect on measured TFP growth. Depending on the relative shares of high-technology assets in investment and

53. Parker and Grimm (2000).

54. Grimm (1997).

55. Brynjolfsson and Kemerer (1996).

56. Gandal (1994); Oliner and Sichel (1994).

57. Grimm (1997). 
capital services, the TFP residual will increase if the output effect dominates and decrease if the effect on capital services dominates. ${ }^{58}$ Greenwood, Hercowitz, and Krusell, following Solow, omit the output effect and attribute the input effect to "investment-specific" (embodied) technical change.$^{59}$ This must be carefully distinguished from the effects of industrylevel productivity growth on TFP growth, discussed below.

Table 4 reports growth accounting results from these three scenarios: the base case, the moderate price decline case, and the rapid price decline case. The results are not surprising: the more rapid the price decline for software and communications, the faster the rate of growth of output and capital services. Relative to the base case, output growth increases by 0.16 percentage point per year for 1995-98 in the moderate price decline case and by 0.34 percentage point per year in the rapid price decline case. Capital input growth shows slightly larger increases across the three cases. Clearly, constant-quality price indexes for IT are essential for further progress in understanding the growth impact of high-technology investment.

The acceleration in output and input growth reflects the increased contributions from IT and determines the effect on the TFP residual. In particular, the output contribution from software for 1995-98 increases from 0.21 percentage point in the base case, to 0.29 percentage point in the moderate price decline case, to 0.40 percentage point in the rapid price decline case. Similarly, the capital services contribution for software increases from 0.19 to 0.29 to 0.45 percentage point. The contribution of communications equipment shows similar changes. Residual TFP growth falls slightly during the 1990 s, as the input effect outweighs the output effect because of the large capital services shares of IT.

This exercise illustrates the sensitivity of the sources of growth to alternative price indexes for IT. We do not propose to argue that either of the two alternative cases is more nearly correct than the base case with the official prices from the NIPAs. Given the paucity of quality-adjusted price data on high-technology equipment, we simply do not know. Rather, we have tried to highlight the importance of correctly measuring prices and quantities to understand the dynamic forces driving U.S. economic growth. As hightechnology assets continue to proliferate through the economy and as other

58. This point was originally made by Jorgenson (1966); Hulten (2000) provides a recent review.

59. Solow (1957); Greenwood, Hercowitz, and Krusell (1997). 
investment goods become increasingly dependent on electronic components, these measurement issues will become increasingly important. Although the task that lies ahead is onerous, the creation of quality-adjusted price indexes for all high-technology assets deserves top priority.

\section{Decomposition of TFP Growth}

We next consider the role of high-technology industries as a source of TFP growth. As discussed above, production of high-technology investment goods has made important contributions to aggregate growth. The CEA, for example, allocates 0.39 percentage point of aggregate TFP growth to computer production, and Oliner and Sichel allocate 0.49 percentage point to the production of computers and computer-related semiconductor production for the period 1995-99. ${ }^{60}$

We employ a methodology based on the price "dual" approach to measurement of productivity at the industry level. Anticipating our complete industry analysis below, it is worthwhile to spell out the decomposition of TFP growth by industry. Using the Domar approach to aggregation, we weight industry-level productivity growth by the ratio of the gross output of each industry to aggregate value added to estimate the industry's contribution to aggregate TFP growth. In the dual approach, the rate of productivity growth is measured as the decline in the price of output, plus a weighted average of the growth rates of input prices.

In the case of computer production, this expression is dominated by two terms: the price of computers and the price of semiconductors, which are a primary intermediate input into the computer-producing industry. If semiconductor industry output is used only as an intermediate good to produce computers, then its contribution to computer industry productivity growth, weighted by computer industry output, precisely cancels its independent contribution to aggregate TFP growth. ${ }^{61}$ This independent contribution from the semiconductor industry, based on the complete Domar weighting scheme, is the value of semiconductor output divided by aggregate value added, multiplied by the rate of price decline in semiconductors.

60. CEA (2000); Oliner and Sichel (2000). Gordon (1999a), Stiroh (1998a), and Whelan (1999) have also provided estimates.

61. This calculation shows that the simplified model of Oliner and Sichel (2000) is a special case of the complete Domar weighting scheme used below. 
Table 5. Information Technology Decomposition of Total Factor Productivity Growth for Alternative Deflation Cases, 1990-98 ${ }^{\text {a }}$

\begin{tabular}{|c|c|c|c|c|c|c|}
\hline \multirow[b]{2}{*}{ Variable } & \multicolumn{2}{|c|}{ Base case } & \multicolumn{2}{|c|}{$\begin{array}{c}\text { Moderate } \\
\text { price decline }\end{array}$} & \multicolumn{2}{|c|}{$\begin{array}{c}\text { Rapid } \\
\text { price decline }\end{array}$} \\
\hline & 1990-95 & $1995-98$ & 1990-95 & $1995-98$ & $1990-95$ & $1995-98$ \\
\hline \multirow[t]{2}{*}{ Aggregate TFP growth } & 0.36 & 0.99 & 0.27 & 0.93 & 0.23 & 0.85 \\
\hline & \multicolumn{6}{|c|}{ TFP contribution } \\
\hline Information technology & 0.25 & 0.44 & 0.46 & 0.64 & 0.64 & 0.86 \\
\hline Computers & 0.16 & 0.32 & 0.16 & 0.32 & 0.16 & 0.32 \\
\hline Software & 0.05 & 0.08 & 0.17 & 0.18 & 0.28 & 0.34 \\
\hline Communications & 0.04 & 0.04 & 0.13 & 0.13 & 0.21 & 0.20 \\
\hline \multirow[t]{2}{*}{ Non-information technology } & 0.11 & 0.55 & -0.19 & 0.29 & -0.41 & -0.01 \\
\hline & \multicolumn{6}{|c|}{ Relative price change } \\
\hline Computers & -16.6 & -29.6 & -16.6 & -29.6 & -16.6 & -29.6 \\
\hline Software & -3.4 & -4.2 & -11.3 & -9.7 & -18.0 & -18.0 \\
\hline \multirow[t]{2}{*}{ Communications } & -3.5 & -3.8 & -12.7 & -12.7 & -19.9 & -19.9 \\
\hline & \multicolumn{6}{|c|}{ Average nominal share } \\
\hline Computers & 0.96 & 1.09 & 0.96 & 1.09 & 0.96 & 1.09 \\
\hline Software & 1.54 & 1.88 & 1.54 & 1.88 & 1.54 & 1.88 \\
\hline Communications & 1.05 & 1.02 & 1.05 & 1.02 & 1.05 & 1.02 \\
\hline
\end{tabular}

Source: Authors' calculations based on BEA, BLS, Census Bureau, and other data sources.

a. The base case uses official price data from the NIPAs. The moderate price decline case uses the deflator for prepackaged software for all software and annual price changes of -10.7 percent for communications equipment. The rapid price decline case uses annual price changes of -16 percent for software and -17.9 percent for communications equipment. See the text for details. A TFP contribution is defined as the share-weighted, real growth rate of relative prices.

Table 5 reports details of our TFP decomposition for the three alternative cases described above for 1990-95 and 1995-98, and figure 10 summarizes the IT versus non-IT comparison. In our base case, using official NIPA data, we estimate that the production of IT accounts for 0.44 percentage point of TFP growth for 1995-98, compared with 0.25 percentage point for $1990-95$. This reflects the accelerating relative price changes due to radical shortening of the product cycle for semiconductors. ${ }^{62}$

62. Relative price changes in the base case are taken from the investment prices in table 5. Output shares are estimated based on final demand sales for computers, available from the BEA website (www.bea.doc.gov/bea/dnl.htm) and from Parker and Grimm (2000) for software. Investment in communications equipment is from the NIPAs, and we estimate other final demand components for communications equipment using ratios relative to final demand for computers. This is an approximation necessitated by the lack of complete data on sales to final demand by detailed commodity. 
Figure 10. Contribution of Information Technology to Total Factor Productivity Growth for Alternative Deflation Cases, 1990-98 ${ }^{\text {a }}$

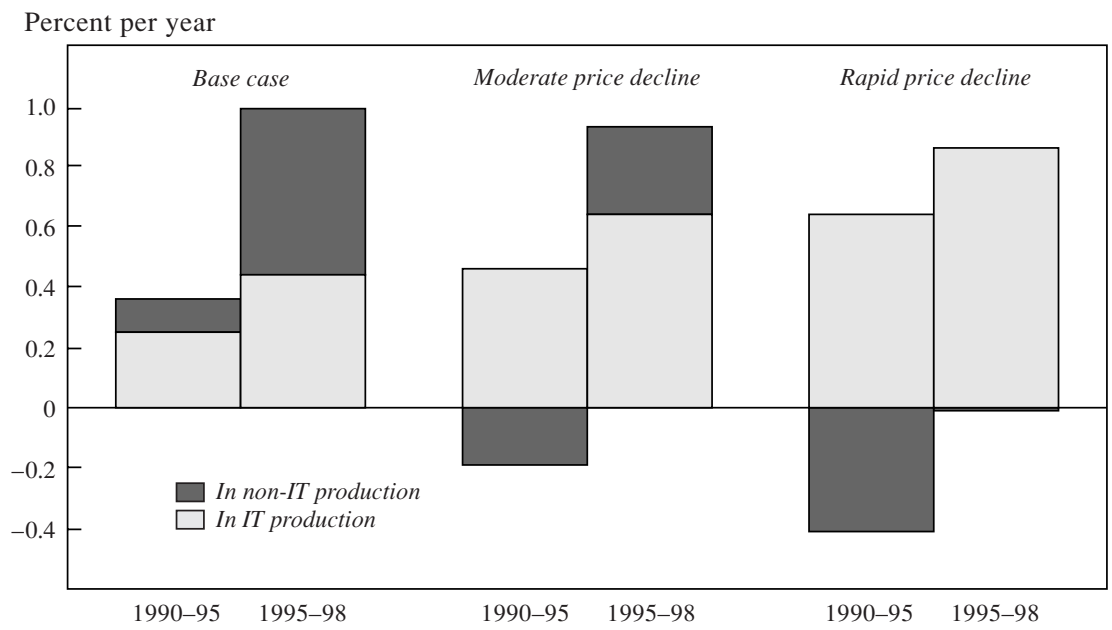

Source: Authors' calculations based on BEA, BLS, Census Bureau, and other data sources. a. Annual contribution of information techology is its share-weighted decline in relative prices.

As already suggested, the estimates of price declines for high-technology investments in our base case calculations may be conservativeindeed, very conservative. Consider our moderate price decline case, which reflects only part of the data we would require for constant-quality estimates of the IT price declines. In this case the contribution of IT to TFP growth during 1995-98 rises to 0.64 percentage point, an increase of 0.20 percentage point. Proceeding to what may appear to be the outer limit of plausibility, but still consistent with the available evidence, we consider also the case of a rapid price decline. The contribution of IT to TFP growth in this case is a robust 0.86 percentage point, accounting for all of TFP growth in 1995-98.

A final observation from the TFP decomposition is that the TFP acceleration in the late 1990s does not appear to be entirely located within ITproducing industries. Although the actual growth rates vary considerably across our three alternative cases, non-IT TFP growth increases markedly in each case when the early 1990s are compared with the late 1990s. This runs counter to the conclusion of Gordon, who reports that the entire acceleration of labor productivity growth in the late 1990 s reflects gains in IT 
production. ${ }^{63}$ This divergence likely reflects Gordon's detrending procedure, which attributes a sizable portion of recent productivity growth to cyclical factors, as well as his focus on labor productivity and our focus on TFP growth.

This acceleration of non-IT TFP growth could also be interpreted as evidence of a new economy. If these productivity gains do indeed reflect spillovers from IT into non-IT industries, this would provide some missing evidence for the "new economy" argument. Alternatively, however, it could reflect technological progress in non-IT industries that is entirely independent of the IT revolution. Differentiation between these two hypotheses is impossible at the aggregate level; rather, it requires detailed industry data for the most recent period 1995-98. Without these data, identification problems prevent us from drawing firm conclusions about the sources and implications of the acceleration of TFP in non-IT industries.

\section{Setting the Speed Limit}

We now consider the sustainability of recent U.S. growth trends over longer time horizons. Rapid output growth is highly desirable, of course, but it cannot continue indefinitely if fueled only by a falling unemployment rate and higher labor force participation. Output growth driven by continuing TFP improvements, on the other hand, is more likely to persist. The sustainability of growth has clear implications for government policies. Because economic growth affects tax revenue, potential government expenditure, and the long-term viability of programs such as social security and medicare, it is closely studied by government agencies. This section examines the impact of the recent success of the U.S. economy on official growth forecasts.

\section{A Brief Review of Forecast Methodologies}

The importance of economic growth for the U.S. government is evident in the considerable effort it expends on projecting future growth. No fewer than five government agencies-the CBO, the Social Security 
Administration (SSA), the Office of Management and Budget (OMB), the CEA, and the General Accounting Office (GAO)—report estimates of future growth for internal use or public discussion. This section briefly discusses their methodologies. ${ }^{64}$

All of these agencies base their forecasts on models that rest securely on neoclassical foundations. Although their details and assumptions vary, all employ, either explicitly or implicitly, an aggregate production model similar to equation 1 . In addition, they all incorporate demographic projections from the SSA as the basic building block for labor supply estimates. The $\mathrm{CBO}$, the $\mathrm{CEA}$, and the GAO employ an aggregate production function and explicitly describe the role of labor growth, capital accumulation, and technical progress. ${ }^{65}$ The SSA and the OMB, on the other hand, employ a simplified relationship where output growth equals the sum of growth in hours worked and labor productivity. ${ }^{66}$ Projections over longer time horizons are driven by aggregate supply, with relatively little attention given to business cycle fluctuations or aggregate demand effects.

Given the common framework and source data, it is not surprising that the agencies' projections are quite similar. Reporting on estimates released in 1997, Stiroh finds that the SSA and GAO projections of GDP per capita in 2025 were virtually identical, whereas the CBO's projection was about 9 percent higher, because of economic feedback effects from the improving government budget situation. ${ }^{67}$ More recently, the CBO projects real annual GDP growth of 2.8 percent, and the OMB 2.7 percent, for 1999-2010, whereas the CEA projects growth of 2.8 percent for 1999-2007. ${ }^{68}$ Although the timing is slightly different-the CBO projects faster growth than does the OMB earlier in the period, and the CEA reports projections only through 2007-the estimates are virtually identical. All three projections identify the recent investment boom as a contributor to rising labor productivity, and capital deepening as a source of continuing economic growth. We now consider the $\mathrm{CBO}$ projections in greater detail.

64. Stiroh (1998b) provides details and references to supporting documents.

65. CBO (1995, 1997, 1999a, 1999b, 2000); GAO (1995, 1996); CEA (2000).

66. SSA $(1992,1996)$; OMB $(1997,2000)$.

67. Stiroh (1998b).

68. CBO (2000); OMB (2000); CEA (2000). 


\section{CBO Growth Projections}

The CBO utilizes a sophisticated, detailed, multisector growth model of the U.S. economy. ${ }^{69}$ The core of this model is a two-factor production function for the nonfarm business sector, with $\mathrm{CBO}$ projections based on labor force growth, national saving and investment, and exogenous TFP growth. Production function parameters are calibrated to historical data using a Cobb-Douglas model:

$$
Y=A \cdot H^{0.7} \cdot K^{0.3},
$$

where $Y$ is potential output, $H$ is potential hours worked, $K$ is capital input, and $A$ is potential TFP. ${ }^{70}$

The CBO projects hours worked on the basis of demographic trends, with separate estimates for different age and sex classifications. These estimates incorporate SSA estimates of population growth, as well as internal CBO projections of labor force participation and hours worked for the different categories. However, the CBO does not use this demographic detail to identify changes in labor quality. Capital input is measured as the service flow from four types of capital stocks: producer durable equipment (excluding computers), computers, nonresidential structures, and inventories. Stocks are estimated by the perpetual inventory method and weighted by rental prices, thereby incorporating some changes in capital quality. TFP growth is projected on the basis of recent historical trends, with labor quality growth implicitly included in the estimate of TFP growth.

Turning to the most recent CBO projections, ${ }^{71}$ we focus on the nonfarm business sector, which drives the GDP projections and is based on the most detailed growth model. Table 6 summarizes the CBO's growth rate estimates for the 1980s and 1990s and its projections for 1999-2010. The table also presents estimates from the BLS and our own results. ${ }^{72}$

69. The five sectors in this model-nonfarm business, farm, government, residential housing, and households and nonprofit institutions-follow the breakdown in table 1.7 of the NIPAs.

70. See CBO $(1995,1997)$ for details on the underlying model and the adjustments for business cycle effects that lead to the potential series.

71. These are reported in CBO (2000, table 2.6).

72. BLS (2000). Note that the growth rates in table 6 do not exactly match those in table 2 because of differences in calculating growth rates. All growth rates in table 6 follow the CBO's convention of calculating discrete growth rates as $g=\left[\left(X_{t} / X_{0}\right)^{1 / t}-1\right]^{*} 100$, whereas growth rates in table 2 are calculated as $g=\left[\ln \left(X_{t} / X_{0}\right) / t\right]^{*} 100$. 


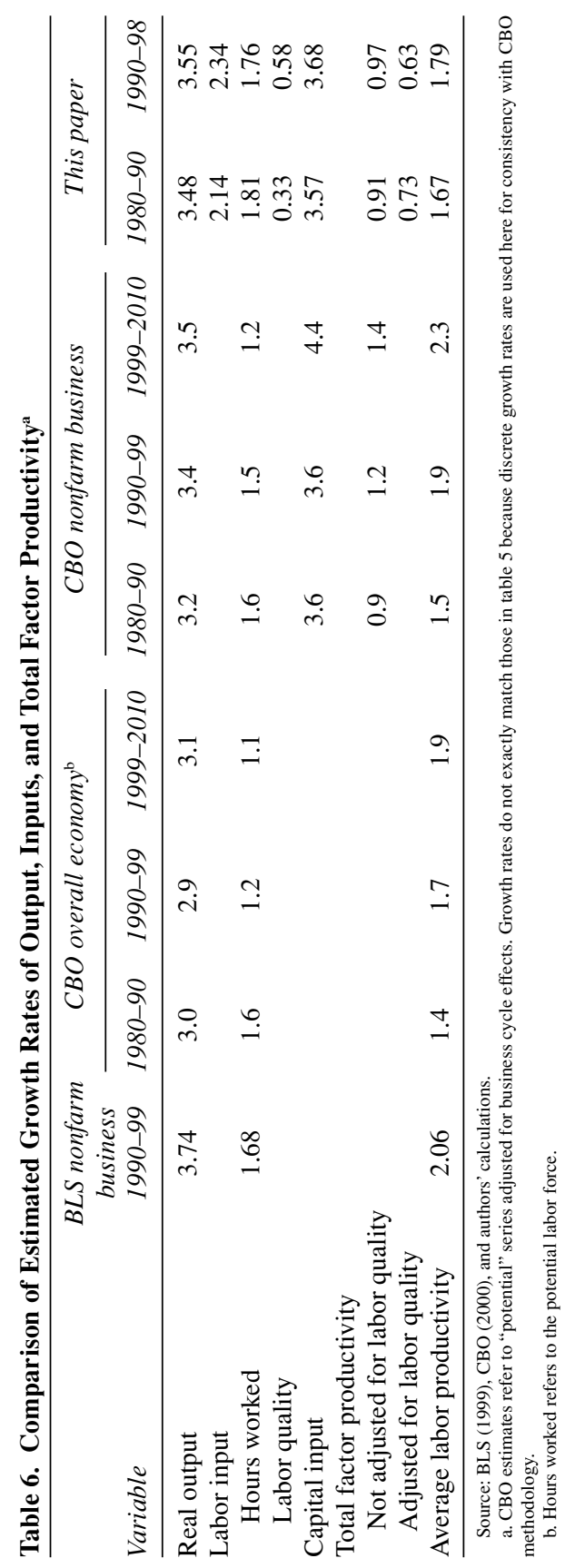


The CBO projects potential GDP growth of 3.1 percent per year for 1999-2010, up slightly from 3.0 percent in the 1980s and 2.9 percent in the 1990s. The agency expects actual GDP growth to be somewhat slower, at 2.8 percent, as the economy moves to a sustainable long-run growth rate. Acceleration in potential GDP growth reflects faster capital accumulation and TFP growth, partly offset by slower growth in hours worked. This projection of GDP growth is 0.4 percentage point higher than earlier estimates. The difference is due to an upward revision in capital growth (0.1 percentage point), slightly more rapid growth in hours ( 0.1 percentage point), and faster TFP growth, reflecting the benchmark revisions of the NIPAs and other technical changes ( 0.2 percentage point) ${ }^{73}$

The CBO's estimates for the nonfarm business sector show strong potential output growth of 3.5 percent per year for 1999-2010. Although this projection is in line with the experience of the 1990s and somewhat faster than in the 1980s, there are significant differences in the underlying sources. Most important, the CBO projects an increasing role for capital accumulation and TFP growth over the next decade, but a slowing in hours growth. This implies that future output growth is driven by ALP growth rather than growth in hours worked.

The CBO projects that potential nonfarm business ALP growth for 1999-2010 will rise to 2.3 percent per year, powered by capital deepening (projected to grow at 3.2 percent) and TFP growth (1.4 percent). This represents a marked jump in ALP growth relative to the 1.5 percent annual rate of the 1980s and the 1.9 percent rate of the 1990s. In considering whether the recent acceleration in ALP growth represents a break in trend, the $\mathrm{CBO}$ "gives considerable weight to the possibility that the experience of the past few years represents such a break." ${ }^{\prime 4}$ Such an assumption appears plausible given recent events, and already low unemployment and high labor force participation make growth in hours worked a less likely source of future growth. Falling investment prices for IT make capital deepening economically attractive, and the recent acceleration in TFP growth gives further grounds for optimistic projections.

As the investment boom continues and firms substitute toward more IT in production, the $\mathrm{CBO}$ has steadily revised upward its projected growth

73. See CBO (1999b) for the earlier estimates, and CBO (2000, p. 25 and p. 43) for details on the changes.

74. CBO (2000, p. 43). 
rates of capital. It is worth noting just how much the role of capital accumulation has grown in successive CBO projections: its projected annual growth rate has risen from 3.6 percent in January 1999, to 4.1 percent in July 1999 , to 4.4 percent in January $2000 .^{75}$ This reflects the inclusion of relatively fast growing software investment in the benchmark revision of the NIPAs, but also the extrapolation of recent investment patterns.

Similarly, the CBO has raised its projected rate of annual TFP growth in successive estimates: from 1.0 percent in January 1999, to 1.1 percent in July 1999 , to 1.4 percent in January $2000 .{ }^{76}$ These upward revisions reflect methodological changes in how the $\mathrm{CBO}$ accounts for the rapid price declines in investment goods, particularly computers, which added 0.2 percentage point to the TFP growth rate. CBO adjustments for the benchmark revision of the NIPAs contributed another 0.1 percentage point.

Table 6 also reports our own estimates of growth. Although the time periods are not precisely identical, our results are similar to those of the CBO. We estimate slightly faster growth during the 1980s, the result of rapidly growing consumer durables services, but slightly lower rates of capital accumulation because of our broader measure of capital. Our growth of hours worked is higher, since we omit the cyclical adjustments made by the CBO to develop its potential series. ${ }^{77}$ Finally, our TFP growth rates are considerably lower, as a result of our labor quality adjustments and inclusion of consumer durables. If we were to drop the labor quality adjustment, our estimate would rise to 1.0 percent per year for 1990-98, which is comparable to the CBO's 1.2 percent figure for 1990-99. The remaining difference reflects the fact that we do not include the rapid TFP growth of 1999 but do include the services of consumer durables, which involve no growth in TFP.

\section{Evaluating the CBO Projections}

Evaluating the CBO's growth projections requires an assessment of their estimates of the growth of capital, labor, and TFP. It is important to

75. CBO (1999a, 1999b, 2000).

76. Earlier upward revisions to TFP growth primarily reflect "technical adjustment ... for methodological changes to various price indexes" and "increased TFP projections" (CBO, 1999b, p. 3).

77. See CBO (1995) for details on the methodology for cyclical adjustments to derive the potential series. 
emphasize that this is not intended as a criticism of the $\mathrm{CBO}$, but rather a description of best practice in the difficult area of growth projections. We also note that comparisons between our estimates and the CBO's are not exact, because of our broader output concept and our focus on actual data series as opposed to the potential series that are the CBO's focus.

We begin with the CBO's projections of potential labor input. These data, based on hours worked from BLS and SSA demographic projections, show a decline in annual hours growth from 1.5 percent in the 1990 s to 1.2 percent for the period 1999-2010. This slowdown reflects the familiar demographic changes associated with the aging of the U.S. population. However, the CBO does not explicitly estimate labor quality, so that labor composition changes are included in its estimates of TFP growth and essentially held constant.

We estimate growth in labor quality of 0.57 percent per year for 1990-98, and our projections based on demographic trends yield a growth rate of only 0.32 percent for the $1998-2010$ period. Assuming the same labor share (0.70) as does the CBO, this implies a decline in the growth contribution from labor quality of about 0.18 percentage point per year over the CBO's projection horizon. Since this labor quality effect is implicitly incorporated into the CBO's TFP estimates, we conclude that their TFP projections are overstated by this 0.18 -percentage-point decline in the labor quality contribution.

TFP growth is perhaps the most problematic issue in long-term projections. Given the recent experience of the U.S. economy, it appears reasonable to expect strong future productivity performance. As discussed above and shown in table 2, TFP growth increased markedly during the period 1995-98. However, extrapolation of this experience runs the risk of mistaking a temporary productivity spurt for a permanent change in trend.

Second, the recent acceleration of TFP growth is due in considerable part to the surge in productivity growth in IT-producing industries. This makes the economy particularly vulnerable to slowing productivity growth in these industries. Computer prices have declined at extraordinary rates in recent years, and it is far from obvious that this can continue. However, the acceleration in the rate of price decline reflects the change in the product cycle for semiconductors, which has shifted from three years to two and may be permanent.

We conclude that the CBO's projection of TFP growth is optimistic in assuming a continuation of recent productivity trends, but nonetheless rea- 
sonable. However, we reduce this projection by 0.18 percentage point per year to reflect the decline in labor quality growth, resulting in projected TFP growth of 1.22 percent per year. To obtain a projection of labor input growth, we add labor quality growth of 0.32 percent per year to the CBO's projection of growth in hours of 1.2 percent per year. Multiplying labor input growth of 1.52 percent per year by the CBO's labor share of 0.7 , we obtain a contribution of labor input of 1.06 percentage points per year.

The CBO's projected annual growth rate of capital input of 4.4 percent is higher than has been witnessed in any previous decade, and 0.8 percentage point higher than in the 1990s. ${ }^{78}$ This projection extrapolates recent increases in the relative importance of computers, software, and communications equipment. Continuing rapid capital accumulation is also predicated on the persistence of high rates of decline in asset prices, resulting from rapid productivity growth in the IT-producing sectors. Any attenuation in this rate of decline would produce a double whammy: less TFP growth in the IT-producing industries themselves, and reduced capital deepening elsewhere.

Relative to historical trends, the CBO's capital input growth projection of 4.4 percent seems out of line with the projected growth of potential output of 3.5 percent. During the 1980s, capital growth exceeded potential output growth by 0.4 percentage point, according to the agency's estimates, and by 0.1 percentage point in our estimates. In the 1990 s, capital growth exceeded output growth by only 0.2 percentage point, again according to their estimates, and by 0.1 percentage point in our estimates. This difference jumps to 0.9 percentage point for the period of the CBO's projections, 1999-2010.

Revising the growth of capital input downward, to reflect the difference between the growth of output and the growth of capital input during 1995-98 of 0.2 percentage point, would reduce the CBO's projection of output growth to 3.35 percent per year. This is the sum of their projected growth of TFP of 1.22 percentage points per year, the contribution of labor input of 1.06 percentage points per year, and the contribution of capital input of 1.07 percentage points per year. This is a very modest reduction from the CBO's projection of 3.5 percent per year and can be attributed to the omission of a projected decline in labor quality growth.

78. These comparisons are from CBO (2000, table 2-6). 
We conclude that the CBO's projections are consistent with the evidence they present, as well as our own analysis of recent trends. However, any slowdown in technical progress in IT could have a major impact on potential growth. Through both output and input channels, the U.S. economy has become highly dependent on IT as the driving force in continued growth. Should productivity growth in these industries falter, the projections we have reviewed could be overly optimistic.

\section{Industry Productivity}

We have so far explored the sources of U.S. economic growth at the aggregate level and demonstrated that accelerated TFP growth is an important contributor to the recent growth resurgence. Aggregate TFP gainsthe ability to produce more output from the same inputs-reflect the evolution of the production structure at the plant or the firm level in response to technological changes, managerial choices, and economic shocks. These firm- and industry-level changes then cumulate to determine aggregate TFP growth. We now turn our attention to industry data in order to trace aggregate TFP growth to its sources in the productivity growth of individual industries, as well as in reallocations of output and inputs among industries.

Our approach utilizes the framework of Jorgenson, Frank Gollop, and Barbara Fraumeni for quantifying the sources of economic growth for U.S. industries. ${ }^{79}$ The industry definitions and data sources have been brought up to date. Their methodology for aggregating over industries is based on Domar's approach to aggregation. ${ }^{80}$ The remainder of this section summarizes our methodology and discusses the results.

\section{Methodology}

As was done for the aggregate production model discussed above, we begin with an industry-level production model for each industry. A crucial distinction, however, is that industry output $Q_{i}$ is measured using a

79. Jorgenson, Gollop, and Fraumeni (1987).

80. Domar (1961). Jorgenson and Stiroh (2000) have presented summary data from our recent work; other recent studies of industry-level productivity growth include BLS (1999), Corrado and Slifman (1999), and Gullickson and Harper (1999). 
gross output concept, which includes output sold as final goods as well as output sold to other industries as intermediate goods. Similarly, inputs include all production inputs, including capital services $K_{i}$ and labor services $L_{i}$, as well as intermediate inputs, energy $E_{i}$ and materials $M_{i}$, purchased from other industries. ${ }^{81}$ Our model is based on the following industry production function:

$$
Q_{i}=A_{i} \cdot X_{i}\left(K_{i}, L_{i}, E_{i}, M_{i}\right),
$$

where time subscripts have been suppressed for clarity.

We can derive a growth accounting equation similar to equation 2 for each industry to measure the sources of economic growth for individual industries. The key difference is the use of gross output and an explicit accounting of the growth contribution of intermediate inputs purchased from other industries. This yields the following equation:

$$
\Delta \ln Q_{i}=\bar{v}_{K_{i}} \Delta \ln K_{i}+\bar{v}_{L_{i}} \Delta \ln L_{i}+\bar{v}_{E_{i}} \Delta \ln E_{i}+\bar{v}_{M_{i}} \Delta \ln M_{i}+\Delta \ln A_{i},
$$

where $\bar{v}_{i}$ is the average share of the subscripted input in the $i$ th industry, and the assumptions of constant returns to scale and competitive markets imply $\bar{v}_{K_{i}}+\bar{v}_{L_{i}}+\bar{v}_{E_{i}}+\bar{v}_{M_{i}}=1$.

The augmentation factor $\Delta \ln A_{i}$ represents the growth in output not explained by input growth and is conceptually analogous to the TFP concept used above in the aggregate accounts. It represents efficiency gains, technological progress, scale economies, and measurement errors that allow more measured gross output to be produced from the same set of measured inputs. We refer to this term as industry productivity, or simply productivity, to distinguish it from TFP, which is estimated from a value-added concept of output. (The BLS refers to the same concept as multifactor productivity.)

Domar first developed an internally consistent methodology that linked industry-level productivity growth as in equation 8 with aggregate TFP growth as in equation $2 .^{82} \mathrm{He}$ showed that aggregate TFP growth can be expressed as a weighted average of industry productivity growth:

$$
\Delta \ln A=\sum_{i=1}^{37} \bar{w}_{i} \cdot \Delta \ln A_{i}, \bar{w}_{i}=\frac{1}{2}\left(\frac{P_{i, t} \cdot Q_{i, t}}{P_{Y, t} \cdot Y_{t}}+\frac{P_{i, t-1} \cdot Q_{i, t-1}}{P_{Y, t-1} \cdot Y_{t-1}}\right),
$$

81. This is analogous to the sectoral output concept used by the BLS. See Gullickson and Harper (1999), particularly pp. 49-53, for a review of the concepts and terminology used by the BLS.

82. Domar (1961). 
where $\bar{w}_{i}$ is the "Domar weight," $P_{i} \cdot Q_{i}$ is current dollar gross output in sector $i$, and $P_{Y} \cdot Y$ is current dollar aggregate value added. This simplified version of the aggregation formula given by Jorgenson, Gollop, and Fraumeni excludes reallocations of value added, capital input, and labor input by sector; Jorgenson and Stiroh show that these terms are negligible for the period 1958-96, which is consistent with the results of Jorgenson, Gollop, and Fraumeni and of Jorgenson for periods of similar duration. ${ }^{83}$

Domar weights have the notable feature that they do not sum to unity. This reflects the different output concepts used at the aggregate and industry levels in equations 1 and 7, respectively. At the aggregate level, only primary inputs are included, whereas both primary and intermediate inputs are included in the industry production functions. For the typical industry, gross output considerably exceeds value added, and therefore the sum of gross output across industries exceeds the sum of value added. This weighting methodology implies that economy-wide TFP growth can grow faster than productivity in any industry, since productivity gains are magnified as they work their way through the production process. $^{84}$

In addition to providing an internally consistent aggregation framework, industry-level gross output allows an explicit role for intermediate goods as a source of industry growth. For example, Jack Triplett shows that a substantial portion of the price declines in computer output can be traced to steep price declines in semiconductors, the major intermediate input in the computer-producing industry. ${ }^{85}$ Price declines in semiconductors reflect technological progress-Moore's law in action. ${ }^{86}$ This should be measured as productivity growth in the industry that produces semiconductors. By correctly accounting for the quantity and quality of intermediate inputs, the gross output concept allows aggregate TFP gains to be correctly allocated among industries.

83. Jorgenson, Gollop, and Fraumeni (1987); Jorgenson and Stiroh (2000); Jorgenson (1990).

84. Jorgenson, Gollop, and Fraumeni (1987), particularly chapter 2, provide details and earlier references; Gullickson and Harper (1999, p. 50) discuss how aggregate productivity can exceed industry productivity in the Domar weighting scheme.

85. Triplett (1996).

86. Moore's law states that the power of state-of-the-art semiconductors doubles approximately every eighteen months to two years. 


\section{Data Sources}

Our primary data include a set of interindustry transactions accounts developed by the Employment Projections Office at the BLS. These data cover a relatively short time period from 1977 to 1995 . We linked the BLS estimates to industry-level estimates going back to 1958, described by Stiroh, ${ }^{87}$ and extrapolated to 1996 using current BLS and BEA industry data. ${ }^{88}$ This generated a time series for the period 1958-96 for thirtyseven industries, at roughly the two-digit Standard Industrial Classification (SIC) level, including the private household and general government "industries." 89 Table 7 lists the thirty-seven industries, the size of each in terms of 1996 value added and gross output, and the underlying SIC codes for each industry.

Before proceeding to the empirical results, we should point out two limitations of this industry-level analysis. First, given the long lag in the release of detailed interindustry transactions, investment, and output data by industry, our industry data are not consistent with the BEA benchmark revision of the NIPAs published in December 1999; rather, they correspond to the NIPAs produced by the BEA in November 1997. As a consequence, they are not directly comparable to the aggregate data described in tables 1 through 6 . Since the impact of the benchmark revision was to raise estimates of output and aggregate TFP growth, it is not surprising that the industry data show slower output and productivity growth. Second, our estimates of rental prices for all assets in this industry analysis are based on industry-wide asset revaluation terms, and we assume that services are proportional to the lagged stock for individual assets, as in Jorgenson and Stiroh. ${ }^{90}$ They are not directly comparable to the aggregate data on capital input, where asset-specific revaluation terms are included in the rental price estimates and averages of current and lagged stocks are used in the service flow estimates. This tends to reduce the growth in capital services, since assets with falling relative prices, such as computers, have high service prices and rapid accumulation rates.

87. Stiroh (1998a).

88. We are grateful to Mun Ho for his extensive contributions to the construction of the industry data.

89. Appendix D provides details on the component data sources and linking procedures.

90. Jorgenson and Stiroh (2000). 
Table 7. Value Added and Gross Output by Industry, 1996

Billions of current dollars

\begin{tabular}{|c|c|c|c|}
\hline Industry & SIC codes & Value added & Gross output ${ }^{\mathrm{b}}$ \\
\hline Agriculture & $01-02,07-09$ & 133.3 & 292.2 \\
\hline Metal mining & 10 & 8.8 & 10.7 \\
\hline Coal mining & $11-12$ & 14.7 & 21.1 \\
\hline Petroleum and gas & 13 & 57.4 & 83.3 \\
\hline Nonmetallic mining & 14 & 10.5 & 17.0 \\
\hline Construction & $15-17$ & 336.0 & 685.5 \\
\hline Food products & 20 & 147.2 & 447.6 \\
\hline Tobacco products & 21 & 26.7 & 32.7 \\
\hline Textile mill products & 22 & 19.9 & 58.9 \\
\hline Apparel and textiles & 23 & 40.7 & 98.5 \\
\hline Lumber and wood & 24 & 34.2 & 106.7 \\
\hline Furniture and fixtures & 25 & 23.4 & 54.5 \\
\hline Paper products & 26 & 68.3 & 161.0 \\
\hline Printing and publishing & 27 & 113.5 & 195.6 \\
\hline Chemical products & 28 & 184.0 & 371.2 \\
\hline Petroleum refining & 29 & 44.7 & 184.3 \\
\hline Rubber and plastic & 30 & 64.1 & 148.9 \\
\hline Leather products & 31 & 3.4 & 8.1 \\
\hline Stone, clay, and glass & 32 & 40.4 & 79.1 \\
\hline Primary metals & 33 & 57.6 & 182.1 \\
\hline Fabricated metals & 34 & 98.4 & 208.8 \\
\hline Industrial machinery and equipment & 35 & 177.8 & 370.5 \\
\hline Electronic and electric equipment & 36 & 161.9 & 320.4 \\
\hline Motor vehicles & 371 & 84.9 & 341.6 \\
\hline Other transportation equipment & $372-379$ & 68.0 & 143.8 \\
\hline Instruments & 38 & 81.3 & 150.0 \\
\hline Miscellaneous manufacturing & 39 & 24.8 & 49.3 \\
\hline Transport and warehouse & $40-47$ & 258.6 & 487.7 \\
\hline Communications & 48 & 189.7 & 315.8 \\
\hline Electric utilities & $491, \% 493$ & 111.8 & 186.7 \\
\hline Gas utilities & $492, \% 493,496$ & 32.9 & 57.9 \\
\hline Trade & $50-59$ & $1,201.2$ & $1,606.4$ \\
\hline $\mathrm{FIRE}^{\mathrm{c}}$ & $60-67$ & 857.8 & $1,405.1$ \\
\hline Services & $70-87,494-495$ & $1,551.9$ & $2,542.8$ \\
\hline Government enterprises & & 95.2 & 220.2 \\
\hline Private households & 88 & $1,248.4$ & $1,248.4$ \\
\hline General government & & $1,028.1$ & $1,028.1$ \\
\hline
\end{tabular}

Source: Authors' calculations based on BLS and BEA data.

a. Refers to payments to capital, labor, and taxes.

b. Includes payments for intermediate inputs.

c. Finance, insurance, and real estate. 


\section{Empirical Results}

SOURCES OF INDUSTRY GROWTH. Table 8 reports estimates of the components of equation 8 for the period 1958-96. For each industry we show the growth in output, the contribution of each input (defined as the nominal share-weighted growth rate of the input), and productivity growth. We also report growth in ALP, defined as real gross output per hour worked, and the Domar weights calculated from equation 9 . We focus the discussion of our results on industry productivity and ALP growth.

Industry productivity growth was highest in two high-technology industries, industrial machinery and equipment, and electronic and electric equipment, at 1.5 percent and 2.0 percent per year, respectively. Industrial machinery and equipment includes the production of computer equipment (SIC 357), and electronic and electric equipment includes the production of semiconductors (SIC 3674) and communications equipment (SIC 366). Enormous technological progress in the production of these high-technology capital goods has generated falling prices and productivity growth and fueled the substitution toward IT.

An important feature of these data is that we can isolate productivity growth for industries, such as the electronic and electric equipment industry, that produce important intermediate goods. (Our industry classification is too broad to specifically isolate the production of semiconductors, however.) Consider the contrast between computer production and semiconductor production. Computers are part of final demand, sold as consumption and investment goods, and can be identified in the aggregate data, as we did in table 2. Semiconductors, on the other hand, do not appear at the aggregate level, since they are sold almost exclusively as an input to computers, telecommunications equipment, and an increasingly broad range of other products such as machine tools, automobiles, and virtually all recent vintages of appliances. Nonetheless, improved semiconductor production is an important source of aggregate TFP growth, since it is ultimately responsible for the lower prices and improved quality of goods, such as computers, produced for final demand.

The enormous price declines in computer equipment and the prominent role of investment in computers in the GDP accounts have led some researchers to emphasize technological progress in the production of computers. Triplett, however, quantifies the role of semiconductors as an intermediate input and estimates that falling semiconductor prices may account 


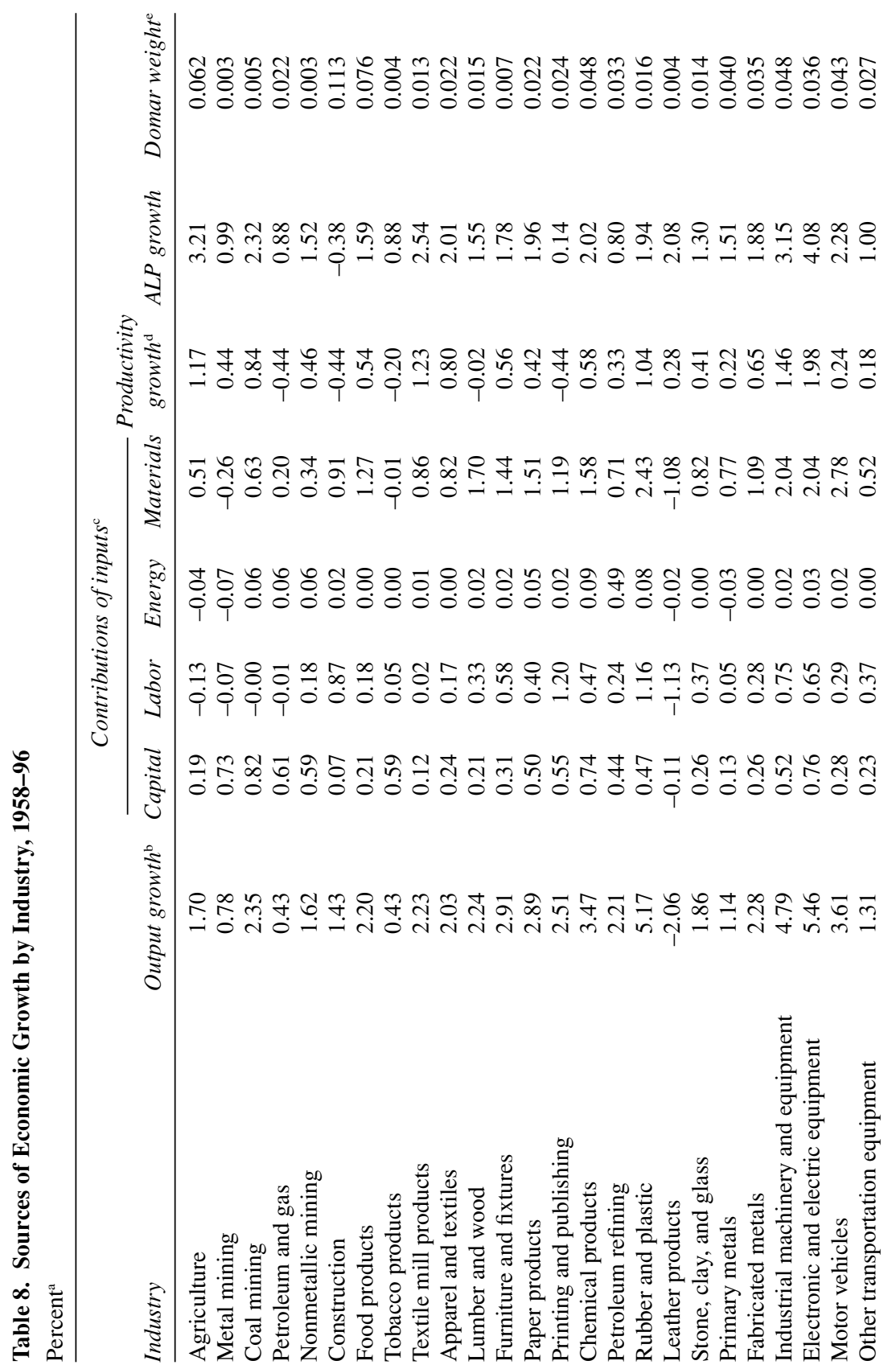




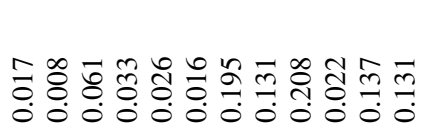

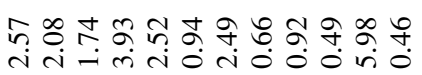

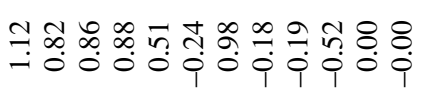

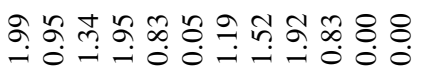

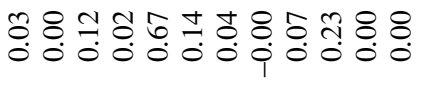

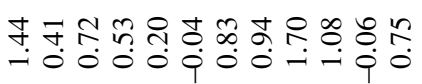

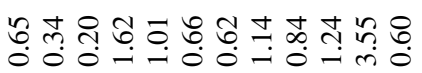

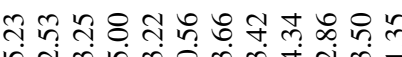

तं लं लं

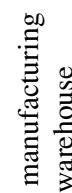


for virtually all of the relative price declines in computer equipment. He concludes, "productivity in the computer industry palls beside the enormous increases in productivity in the semi-conductor industry." 91

The decline in prices of semiconductors is reflected in the prices of intermediate inputs into the computer industry, effectively moving productivity away from computers and toward semiconductor production. Building on this observation, Oliner and Sichel present a model that includes three sectors-semiconductor production, computer production, and other goods - and shows that semiconductor productivity is substantially more important than computer productivity. ${ }^{92}$ Our complete industry framework with Domar aggregation over all industries captures the contributions of productivity growth from all industries.

The impact of intermediate inputs can be seen in table 8 in the large contribution of material inputs in the industrial machinery industry. Since a substantial portion of these inputs consists of semiconductors purchased from the electronic equipment industry, productivity gains that lower the price of semiconductors increase the flow of intermediate inputs into the industrial machinery industry. When we account for these inputs correctly, industry productivity growth in the industrial machinery industry falls, and we can rightly allocate technological progress to the electronic equipment industry, which produces semiconductors. Although this type of industry reallocation does not affect aggregate productivity growth, it is important to identify the sources of productivity growth and allocate this among industries in order to assess the sustainability of the recent acceleration.

The two high-technology industries also show high rates of ALP growth of 3.1 percent and 4.1 percent per year, respectively. This reflects an underlying relationship similar to equation 3 for the aggregate data, where industry ALP growth reflects industry productivity growth, labor quality

91. Triplett (1996, p. 137). This conclusion rests critically on the input share of semiconductors in the computer industry. Triplett reports an estimate of this share, based on Bureau of the Census data, of 15 percent for 1978-94, but he states that industry sources estimate this share to be closer to 45 percent. This has an important impact on his results. At one end of the spectrum, if no account is made for semiconductor price declines, relative productivity in computer equipment increases 13.4 percent for 1978-94. Assuming a 15 percent share for semiconductors causes this to fall to 9 percent; assuming a 45 percent share causes a fall to 1 percent.

92. Oliner and Sichel (2000). 
growth, and increases in input intensity, including increases in capital as well as in intermediate inputs per hour worked. As implied by table 8 , these industries showed rapid accumulation of capital and intermediate inputs, which raised ALP growth above productivity growth. It is also worthwhile to note that communications, another high-technology industry, shows ALP growth much faster than industry productivity growth, because of the rapid accumulation of inputs, notably intermediate materials. These results highlight the crucial importance of accounting for all inputs when examining the sources of industry growth.

Productivity growth in IT provides a final perspective on the conclusions of Greenwood, Hercowitz, and Krusell and of Hercowitz..$^{93}$ They argue that some 60 percent of postwar U.S. growth can be attributed to investment-specific (embodied) productivity growth, which they distinguish from input accumulation and (disembodied) productivity growth. As evidence, they note that the relative price of equipment in the United States has fallen 3 percent per year, which they interpret as evidence of technical change that affects capital goods but not consumption goods. Our decomposition, however, reveals that declines in the prices of investment goods are the consequence of improvements in industry (disembodied) productivity. Domar aggregation shows how these improvements contribute directly to aggregate TFP growth. There is no separate role for investment-specific technical change.

Other industries that show relatively strong productivity growth include agriculture, textile mill products, rubber and plastic, instruments, and trade. All of these industries experienced productivity growth in the range of 1.0 percent per year, and ALP growth in the range of 2 to 3 percent. Industries with the slowest productivity growth include petroleum and gas, construction, printing and publishing, and government enterprises, all of which showed declines in productivity of nearly 0.5 percent per year.

It is worth emphasizing that nine industries showed negative productivity growth for the entire period, a counterintuitive result if one were to interpret productivity growth solely as technological progress. It is difficult to envision technology steadily worsening for a period of nearly forty years as these estimates imply. The perplexing phenomenon of negative technical progress was a primary motivation of the work of Carol Corrado and Lawrence Slifman, and of Gullickson and Harper, who suggest

93. Greenwood, Hercowitz, and Krusell (1997); Hercowitz (1998). 
persistent measurement problems as a plausible explanation. ${ }^{94}$ Corrado and Slifman conclude, "a more likely statistical explanation for the implausible productivity, profitability, and price trends . . . is that they reflect problems in measuring prices. ${ }^{95}$ If prices are systematically overstated because quality change is not accurately measured, then output and productivity are correspondingly understated. We do not pursue this idea here, but simply point out that some statistical agencies consider measurement problems a reasonable explanation. ${ }^{96}$

An alternative interpretation of negative productivity growth is the possibility of declines in efficiency that have no association with technology. These might include lower quality of management and a worsening of industrial organization through the growth of barriers to entry. This appears to be a plausible explanation, given the widespread occurrence of negative productivity growth for extended periods. Until more careful research linking firm- and plant-level productivity to industry productivity estimates has been done, it would be premature to leap to the conclusion that estimates of economic performance should be adjusted so as to eliminate negative productivity growth rates, wherever they occur.

Low productivity growth rates are particularly surprising in light of the fact that many of the affected industries are heavy investors in IT. Stiroh, for example, reports that nearly 80 percent of computer investment in the early 1990s was in three service-related industries: trade, FIRE, and services; Triplett reports a high concentration in service industries using the BEA's capital use survey. ${ }^{97}$ The apparent combination of slow productivity growth and heavy computer use remains an important obstacle for "new economy" proponents who argue that the use of IT is fundamentally changing business practices and raising productivity throughout the U.S. economy.

COMPARISONS WITH OTHER RESULTS. Before proceeding to the Domar aggregation results, it is useful to compare the results just presented with those of three other recent studies. A BLS study reports industry produc-

94. Corrado and Slifman (1999); Gullickson and Harper (1999).

95. Corrado and Slifman (1999, p. 331).

96. Dean (1999) summarizes the BLS view on this issue. McGuckin and Stiroh (forthcoming) attempt to quantify the magnitude of the potential mismeasurement effects.

97. Stiroh (1998a); Triplett (1999). 
tivity growth for nineteen manufacturing industries for 1949-96; Corrado and Slifman report estimates of ALP growth for selected one- and twodigit SIC industries for the period 1977-97; Gullickson and Harper report industry productivity growth for certain one- and two-digit SIC industries based on two output series for the period 1947-92..$^{98}$ Like the BLS, Gullickson and Harper use a "sectoral output" concept estimated by the Employment Projections staff at the BLS, and they use, for 1977-92, the BEA's gross output series "adjusted for consistency." 99 Note that none of these studies reflect the BEA's benchmark revision of the NIPAs.

Differences with respect to time period, industry classification, and methodology make a definitive reconciliation with our results impossible. For example, the BLS reports detailed manufacturing industries; Corrado and Slifman use a value-added concept, the BEA's "gross product originating," for output; Gullickson and Harper (1999) use the same data sources we do but make different adjustments for consistency and do not account for labor quality growth. Nonetheless, it is useful to compare the broad trends in the results of these different studies over similar time periods to assess the robustness of our findings.

We first consider the ALP estimates of Corrado and Slifman. We can compare similar time periods, but relatively few of their industries overlap with ours, since our industry breakdown focuses on manufacturing industries, whereas they provide details primarily for service industries. For comparable industries, however, the results are quite similar. For seven industries with comparable definitions, five show differences in ALP growth of less than 0.25 percentage point when we compare our estimates for 1977-96 with Corrado and Slifman's estimates for 1977-97. ${ }^{100}$ Our ALP growth rates for communications and trade are below theirs by 1.3 and 0.4 percentage points, respectively, for these periods.

Our productivity estimates for 1977-92 for the majority of industries are similar to those of Gullickson and Harper. The range of discrepancies is somewhat greater because of the difficulty of linking the various data sets needed to estimate intermediate inputs and industry productivity

98. BLS (1999); Corrado and Slifman (1999); Gullickson and Harper (1999).

99. See Gullickson and Harper (1999, particularly pp. 55-56) for details.

100. Corrado and Slifman (1999, table 2). These five industries are agriculture, construction, transportation, FIRE, and services. Note that our estimates for 1977-96 are not given in table 10 . 
growth. For seven of the eleven comparable industries, productivity differences are less than 0.5 percentage point; the discrepancies are greater for four industries: metal mining, coal mining, petroleum and gas, and services. ${ }^{101}$ Similar differences can also be seen in Gullickson and Harper's comparison of productivity growth estimated from the BLS and BEA gross output series, where they find differences of 0.5 percentage point or more in seventeen out of forty industries and aggregates. Methodological differences, such as the inclusion of labor quality growth in our estimates of labor input growth, contribute to this divergence, as do different methods for linking data sets.

Neither Corrado and Slifman nor Gullickson and Harper break out ALP growth or industry productivity growth for detailed manufacturing industries. To gauge these results, we have compared our manufacturing results with the manufacturing industry estimates made by the BLS. ${ }^{102}$ Of the eighteen industries that are comparable, ten showed productivity differences of less than 0.25 percentage point for 1979-96; two showed differences between 0.25 and 0.5 percentage point; and the remaining six industries-textile mill products; lumber and wood; petroleum refining; leather products; stone, clay, and glass; and instruments-showed differences greater than 0.5 percentage point. ${ }^{103}$

DOMAR AGGREGATION. We now turn to the aggregation of industry productivity growth described by equation 9 . This exercise is not directly comparable to our estimates of aggregate productivity, because of different vintages of data and a broader definition of output. Nonetheless, it is useful to quantify an industry's contribution to aggregate TFP growth and to trace aggregate productivity growth back to its sources at the level of the individual industry. These results update the earlier estimates of Jorgenson, Gollop, and Fraumeni; Gordon presents a similar decomposition for ALP growth, although he focuses exclusively on the contribution from computer production. ${ }^{104}$

101. The seven industries that are comparable are agriculture, nonmetallic mining, construction, transportation, communications, trade, and FIRE.

102. BLS (1999).

103. The ten industries with small differences are food products, apparel and textiles, furniture and fixtures, paper products, printing and publishing, chemical products, primary metals, industrial machinery and equipment, electronic and electric equipment, and miscellaneous manufacturing. The two industries with slightly larger differences are rubber and plastic, and fabricated metals.

104. Jorgenson, Gollop, and Fraumeni (1987); Gordon (1999b). 
Figure 11 presents our estimates of each industry's contribution to aggregate TFP growth for the period 1958-96. This follows equation 9 by weighting industry productivity growth by the Domar weight, defined as industry gross output divided by aggregate value added. Summing across industries gives an estimate of aggregate TFP growth of 0.48 percent per year for 1958-96. This is lower than the number implied by table 2, for two reasons. First, the data are from before the BEA benchmark revision, which raised estimates of output and TFP growth. Second, the estimates include a broader output concept that includes government enterprises, which we estimate has negative industry productivity growth, and general government, which has zero productivity growth by definition. The estimate is consistent, however, with the estimates in Mun Ho, Jorgenson, and Stiroh and in Jorgenson and Stiroh, which are based on data of the same vintage. ${ }^{105}$

The most striking feature of figure 11 is the wide range of industry contributions. Trade, electronic and electric equipment, and industrial machinery and equipment make the largest contributions among nonagricultural industries, although for different reasons. Trade displays solid, but not exceptionally strong, productivity growth of almost 1 percent per year, but makes the largest contribution because of its large relative size; it receives a Domar weight of nearly 0.20 . Industrial machinery and electronic equipment, on the other hand, make important contributions because of their rapid productivity growth, 1.5 percent and 2.0 percent, respectively, in spite of their relatively small size, with Domar weights of 0.05 and 0.04 , respectively. An industry's contribution to aggregate productivity growth depends on both productivity performance and relative size.

Figure 11 also highlights the impact of the nine industries that experienced negative productivity growth over this period. Again, both performance and relative size matter. Services makes a negative contribution of 0.07 percentage point because of its large weight and productivity growth of -0.19 percent per year. Construction, on the other hand, shows even slower industry productivity growth, -0.44 percent per year, but makes a smaller negative contribution, since it is so much smaller than services. We can also do a "thought experiment" similar to that of Corrado and Slifman, and Gullickson and Harper, and imagine that productivity growth is zero in these nine industries rather than negative. ${ }^{106}$ By zeroing out the negative

105. Ho, Jorgenson, and Stiroh (1999); Jorgenson and Stiroh (1999).

106. Corrado and Slifman (1999); Gullickson and Harper (1999). 
Figure 11. Industry Contributions to Aggregate TFP Growth, 1958-96 ${ }^{\text {a }}$

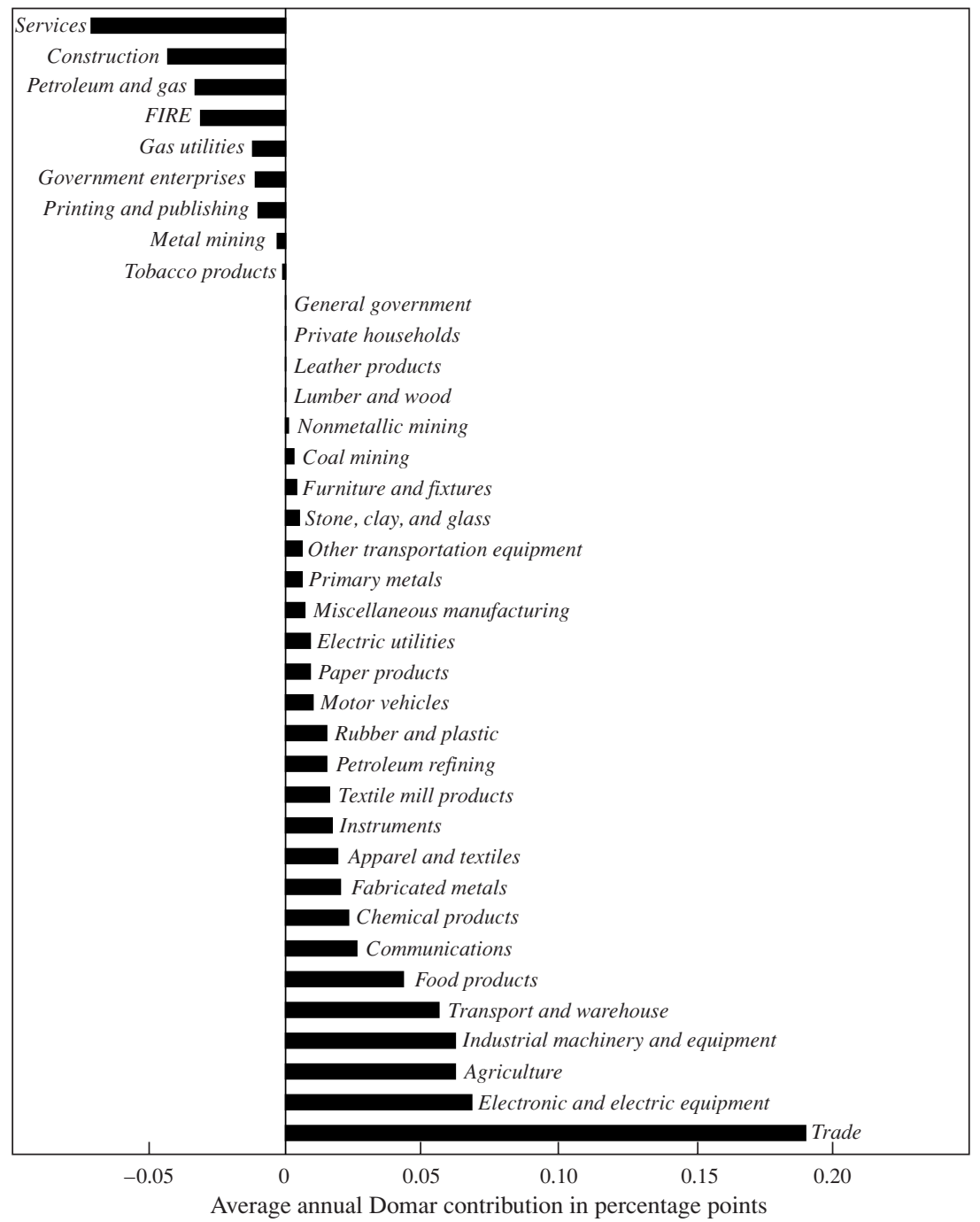

Source: Authors' calculations based on BEA, BLS, Census Bureau, and other data sources.

a. Each industry's contribution is calculated as the product of its productivity growth and its Domar weight, averaged for $1958-96$. 
contributions, we find that aggregate TFP growth would have been 0.22 percentage point higher, an increase of nearly half. ${ }^{107}$ Clearly, negative productivity growth in these industries is an important part of the aggregate productivity story.

Finally, these data enable us to provide some new perspective on an argument made by Gordon, who decomposes trend-adjusted ALP growth into a portion due to computer production and a residual portion for the rest of the economy. ${ }^{108} \mathrm{He}$ finds that the former accounts for virtually all of the productivity acceleration since 1997. Although we cannot comment directly on his empirical estimates, since our industry data end in 1996 and we examine TFP growth rather than ALP growth, we can point to an important qualification to his argument. The U.S. economy is made up of industries with both positive and negative productivity growth rates, so that comparing one industry with the aggregate of all others necessarily involves aggregation over offsetting productivity trends. The fact that this aggregate does not show net productivity growth does not necessarily entail the absence of gains in productivity in any of the component industries, since these gains could be offset by declines in other industries.

Consider our results for 1958-96 and the importance of the negative contributions. The five industries with the largest positive contributions - trade, electronic equipment, agriculture, industrial machinery, and transport—cumulatively account for the sum across all industries, about 0.5 percent per year. Nonetheless, we find sizable productivity growth in some remaining industries that are offset by negative contributions in others. This logic, and the prevalence of negative measured productivity growth rates at the industry level, ${ }^{109}$ suggest that a similar argument could hold for ALP and for the most recent period. This raises the question of whether offsetting productivity growth rates are responsible for Gordon's finding that there is " $n o$ productivity growth in the 99 percent of the

107. This aggregate impact is smaller than that estimated by Gullickson and Harper (1999), partly because our shares differ as a result of the inclusion of household and government "industries." Also, as Gullickson and Harper point out, a complete reestimation would account for the change in intermediate inputs implied by the productivity adjustments.

108. Gordon (1999b). Oliner and Sichel (2000) argue that Gordon's conclusion is weakened by the new NIPA data released in the benchmark revision, which allow a larger role for ALP growth outside of computer production.

109. As found in BLS (1999), Corrado and Slifman (1999), and Gullickson and Harper (1999). 
economy located outside the sector which manufactures computer hardware." ${ }^{110}$ Assessing the breadth of recent productivity gains and identifying the sources of productivity growth at the industry level remain important tasks for future research.

\section{Conclusions}

The performance of the U.S. economy in the late 1990s has been nothing short of phenomenal. After a quarter century of economic malaise, accelerating total factor productivity growth and capital deepening have led to a remarkable growth resurgence. The pessimism of the famous Solow paradox, that we see computers everywhere but in the productivity statistics, ${ }^{111}$ has given way to the optimism of the information age. The productivity statistics, beginning in 1995, have begun to reveal a clearly discernible impact of IT. Both labor productivity growth and TFP growth have jumped to rates not seen for such an extended period since the 1960s. Although a substantial portion of these gains can be attributed to computers, there is growing evidence of similar contributions from software and communications equipment-each equal in importance to computers.

The forces shaping the information economy originate in the rapid progress of semiconductor technology-Moore's law at work. These gains are driving down the relative prices of computers, software, and communications equipment and inducing massive investments in these assets by firms and households. Technological progress and the induced capital deepening are the primary factors behind accelerating output growth in recent years. The sustainability of recent growth trends therefore hinges to a great degree on the prospects for continuing progress, especially in the production of semiconductors. Although this seems plausible and perhaps even likely, the contribution of high-technology assets to the growth resurgence remains subject to considerable uncertainty, owing to incomplete information on price trends for these assets.

The strong performance of the U.S. economy has not gone unnoticed. Forecasters have had to raise their projected growth rates and raise them

110. Gordon (1999b, p. 1, italics in original).

111. Robert M. Solow, "We'd Better Watch Out." New York Times Book Review, July 12, 1987, p. 36. 
again. The moderate speed limits set by Alan Blinder and Paul Krugman, ${ }^{112}$ reflecting the best evidence available only a few years ago, have given way to optimism on the part of the ordinarily conservative community of official forecasters. Our review of the evidence now available suggests that the official forecasters are relying very heavily on a continuation of the acceleration in U.S. economic growth since 1995.

Upward revision of growth projections seems a reasonable response as evidence accumulates of a possible break in trend productivity growth. Nonetheless, caution is warranted until productivity patterns have been observed for a longer period. Should the pace of technological progress in high-technology industries diminish, economic growth would be hit with a double whammy: slower TFP growth in important industries that produce high-technology equipment, and slower capital accumulation in other sectors that invest in and use that equipment. Both factors have made important contributions to the recent success of the U.S. economy, so that any slowdown would retard future growth potential.

At the same time, we must emphasize that the uncertainty surrounding intermediate-term projections has become much greater as a consequence of widening gaps in our knowledge, rather than changes in the volatility of economic activity. The excellent research that underlies the estimates of prices and quantities of computer investment in the NIPAs has provided much-needed illumination of the impact of IT. But this is only part of the contribution of IT to economic growth, and it may not be the largest part. As the role of technology continues to increase, ignorance of the most basic empirical facts about the information economy will plague researchers as well as forecasters. The uncertainties about past and future economic growth will not be resolved quickly. This is, of course, a guarantee that the lively economic debate now unfolding will continue for the foreseeable future.

The first priority for empirical research must be constant-quality price indexes for a wider variety of high-technology assets. These assets are becoming increasingly important in the U.S. economy, but only a small portion have constant-quality price deflators that translate the improved production characteristics into accurate measures of investment and output. This echoes the earlier findings of Gordon, who reported that official price measures substantially overstate price changes for capital goods; in 
fact, Gordon identified computers and communications equipment as two assets with the largest overstatements, together with aircraft, which we have not included. ${ }^{113}$ Much remains to be done to complete Gordon's program of implementing constant-quality price deflators for all components of investment in the NIPAs.

The second priority for research is to decompose the sources of economic growth to the industry level. Fortunately, the required methodology is well established and increasingly familiar. Domar aggregation over industries underlies our back-of-the-envelope calculations of the contribution of IT to economic growth, as well as our more careful and comprehensive view of the contributions of industry-level productivity. This view will require considerable refinement to discriminate among alternative perspectives on the rapidly unfolding information economy. However, the evidence already available is informative on the most important issue. This is the "new economy" view that the impact of IT is like phlogiston, an invisible substance that spills over into every kind of economic activity and reveals its presence by increases in industry-level productivity growth across the U.S. economy. This view is simply inconsistent with the empirical evidence.

Our results suggest that although technology is clearly the driving force in the growth resurgence, familiar economic principles can be applied. Productivity growth in the production of IT is responsible for a sizable part of the recent spurt in TFP growth and can be identified with price declines in high-technology assets and semiconductors. This has induced an eruption of investment in these assets, which is responsible for capital deepening in those industries that use IT. IT thus provides a dramatic illustration of economic incentives at work. However, there has been no corresponding eruption of industry-level productivity growth in these sectors that would herald the arrival of phlogiston-like spillovers from production in the IT sectors.

Many of the goods and services produced using high-technology capital may not be adequately measured, as suggested in the already classic paper by Griliches. ${ }^{14}$ This may help to explain the surprisingly low productivity growth observed in many of the high-technology-intensive 
service industries. If the official data are understating both real investment in high-technology assets and real consumption of commodities produced from these assets, the resulting underestimation of U.S. economic performance may be far more serious than we have suggested. Only as the statistical agencies continue their slow progress toward improved data and implementation of state-of-the-art methodology will this murky picture become more transparent.

APPENDIX A

Estimating Output

WE BEGIN WITH the NIPAs as our primary data source. These data correspond to the most recent benchmark revision published by the BEA on October 29, 1999. They provide measures of investment and consumption in both current and chained 1996 dollars. The framework developed by Laurits Christensen and Jorgenson, however, calls for a somewhat broader treatment of output than in the national accounts. ${ }^{115}$ Most important, consumer durable goods are treated symmetrically with investment goods, since both are long-lived assets that are accumulated and provide a flow of services over their lifetimes. We use a rental price to impute a flow of consumer durable services to be included in both consumption output and capital input. We also employ a rental price to make relatively small imputations for the service flows from owner-occupied housing and institutional equipment.

Table A1 presents the time series of total output in current dollars and the corresponding price index for 1959-98. The table also includes the current dollar value and price index for the various IT output componentscomputer investment, software investment, communications investment, computer and software consumption, and the imputed service flow of computer and software consumer durables-as described in equation 4 in the text.

115. Christensen and Jorgenson (1973). 


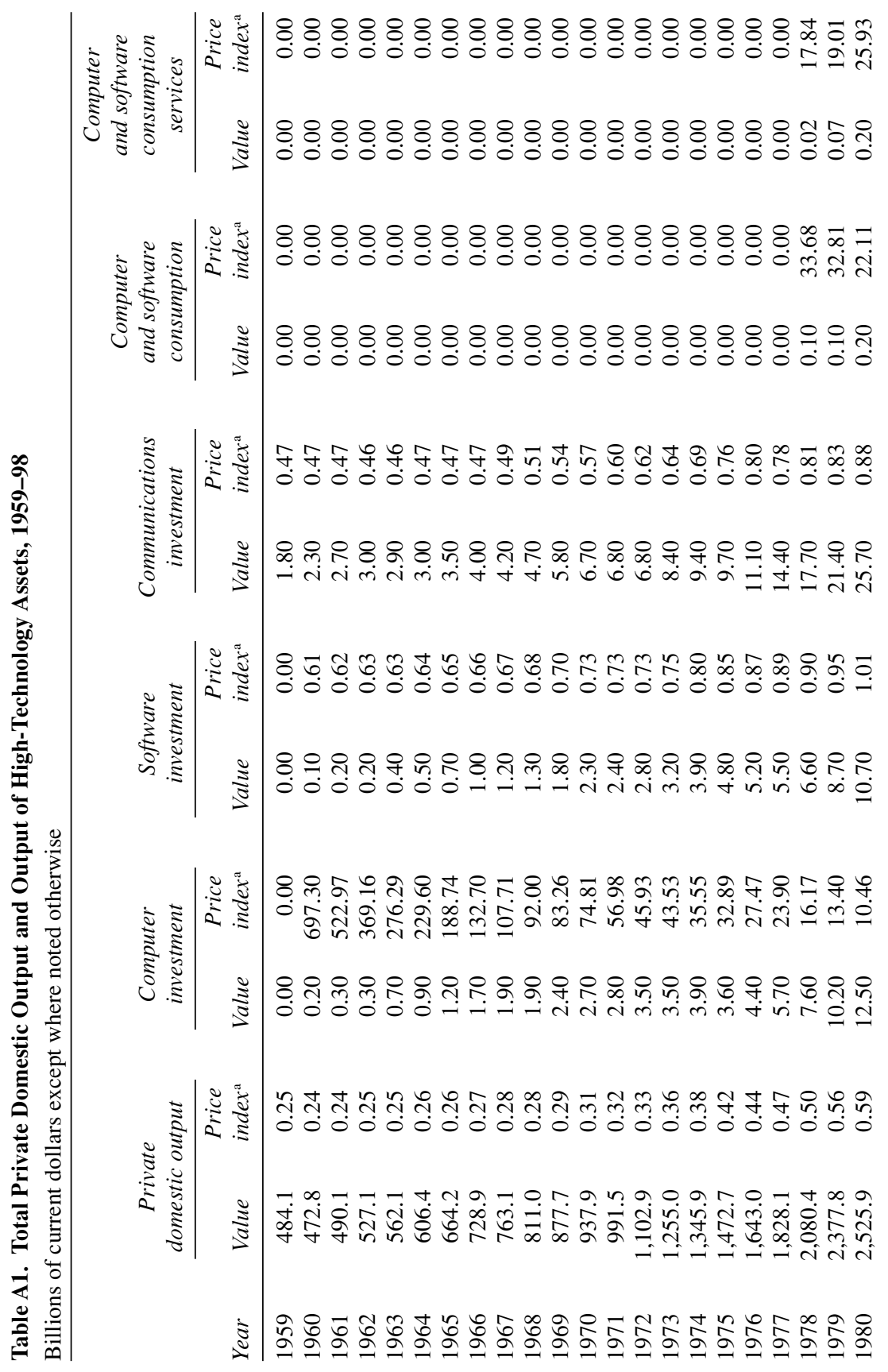




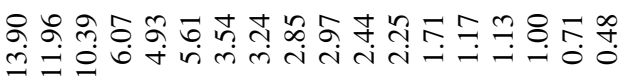

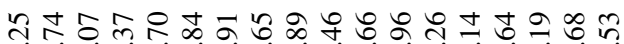
○े

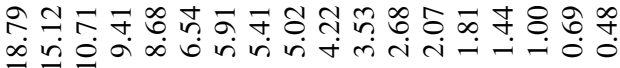

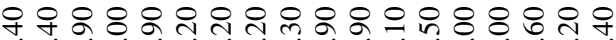

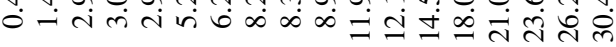

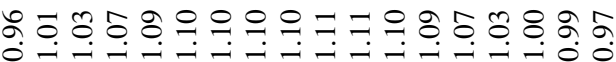

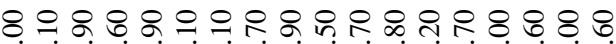

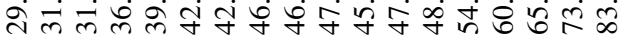

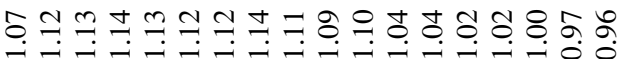

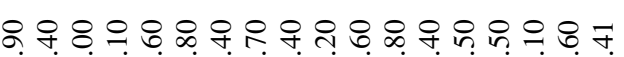

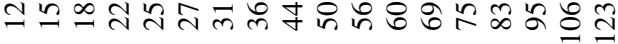

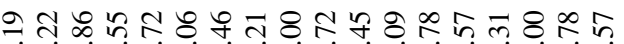
वं

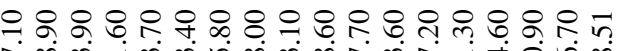

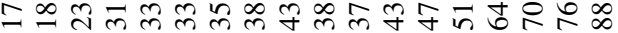

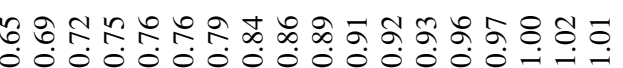

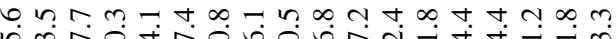

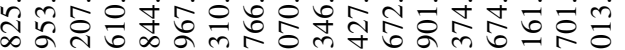

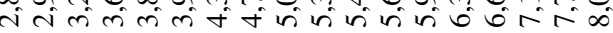


APPENDIX B

\section{Estimating Capital Services}

\section{Capital Services Methodology}

We begin with some notation for measures of investment, the capital stock, and capital services, for both individual assets and aggregates. For individual assets,

$I_{i, t}=$ quantity of investment in asset $i$ at time $t$

$P_{i, t}=$ price of investment in asset $i$ at time $t$

$\delta_{i}=$ geometric depreciation rate for asset $i$

$S_{i, t}=$ quantity of capital stock of asset $i$ at time $t$

$P_{i, t}=$ price of capital stock of asset $i$ at time $t$

$K_{i, t}=$ quantity of capital services from asset $i$ at time $t$, and

$c_{i, t}=$ the price of capital services from asset $i$ at time $t$,

where the $i$ subscript refers to different types of tangible assets-many different equipment and structure assets, as well as consumer durable assets, inventories, and land-all for time period $t$.

For economy-wide aggregates,

$I_{t}=$ quantity index of aggregate investment at time $t$

$P_{I, t}=$ price index of aggregate investment at time $t$

$S_{t}=$ quantity index of aggregate capital stock at time $t$

$P_{S, t}=$ price index of aggregate capital stock at time $t$

$K_{t}=$ quantity index of aggregate capital services at time $t$

$c_{t}=$ price index of aggregate capital services at time $t$, and

$q_{K, t}=$ quality index of aggregate capital services at time $t$.

Our starting point is investment in individual assets. We assume that the price index for each asset measures investment goods in identically productive "efficiency units" over time. For example, the constant-quality price deflators in the NIPAs measure the large increase in computing power as a decline in the price of computers. ${ }^{116}$ Thus a faster computer is

116. See BLS (1997), particularly chapter 14, for details on the quality adjustments incorporated into the producer price indexes that are used as the primary deflators for the capital stock study. Cole and others $(1986)$ and Triplett $(1986,1989)$ provide details on the estimation of hedonic regressions for computers. 
represented by more $I_{i, t}$ in a given period and a larger accumulation of $S_{i, t}$, as measured by the perpetual inventory equation:

$$
S_{i, t}=S_{i, t-1}\left(1-\delta_{i}\right)+I_{i, t}=\sum_{\tau=0}^{t}\left(1-\delta_{i}\right)^{\tau} I_{i, t-\tau},
$$

where capital is assumed to depreciate geometrically at the rate $\delta_{i}$.

Equation B1 has the familiar interpretation that the capital stock is the weighted sum of past investments, where weights are derived from the relative efficiency profile of capital of different ages. Moreover, since $S_{i, t}$ is measured in base-year efficiency units, the appropriate price for valuing the capital stock is simply the investment price deflator, $P_{i, t}$. Furthermore, $S_{i, t}$ represents the installed stock of capital, but we are interested in $K_{i, t}$, the flow of capital services from that stock over a given period. This distinction is not critical at the level of individual assets, but it becomes important when we aggregate heterogeneous assets.

For individual assets, we assume the flow of capital services is proportional to the average of the stock available at the end of the current and prior periods:

$$
K_{i, t}=q_{K, i} \frac{S_{i, t}+S_{i, t-1}}{2},
$$

where $q_{K, i}$ denotes this constant of proportionality, set equal to unity. Note that this differs from our earlier work and the industry-level analysis, where capital service flows were assumed proportional to the lagged stock for individual assets. ${ }^{17}$

Our approach assumes that any improvement in input characteristics, such as a faster processor in a computer, is incorporated into investment $I_{i, t}$ through deflation of the nominal investment series. That is, investment deflators transform recent vintages of assets into an equivalent number of efficiency units of earlier vintages. This is consistent with the perfect substitutability assumption across vintages and with our use of the perpetual inventory method, where vintages differ in productive characteristics because of the age-related depreciation term.

117. For example, Jorgenson (1990); Jorgenson and Stiroh (1999); Ho, Jorgenson, and Stiroh (1999). 
We estimate a price of capital services that corresponds to the quantity flow of capital services via a rental price formula. In equilibrium, an investor is indifferent between two alternatives: earning a nominal rate of return, $i_{t}$, on a different investment or buying a unit of capital, collecting a rental fee, and then selling the depreciated asset in the next period. The equilibrium condition, therefore, is

$$
\left(1+i_{t}\right) P_{i, t-1}=c_{i, t}+\left(1-\delta_{i}\right) P_{i, t},
$$

and rearranging yields a variation of the familiar cost-of-capital equation:

$$
c_{i, t}=\left(i_{t}-\pi_{i, t}\right) P_{i, t-1}+\delta_{i} P_{i, t},
$$

where the asset-specific capital gains term is $\pi_{i, t}=\left(P_{i, t}-P_{i, t-1}\right) / P_{i, t-1}$.

This formulation of the cost of capital effectively includes assetspecific revaluation terms. An investor who expects capital gains on his or her investment will be willing to accept a lower service price. Conversely, investors will require high service prices for assets such as computers with large capital losses. Empirically, asset-specific revaluation terms can be problematic because of wide fluctuations in prices from period to period that can result in negative rental prices. However, assetspecific revaluation terms are becoming increasingly important as prices continue to decline for high-technology assets. Jorgenson and Stiroh, for example, incorporated economy-wide asset revaluation terms for all assets and estimated a relatively modest growth contribution from computers. ${ }^{118}$

As discussed by Jorgenson and Yun, tax considerations also play an important role in rental prices. ${ }^{119}$ Following Jorgenson and Yun, we account for investment tax credits, capital consumption allowances, the statutory tax rate, property taxes, debt versus equity financing, and personal taxes by estimating an asset-specific, after-tax real rate of return, $r_{i, t}$, that enters the cost-of-capital formula:

$$
c_{i, t}=\frac{1-I T C_{i, t}-\tau_{t} Z_{i, t}}{1-\tau_{t}}\left[r_{i, t} P_{i, t-1}+\delta_{i} P_{i, t}\right]+\tau_{p} P_{i, t-1},
$$


where $I T C_{i, t}$ is the investment tax credit, $\tau_{t}$ is the statutory tax rate, $Z_{i, t}$ is the capital consumption allowance, and $\tau_{p}$ is a property tax rate, all for asset $i$ at time $t$, and $r_{i, t}$ is calculated as

$$
r_{i, t}=\beta\left[\left(1-\tau_{t}\right) i_{t}-\pi_{i, t}\right]+(1-\beta)\left[\frac{\rho_{t}-\pi_{i, t}\left(1-t_{q}^{g}\right)}{\left(1-t_{q}^{e}\right) \alpha+\left(1-t_{q}^{g}\right)(1-\alpha)}\right],
$$

where $\beta$ is the debt-capital ratio, $i_{t}$ is the interest cost of debt, $\rho_{t}$ is the rate of return to equity, $\alpha$ is the dividend payout ratio, and $t_{q}^{g}$ and $t_{q}^{e}$ are the tax rates on capital gains and dividends, respectively. $\pi_{i, t}$ is the inflation rate for asset $i$, which allows $r_{i, t}$ to vary across assets. ${ }^{120}$

Equations B1 through B6 describe the estimation of the price and quantity of capital services for individual assets: $P_{i, t}$ and $I_{i, t}$ for investment; $P_{i, t}$ and $S_{i, t}$ for the capital stock; and $c_{i, t}$ and $K_{i, t}$ for capital services. For an aggregate production function analysis, we require an aggregate measure of capital services, $K_{t}=f\left(K_{1, t}, K_{2, t}, \ldots K_{n, t}\right)$, where $n$ includes all types of reproducible fixed assets, consumer durable assets, inventories, and land. We employ quantity indexes to generate aggregate capital services, the capital stock, and investment series. ${ }^{121}$

The growth rate of aggregate capital services is defined as a shareweighted average of the growth rate of the components:

$$
\Delta \ln K_{t}=\sum_{i} \bar{v}_{i, t} \Delta \ln K_{i, t},
$$

where the weights are value shares of capital income:

$$
\bar{v}_{i, t}=\frac{1}{2}\left(\frac{c_{i, t} K_{i, t}}{\sum_{i} c_{i, t} K_{i, t}}+\frac{c_{i, t-1} K_{i, t-1}}{\sum_{i} c_{i, t-1} K_{i, t-1}}\right),
$$

and the price index of aggregate capital services is defined as

$$
c_{t}=\frac{\sum_{i} c_{i, t} K_{i, t}}{K_{t}} .
$$

120. A complication, of course, is that $\rho_{t}$ is endogenous. We assume that the after-tax rate of return to all assets is the same and estimate $\rho_{t}$ as the return that exhausts the payment of capital across all assets in the corporate sector. In addition, tax considerations vary across ownership classes (for example, corporate, noncorporate, and household). We account for these differences in our empirical work but do not go into detail here. See Jorgenson and Yun (1991, chapter 2).

121. See Diewert (1980) and Fisher (1992) for details. 
Similarly, the quantity index of capital stock is given by

$$
\Delta \ln S_{t}=\sum_{i} \bar{w}_{i, t} \Delta \ln S_{i, t}
$$

where the weights are now value shares of the aggregate capital stock:

$$
\bar{w}_{i, t}=\frac{1}{2}\left(\frac{P_{i, t} S_{i, t}}{\sum_{i} P_{i, t} S_{i, t}}+\frac{P_{i, t-1} S_{i, t-1}}{\sum_{i} P_{i, t-1} S_{i, t-1}}\right),
$$

and the price index for the aggregate capital stock index is

$$
P_{S, t}=\frac{\sum_{i} P_{i, t} S_{i, t}}{S_{t}} .
$$

Finally, the aggregate quantity index of investment is given by

$$
\Delta \ln I_{t}=\sum_{i} \bar{u}_{i, t} \Delta \ln I_{i, t},
$$

where the weights are now value shares of aggregate investment:

$$
\bar{u}_{i, t}=\frac{1}{2}\left(\frac{P_{i, t} I_{i, t}}{\sum_{i} P_{i, t} I_{i, t}}+\frac{P_{i, t-1} I_{i, t-1}}{\sum_{i} P_{i, t-1} I_{i, t-1}}\right),
$$

and the price index for the aggregate investment index is

$$
P_{I, t}=\frac{\sum_{i} P_{i, t} I_{i, t}}{I_{t}} .
$$

The most important point from this derivation is the difference between the growth rate of aggregate capital services, from equation $\mathrm{B} 7$, and the growth rate of the capital stock, from equation B10. This reflects two factors. First, the weights are different. The index of aggregate capital services uses rental prices as weights, whereas the index of the aggregate capital stock uses investment prices. Assets with rapidly falling asset prices will have relatively high rental prices. Second, as can be seen from equation B2, capital services are proportional to a two-period-average stock, so the timing of capital services growth and capital stock growth differs for individual assets. In steady state with a fixed capital-output 
ratio, this distinction is not significant, but if asset accumulation is either accelerating or decelerating, this timing matters.

A second point to emphasize is that we can define an aggregate index of capital quality, $q_{K, t}$, analogously to equation B2. We define this index as $q_{K, t}=K_{t} /\left[\left(S_{t}+S_{t-1}\right) / 2\right]$, and it follows that the growth of capital quality is defined as

(B16) $\Delta \ln q_{K, t}=\Delta \ln K_{t}-\Delta \ln \left(\frac{S_{t}+S_{t-1}}{2}\right)=\sum_{i}\left(\bar{v}_{i, t}-\bar{w}_{i, t}\right) \Delta \ln \left(\frac{S_{t, i}+S_{t-1, i}}{2}\right)$.

Equation B16 defines growth in capital quality as the difference between growth in capital services and growth in the average capital stock. This difference reflects substitution toward assets with relatively high rental price weights and high marginal products. For example, the rental price for computers is declining rapidly as prices fall, which induces substitution toward computers and rapid capital accumulation. However, the high depreciation rate and large negative revaluation term imply that computers have a high marginal product, so that their rental price weight greatly exceeds their asset price weight. Substitution toward assets with higher marginal products is captured by our index of capital quality.

\section{Investment and Capital Data}

Our primary data source for estimating the aggregate flow of capital services is the BEA publication "Investment Estimates of Fixed Reproducible Tangible Wealth, 1925-1997." ${ }^{122}$ These data contain historical cost investment and chain-type quantity indexes for forty-seven types of nonresidential assets, five types of residential assets, and thirteen types of consumer durable assets from 1925 to 1997. Table B1 shows our reclassification of the BEA data into fifty-two nonresidential assets, five residential assets, and thirteen consumer durable assets. ${ }^{123}$

Table B2 presents the value and the price index of the broadly defined capital stock, as well as those of individual IT assets. Table B3 presents

122. BEA (1998b, 1998c).

123. Katz and Herman (1997) and Fraumeni (1997) provide details on the BEA methodology and underlying data sources. 


\begin{tabular}{|c|c|c|c|}
\hline \multirow[b]{2}{*}{ Asset } & \multicolumn{2}{|c|}{$\begin{array}{l}\text { Billions of } \\
\text { current dollars }\end{array}$} & \multirow{2}{*}{$\begin{array}{c}\text { Geometric } \\
\text { depreciation } \\
\text { rate }\end{array}$} \\
\hline & Investment & $\begin{array}{l}\text { Capital } \\
\text { stock }\end{array}$ & \\
\hline Total capital & & $27,954.7$ & $\cdots$ \\
\hline Fixed reproducible assets & $4,161.7$ & $20,804.2$ & $\ldots$ \\
\hline Equipment and software ${ }^{a}$ & 829.1 & $4,082.0$ & \\
\hline Household furniture & 2.3 & 13.1 & 0.1375 \\
\hline Other furniture & 37.6 & 224.4 & 0.1179 \\
\hline Other fabricated metal products & 15.9 & 134.5 & 0.0917 \\
\hline Steam engines & 2.7 & 60.1 & 0.0516 \\
\hline Internal combustion engines & 1.6 & 6.9 & 0.2063 \\
\hline Farm tractors & 10.8 & 60.7 & 0.1452 \\
\hline Construction tractors & 2.9 & 15.3 & 0.1633 \\
\hline Agricultural machinery, except tractors & 13.1 & 89.2 & 0.1179 \\
\hline Construction machinery, except tractors & 20.6 & 99.5 & 0.1550 \\
\hline Mining and oilfield machinery & 2.4 & 15.6 & 0.1500 \\
\hline Metalworking machinery & 37.1 & 228.6 & 0.1225 \\
\hline $\begin{array}{l}\text { Special industry machinery, not elsewhere } \\
\text { classified }\end{array}$ & 38.6 & 288.7 & 0.1031 \\
\hline $\begin{array}{l}\text { General industrial, including materials handling, } \\
\text { equipment }\end{array}$ & 34.5 & 247.5 & 0.1072 \\
\hline Computers and peripheral equipment & 88.5 & 164.9 & 0.3150 \\
\hline Service industry machinery & 17.9 & 92.0 & 0.1650 \\
\hline Communications equipment & 83.6 & 440.5 & 0.1100 \\
\hline $\begin{array}{l}\text { Electrical transmission, distribution, and industrial } \\
\text { apparatus }\end{array}$ & 26.7 & 313.0 & 0.0500 \\
\hline Household appliances & 1.5 & 6.9 & 0.1650 \\
\hline $\begin{array}{l}\text { Other electrical equipment, not elsewhere } \\
\text { classified }\end{array}$ & 15.2 & 64.5 & 0.1834 \\
\hline Trucks, buses, and truck trailers & 104.5 & 367.0 & 0.1917 \\
\hline Automobiles & 19.4 & 70.2 & 0.2719 \\
\hline Aircraft & 23.0 & 174.5 & 0.0825 \\
\hline Ships and boats & 3.0 & 48.4 & 0.0611 \\
\hline Railroad equipment & 5.3 & 69.1 & 0.0589 \\
\hline Instruments (scientific and engineering) & 30.9 & 172.6 & 0.1350 \\
\hline Photocopy and related equipment & 22.6 & 103.0 & 0.1800 \\
\hline Other nonresidential equipment ${ }^{\mathrm{a}}$ & 35.4 & 184.3 & 0.1473 \\
\hline Other office equipment & 8.4 & 24.5 & 0.3119 \\
\hline Software & 123.4 & 302.4 & 0.3150 \\
\hline Nonresidential structures & $2,271.3$ & $5,430.6$ & \\
\hline Industrial buildings & 36.4 & 766.6 & 0.0314 \\
\hline Mobile structures (offices) & 0.9 & 9.8 & 0.0556 \\
\hline Office buildings & 44.3 & 829.8 & 0.0247 \\
\hline Commercial warehouses & 0.0 & 0.0 & 0.0222 \\
\hline $\begin{array}{l}\text { Other commercial buildings, not elsewhere } \\
\text { classified }\end{array}$ & 55.7 & 955.8 & 0.0262 \\
\hline
\end{tabular}


Table B1. (continued)

\begin{tabular}{|c|c|c|c|}
\hline \multirow[b]{2}{*}{ Asset } & \multicolumn{2}{|c|}{$\begin{array}{c}\text { Billions of } \\
\text { current dollars }\end{array}$} & \multirow{2}{*}{$\begin{array}{c}\text { Geometric } \\
\text { depreciation } \\
\text { rate }\end{array}$} \\
\hline & Investment & $\begin{array}{c}\text { Capital } \\
\text { stock }\end{array}$ & \\
\hline Religious buildings & 6.6 & 155.3 & 0.0188 \\
\hline Educational buildings & 11.0 & 157.4 & 0.0188 \\
\hline Hospital and institutional buildings & 17.76 & 355.12 & 0.0188 \\
\hline Hotels and motels & 17.08 & 210.57 & 0.0281 \\
\hline Amusement and recreational buildings & 9.14 & 103.55 & 0.0300 \\
\hline Other nonfarm buildings, not elsewhere classified & 2.07 & 67.68 & 0.0249 \\
\hline Railroad structures & 5.78 & 210.36 & 0.0166 \\
\hline Telecommunications & 13.19 & 282.09 & 0.0237 \\
\hline Electric light and power (structures) & 12.12 & 490.04 & 0.0211 \\
\hline Gas (structures) & 4.96 & 170.98 & 0.0237 \\
\hline Local transit buildings & 0.00 & 0.00 & 0.0237 \\
\hline Petroleum pipelines & 1.11 & 39.20 & 0.0237 \\
\hline Farm-related buildings and structures & 4.59 & 202.73 & 0.0239 \\
\hline Petroleum and natural gas & 22.12 & 276.99 & 0.0751 \\
\hline Other mining exploration & 2.03 & 38.96 & 0.0450 \\
\hline Other nonfarm structures & 6.39 & 107.70 & 0.0450 \\
\hline Railroad track replacement & 0.00 & 0.00 & 0.0275 \\
\hline Nuclear fuel rods & 0.00 & 0.00 & 0.0225 \\
\hline Residential structures & 363.18 & $8,309.62$ & \\
\hline One- to four-unit homes & 240.27 & $5,628.27$ & 0.0114 \\
\hline Five-or-more-unit homes & 21.11 & 871.81 & 0.0140 \\
\hline Mobile homes & 14.64 & 147.17 & 0.0455 \\
\hline Improvements & 86.29 & $1,634.15$ & 0.0255 \\
\hline Other residential & 0.87 & 28.23 & 0.0227 \\
\hline Consumer durables & 698.20 & $2,981.97$ & \\
\hline Automobiles & 166.75 & 616.53 & 0.2550 \\
\hline Trucks & 92.53 & 327.85 & 0.2316 \\
\hline Other (recreational vehicles) & 18.63 & 64.98 & 0.2316 \\
\hline Furniture & 56.02 & 372.26 & 0.1179 \\
\hline Kitchen appliances & 29.83 & 161.75 & 0.1500 \\
\hline China, glassware & 29.65 & 141.44 & 0.1650 \\
\hline Other durable goods & 64.03 & 309.67 & 0.1650 \\
\hline Computers and software & 30.40 & 52.30 & 0.3150 \\
\hline Video, audio & 75.15 & 289.22 & 0.1833 \\
\hline Jewelry & 44.58 & 228.38 & 0.1500 \\
\hline Ophthalmic & 16.53 & 53.44 & 0.2750 \\
\hline Books and maps & 25.34 & 132.51 & 0.1650 \\
\hline Wheel goods & 48.76 & 231.66 & 0.1650 \\
\hline Land & & $5,824.18$ & 0.0000 \\
\hline Inventories & & $1,326.31$ & 0.0000 \\
\hline
\end{tabular}

Source: BEA (1998a, 1998b, 1998c) and authors' calculations.

a. Includes NIPA residential equipment. 


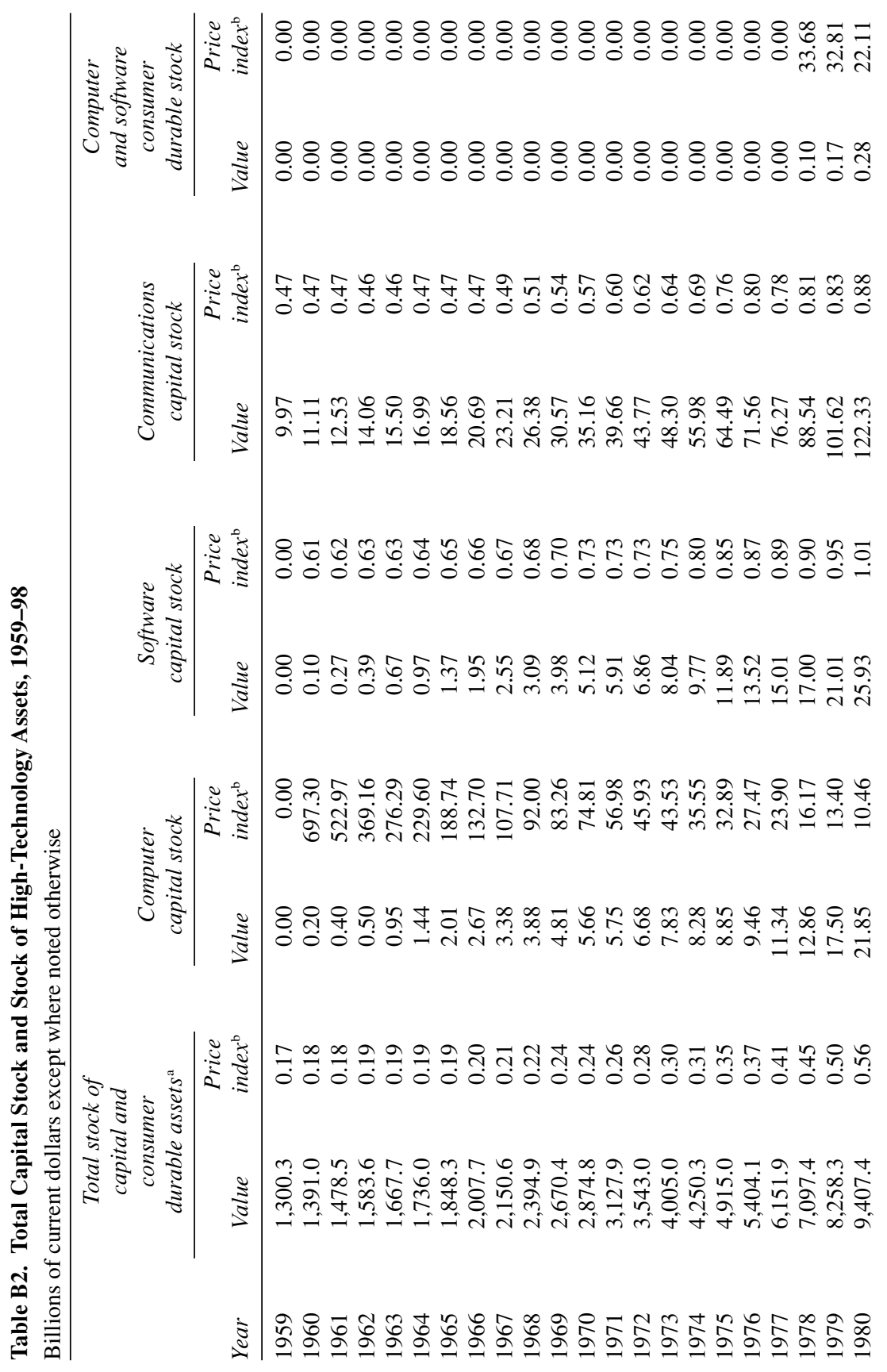




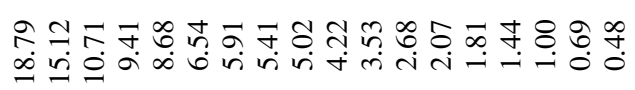

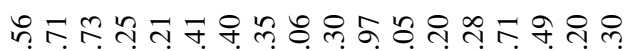

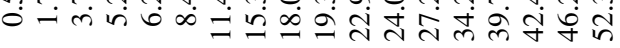

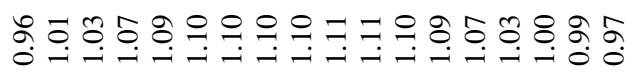

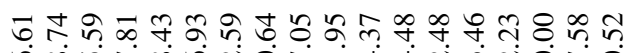

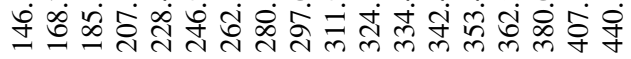

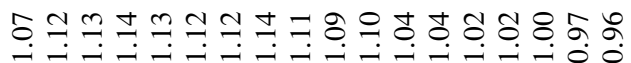

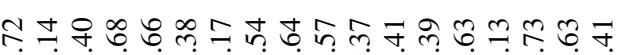
लं

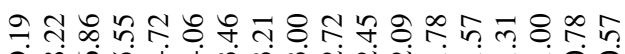

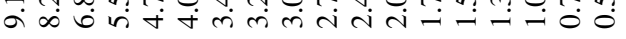

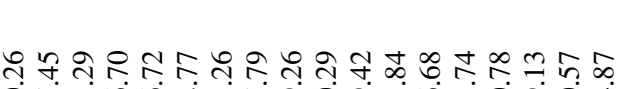

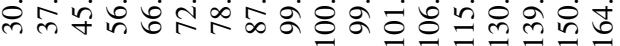

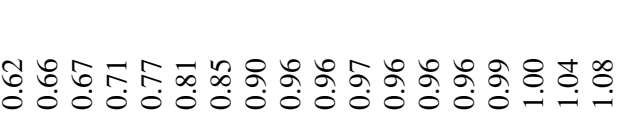

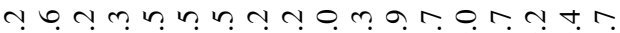

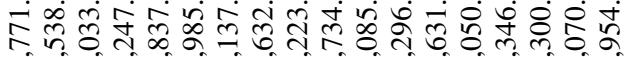

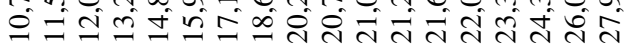




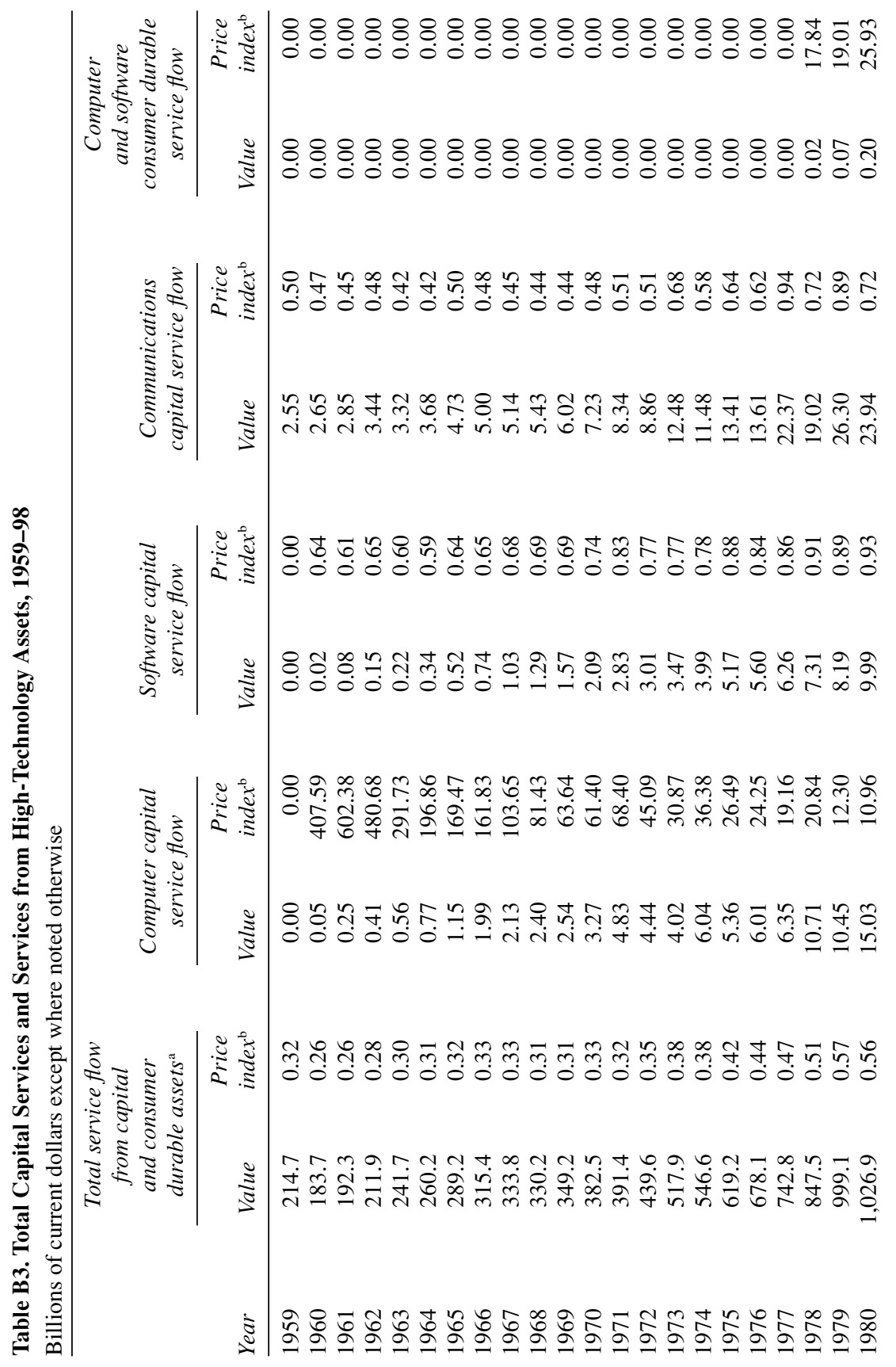




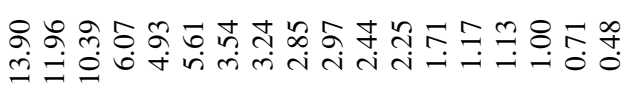

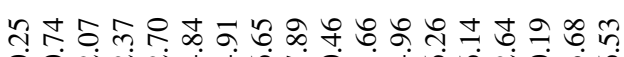

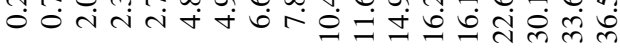

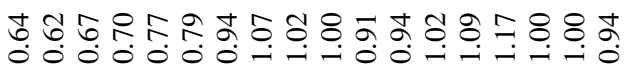

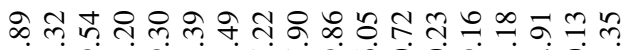

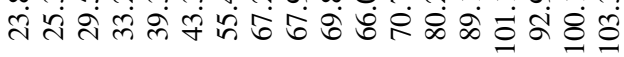

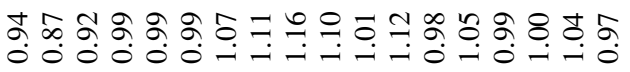

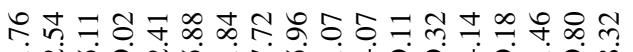

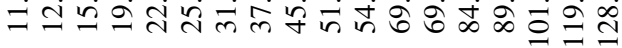

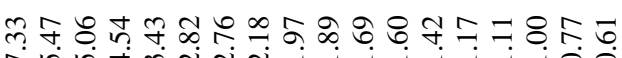

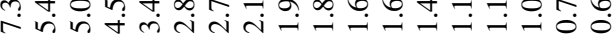

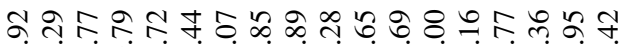

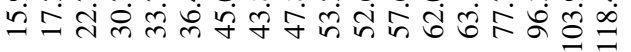

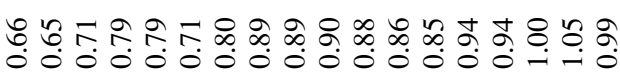

ナ.

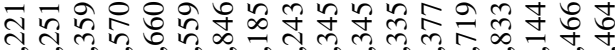

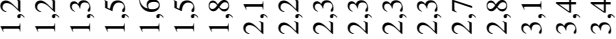

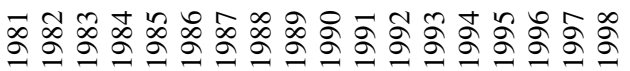


similar data, but for capital service flows rather than capital stocks. ${ }^{124}$ The price of capital stocks for individual assets in table B2 is the same as the investment price in table A1, but the prices differ for aggregates because of differences between weights based on investment flows and those based on asset stocks. The price index for investment grows more slowly than the price index for assets, since short-lived assets with substantial relative price declines are a greater proportion of investment.

An important caveat about the underlying investment data is that these data are available only through 1997 and are therefore not consistent with the BEA benchmark revision of October 1999. We have made several adjustments to reflect the BEA revision, make the data consistent with our earlier work, and extend the investment series to 1998. First, we have replaced the tangible wealth series on computers and peripherals equipment with the NIPA investment series for computers and peripherals equipment, in both current and chained 1996 dollars. These series were identical in the early years and differed by about 5 percent in current dollars in 1997. Similarly, we use the new NIPA series for investment in software, for investment in communications equipment, and for personal consumption of computers, peripherals, and software, in both current and chained 1996 dollars. These NIPA series enable us to maintain a complete and consistent time series that incorporates the latest benchmark revisions and the expanded output concept that includes software.

Second, we have combined investment in residential equipment with "other equipment," a form of nonresidential equipment. This does not change the investment or capital stock totals but reallocates some investment and capital from the residential to the nonresidential category.

Third, we control the total value of investment in major categoriesstructures, equipment and software, residential structures, and total consumer durables- to correspond with the NIPA aggregates. This adjustment maintains a consistent accounting for investment and purchases of consumer durables as inputs and outputs. The computer investment, software investment, communications investment, and consumption of computers, peripherals, and software series are not adjusted.

Fourth, we have extended the investment series through 1998 based on the NIPA estimates. For example, the 1998 growth rate for other fabricated

124. Note that these price indexes have been normalized to equal 1.0 in 1996 , so they do not correspond to the components of the capital service formula in equation B5. 
metal products, steam engines, internal combustion engines, metalworking machinery, special industry machinery, general industrial equipment, and electrical transmission and distribution equipment were taken from the "other" equipment category in the NIPAs. The growth rate of each type of consumer durables was taken directly from the NIPAs.

These procedures generated a complete time series of investment in fifty-seven types of private assets (twenty-nine types of equipment and software, twenty-three types of nonresidential structures, and five types of residential structures) and consumption of thirteen consumer durable assets. The series are in both current dollars and chained 1996 dollars from 1925 to 1998 . For each asset we created a real investment series by linking the historical cost investment and the quantity index in the base year 1996. Capital stocks were then estimated using the perpetual inventory method in equation B1 and a geometric depreciation rate, based on Fraumeni, ${ }^{125}$ and reported in table B1.

Important exceptions are the depreciation rates for computers, software, and automobiles. The BEA reports that its computer depreciation is based on the work of Oliner, is nongeometric, and varies over time. ${ }^{126} \mathrm{We}$ estimated a best geometric approximation to the latest depreciation profile for different types of computer assets and used an average geometric depreciation rate of 0.315 for computer investment, software investment, and consumption of computers, peripherals, and software. Similarly, we estimated a best geometric approximation to the depreciation profile for automobiles of 0.272 .

We also assembled data on inventories and land to complete our capital estimates. The inventory data come primarily from the NIPAs in the form of farm and nonfarm inventories. Inventories are assumed to have a depreciation rate of zero and do not qualify for an investment tax credit or a capital consumption allowance, so the rental price formula is a simplified version of equation B5.

Data on land are somewhat more problematic. Through 1995, the Federal Reserve Board published detailed data on land values and quantities in its "Balance Sheets for the U.S. Economy" study, ${ }^{127}$ but the underlying data became unreliable and are no longer published. We use instead the limited 
land data available in the Fed's "Flow of Funds Accounts of the United States" and historical data to estimate a price and a quantity for private land. ${ }^{128}$ As a practical matter, this quantity series varies very little, so its major impact is to slow the growth of capital by assigning a positive weight to the slow growth rate of land. Depreciation, the investment tax credit, and capital consumption allowances for land are zero, as for inventories.

A final methodological detail involves negative service prices that sometimes result from the use of asset-specific revaluation terms. As can be seen from the simplified cost-of-capital formula in equation B5, an estimated service price can be negative if asset inflation is high relative to the interest and depreciation rates. Economically, this is possible, implying that capital gains were greater than expected. Negative service prices make aggregation difficult, however, and so we made adjustments for several assets. In a small number of cases for reproducible assets and inventories, primarily structures in the 1970s, we used smoothed inflation for the surrounding years rather than the current inflation in the cost-of-capital calculation. For land, which showed large capital gains throughout and has no depreciation, we used the economy-wide rate of asset inflation for all years.

APPENDIX C

\section{Estimating Labor Input}

\section{Labor Input Methodology}

We again begin with some notation for measures of hours worked, labor inputs, and labor quality for categories of workers:

$H_{j, t}=$ quantity of hours worked by worker category $j$ at time $t$

$w_{j, t}=$ price of an hour worked by worker category $j$ at time $t$, and

$L_{j, t}=$ quantity of labor services from worker category $j$ at time $t$,

and for economy-wide aggregates:

$H_{t}=$ quantity of aggregate hours worked at time $t$

$W_{t}=$ average wage for hours worked at time $t$

128. Federal Reserve Board (1997); the historical data are described in Jorgenson (1990). 
$L_{t}=$ quantity index of labor input at time $t$

$P_{L, t}=$ price index of labor input at time $t$, and

$q_{L, t}=$ quality index of labor input at time $t$.

In general, the methodology for estimating labor input parallels that for capital services, but the lack of an investment-type variable makes the labor input somewhat more straightforward. For each individual category of workers, we begin by assuming that the flow of labor service is proportional to hours worked:

$$
L_{j, t}=q_{L, j} H_{j, t},
$$

where $q_{L, j}$ is the constant of proportionality for worker category $j$, set equal to unity.

The growth rate of aggregate labor input is defined as the shareweighted aggregate of the components as

$$
\Delta \ln L_{t}=\sum_{j} \bar{v}_{j, t} \Delta \ln L_{j, t},
$$

where the weights are value shares of labor income:

$$
\bar{v}_{j, t}=\frac{1}{2}\left(\frac{w_{j, t} L_{j, t}}{\sum_{j} w_{j, t} L_{j, t}}+\frac{w_{j, t-1} L_{j, t-1}}{\sum_{j} w_{j, t-1} L_{j, t-1}}\right),
$$

and the price of aggregate labor input is defined as

$$
P_{L, t}=\frac{\sum_{j} w_{j, t} L_{j, t}}{L_{t}} .
$$

We define the aggregate index of labor quality, $q_{L, t}=L_{t} / H_{t}$, where $H_{t}$ is the unweighted sum of labor hours:

$$
H_{t}=\sum_{j} H_{j, t} .
$$

The growth in labor quality is then defined as

$$
\Delta \ln q_{L, t}=\sum_{j} \bar{v}_{j, t} \Delta \ln H_{j, t}-\Delta \ln H_{t} .
$$

Equation C6 defines growth in labor quality as the difference between weighted and unweighted growth in labor hours. As with capital, this 
reflects substitutions among heterogeneous types of labor with different characteristics and different marginal products. As described by Ho and Jorgenson, ${ }^{129}$ one can further decompose labor quality into components associated with different characteristics of labor, such as age, sex, and education.

\section{Labor Data}

Our primary data sources are individual observations from the decennial Censuses of Population for 1970, 1980, and 1990, the NIPAs, and the annual Current Population Survey (CPS). The NIPAs provide totals for hours worked, and the Censuses of Population and the CPS allow us to estimate labor quality growth. ${ }^{130}$ Table $\mathrm{C} 1$ reports the primary labor data used in this study, including the price, quantity, value, and quality of labor input, as well as employment, weekly hours, hourly compensation, and hours worked.

Briefly, the Censuses of Population provide detailed data on employment, hours, and labor compensation across demographic groups in census years. The CPS data are used to interpolate similar data for intervening years, and the NIPA data provide control totals. The demographic groups include 168 different types of workers, cross-classified by sex (male, female), class (employee, self-employed, or unpaid), age (16-17, 18-24, $25-34,35-44,45-54,55-64$, or $65+)$, and education ( $0-8$ years grade school, 1-3 years high school, 4 years high school, 1-3 years college, 4 years college, or $5+$ years college). ${ }^{131}$ Adjustments to the data include allocations of multiple job-holders, an estimation procedure to recover "top-coded" income data, and bridging to maintain consistent definitions of demographic groups over time.

These detailed data cover 1959 to 1995 and are taken from Ho and Jorgenson. ${ }^{132}$ This allows us to estimate the quality of labor input for the private business sector, general government, and government enterprises, where only the private business sector index is used in the aggregate

129. Ho and Jorgenson (1999).

130. Details on the construction of the labor data are found in Ho and Jorgenson (1999). 131. There is also an industry dimension, which we do not exploit in this aggregate framework but is used in the industry productivity analysis discussed below.

132. Ho and Jorgenson (1999). 
growth accounting results. For the years 1996-98 we estimate labor quality growth by holding relative wages across labor types constant and incorporating demographic projections for the labor force. Hours worked by employees are taken from the latest data in the NIPAs; hours worked by the self-employed are estimated by Ho and Jorgenson. ${ }^{133}$

APPENDIX D

\section{Estimating Industry-Level Productivity}

OUR PRIMARY DATA are annual time series of interindustry transactions in current and constant prices, including final demands by commodity, investment and labor inputs by industry, and output by industry. The first building block is a set of interindustry transactions produced by the Employment Projections Office at the BLS. These data report intermediate inputs and total value added (the sum of capital and labor inputs and taxes) for 185 industries from 1977 to 1995 . A major advantage of these BLS interindustry data is that they provide the necessary interpolations between benchmark years.

We aggregate the data from the BLS's "Make" and "Use" tables to generate interindustry transactions for thirty-five private business industries at approximately the two-digit SIC level. These tables enable us to generate growth rates of industry outputs, growth rates of intermediate inputs, and shares of intermediate inputs as needed in equation 8 . They also provide control totals for value added in each industry, as the sum of the values of capital and labor services and taxes.

Estimation of capital services and labor input largely follows the procedures described above for each industry. Key differences include industry-wide revaluation terms in all service price equations and the assumption that services are proportional to the lagged stock for individual assets. We collected information from three sources to estimate prices and quantities of capital and labor inputs by industry. An industry-level breakdown of the value of capital and labor input is available in the "gross product originating" series described by Sherlene Lum and Robert Yuskavage of the BEA. ${ }^{134}$ Investments by asset classes and industries are from the BEA

133. Ho and Jorgenson (1999).

134. Lum and Yuskavage (1997). 


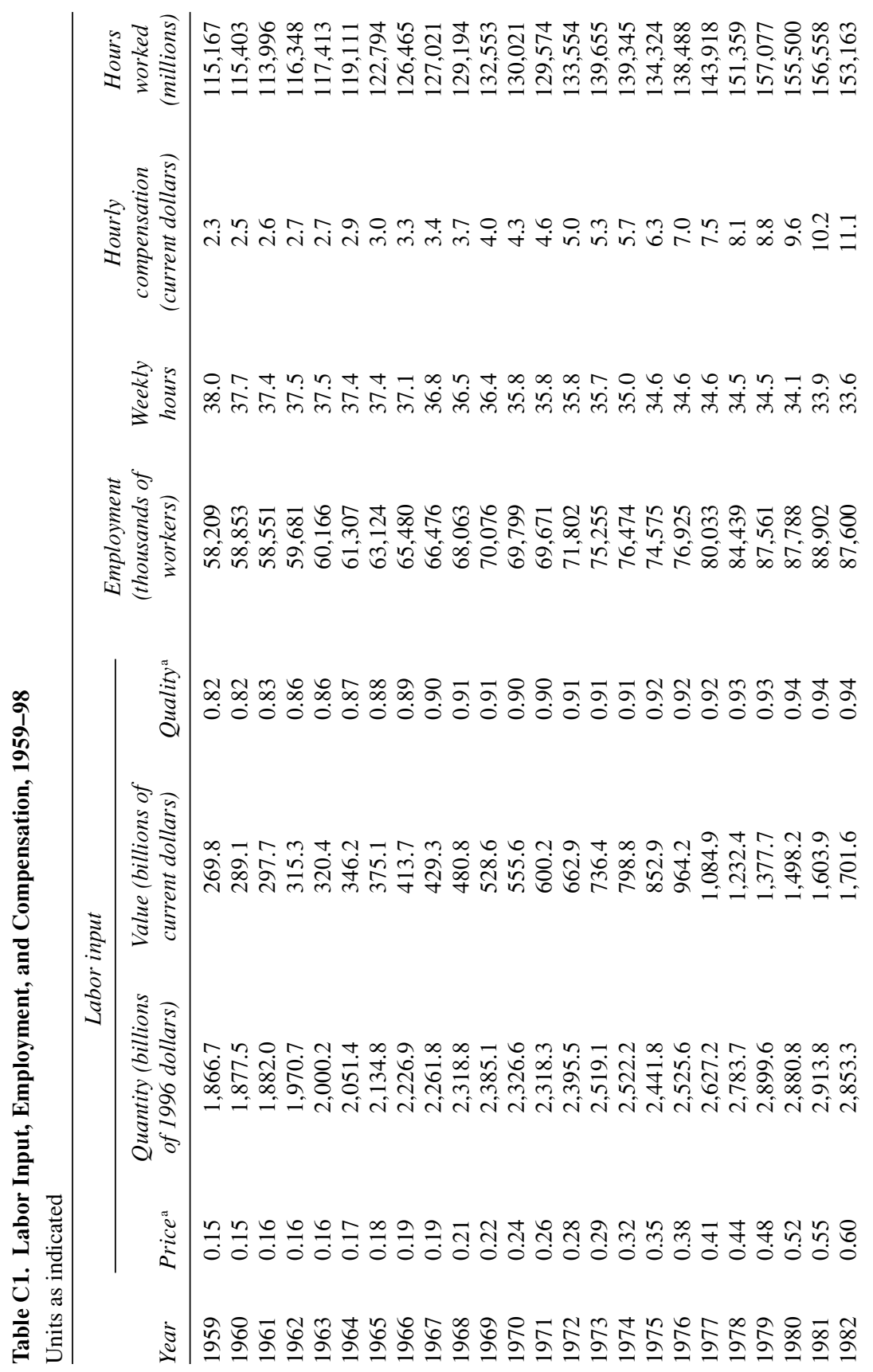




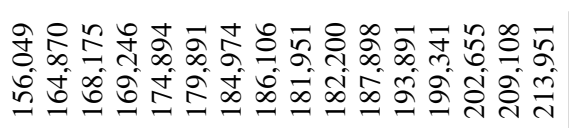

$a+0 n-m m-a m \infty a m \infty m m$

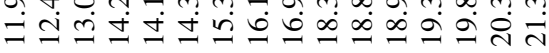

o o a n

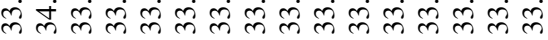

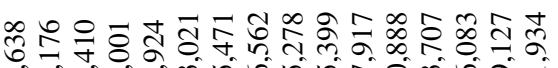

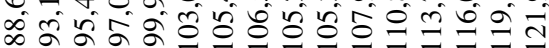

ț

o. 种 की

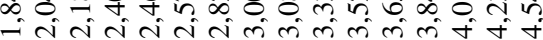

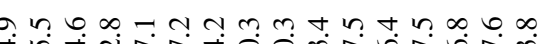
ப்

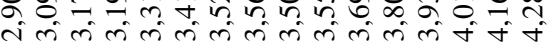

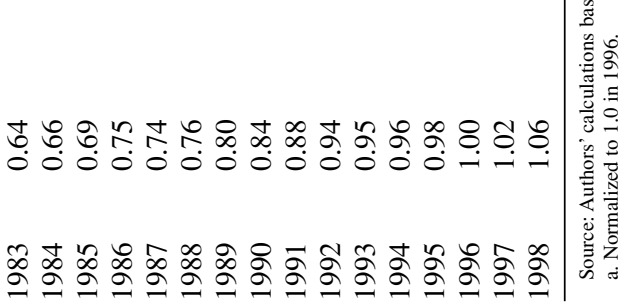


Tangible Wealth Survey, described by Arnold Katz and Shelby Herman. ${ }^{135}$ Labor data across industries are from the decennial Census of Population and the annual CPS. We use the prices and quantities of labor services for each industry constructed by Ho and Jorgenson. ${ }^{136}$

We also generate capital and labor services for a private household sector and the government sector. ${ }^{137}$ For private households, the value of labor services equals labor income in the BLS's private household "industry," whereas capital income reflects the imputed flow of capital services from residential housing, consumer durables, and household land as described above. For government, labor income equals labor compensation of general government employees, and capital income is an estimate of the flow of capital services from government capital. ${ }^{138}$ Note that government enterprises are treated as a private business industry separate from the general government.

\section{APPENDIX E}

\section{Extrapolations for 1999}

TABLE 2 PRESENTS primary growth accounting results through 1998 and preliminary estimates for 1995-99. The data through 1998 are based on the detailed methodology described in appendixes A through D; the 1999 data are extrapolated based on currently available data and recent trends.

Our approach for extrapolating growth accounting results through 1999 was to estimate 1999 shares and growth rates for major categories such as labor, capital, and IT components, as well as growth in output. The 1999 labor share was estimated from 1995-98 data, hours growth is from the BLS, ${ }^{139}$ and labor quality growth is from the projections described above. The 1999 growth rates of IT outputs were taken from the NIPAs, and shares were estimated from 1995-98 data. The 1999 growth rates of IT

135. BEA (1998a); Katz and Herman (1997).

136. Ho and Jorgenson (1999).

137. These sectors include only capital and labor as inputs. Output in these sectors is defined by means of a Tornqvist index of capital and labor inputs, so productivity growth is zero by definition.

138. The BEA uses a similar imputation for the flow of government capital services in the national accounts, but our methodology includes a return to capital, as well as depreciation as estimated by the BEA.

139. BLS (2000). 
inputs were estimated from recent investment data and the perpetual inventory method, and shares were estimated from 1995-98 data. The 1999 growth of other capital was estimated from NIPA investment data for broad categories such as equipment and software, nonresidential structures, and residential structures, as well as consumer durable purchases; the income share was calculated from the estimated labor share. Output growth was estimated from growth in BLS business output and GDP as reported by the BEA, with adjustment made for different output concepts. Finally, TFP growth for 1999 was estimated as the difference between estimated output growth and share-weighted input growth. 


\section{Comments and Discussion}

Robert J. Gordon: The economic miracle of the "Goldilocks" U.S. economy of the late 1990s was the source of pride at home and envy abroad. The miracle was unusual not just for its combination of rapid output and productivity growth, low inflation, and low unemployment, but also for the absence of academic controversy as the news unfolded of one broken record after another. Compared with earlier postwar macroeconomic issues such as the acceleration of inflation in the 1960s, the natural rate hypothesis, the monetarists versus the fiscalists, the supply shocks, and the Reagan-era tax cuts and budget deficits, there has been surprisingly little debate about the sources of the 1990s economic boom.

By the standards of those past debates, there is little disagreement between the paper under discussion and the papers by Stephen Oliner and Daniel Sichel and myself. ${ }^{1}$ All these papers concur that productivity growth ended its long 1972-95 torpor, when it averaged a mere 1.4 percent per year, and suddenly doubled to a rate approaching 2.8 percent after 1995. They also agree that this sudden spurt resulted from an acceleration of technical change in that segment of U.S. manufacturing, often called the information technology sector, that produces computer hardware and peripherals, semiconductors, and software. Almost all the other ingredients of the miracle can be traced, directly or indirectly, to this one critical event of accelerating technical change in IT. Accelerating productivity held down inflation despite accelerating wages; low inflation allowed the

1. Oliner and Sichel (2000); Gordon (2000a, 2000b). The paper cited by Jorgenson and Stiroh as Gordon (1999b) is an earlier version of Gordon (2000b). The data in the earlier version are obsolete because of the major revision of the underlying data in October 1999. 
Federal Reserve (at least until early in 2000) to maintain the Federal funds rate no higher than it had been five years earlier, while long-term government bond rates remained considerably lower; easy monetary policy and rapid economic growth spurred unprecedented growth in profits; and booming profits, together with a wave of optimism about the technological acceleration, propelled stock market valuations to grow far faster than profits. The average American household was showered in stock market wealth, which spurred growth in consumption expenditure greatly in excess of growth in disposable income, with the corollary of a disappearing household saving rate, at least as conventionally measured.

These papers are also complementary. Dale Jorgenson and Kevin Stiroh, like Oliner and Sichel, have produced an imaginative and convincing decomposition of the role of computers, semiconductors, software, and other elements of the "new economy" in the post-1995 acceleration in capital deepening and in total factor productivity. Because they use different concepts and definitions of that portion of the new economy that they cover, their results differ modestly, and I defer to Sichel's comment, which follows, to enlighten us on the sources of those differences. My paper differs from these two papers not in its analysis of the contribution of IT to the productivity acceleration, but rather in its attempt to decompose that acceleration into a permanent, "structural" acceleration in the underlying productivity trend and the remaining, cyclical component. ${ }^{2}$

Before turning to my analysis of the cyclical element in the post-1995 productivity acceleration, a few more general comments on the present paper are in order. It is always a privilege to discuss any paper on economic growth and productivity by Dale Jorgenson and his many former students and other coauthors, for his work since the early 1960s is virtually unique in the continuity and consistency of its research program. The integrity of that program has persuaded the U.S. Bureau of Labor Statistics to adopt his methodology, developed originally in several of his own papers and with the late Zvi Griliches, ${ }^{3}$ for the nation's official measures of growth in output, inputs, and TFP.

A critical element of this research is the emphasis on the role in economic growth of changes in the composition of capital and labor inputs. Because short-lived equipment involves far more depreciation expense per

2. The most recent version is Gordon (2000b).

3. Jorgenson and Griliches (1967). 
dollar of capital cost than do long-lived structures, such equipment must yield a higher marginal product of capital in order to warrant its purchase by firms. As Jorgenson and Griliches showed long ago, equipment and structures must be weighted by their marginal products (or user costs), not their purchase prices, in any analysis of economic production. This adjustment for the shifting composition of the capital stock from structures to equipment gives a substantial boost to the growth rate of capital input, and causes a corresponding reduction in the growth rate of TFP, throughout the postwar period. ${ }^{4}$

Although Jorgenson and Stiroh do not report the magnitude of these capital composition adjustments, the labor composition adjustments for changes in educational attainment and changes in the labor force mix by age and sex are shown explicitly in their table $\mathrm{C} 1$. The average annual growth rate of the labor composition adjustment, 0.53 percent from 1959 to 1998 , is consistent with other estimates, including those of the BLS. As a matter of intellectual history, we should remember that the first estimates of the role of labor composition in aggregate American economic growth were provided not by Jorgenson and Griliches but rather by Edward Denison in his first book. ${ }^{5}$ Moreover, the labor composition adjustment does not vary much from a value of roughly 0.5 percent per year over a long span of history reaching back to the late nineteenth century. ${ }^{6}$

One of my few complaints about this paper is a familiar problem of semantics. The authors continue to label their composition adjustments for capital and labor as changes in "quality." Those of us who have labored in the vineyards of price and output measurement would prefer that this word be reserved for its traditional context of consumer welfare and economic growth. For example, one can refer to the superiority of a home with 3,000 square feet to one with 1,500 square feet, or of one with central air

4. The paper under discussion does not report separate growth rates of the capital stock and composition-adjusted capital services; only data for the latter concept are included in the paper's tables and figures. As shown in Gordon (1999a), the capital composition adjustment in the BLS postwar data based on the Jorgenson approach is always positive (that is, shortlived equipment grows faster than long-lived structures) and varies from 0.6 to 1.5 percentage points per year.

5. Denison (1962).

6. New estimates of both capital and labor composition adjustments for the U.S. economy back to 1870 are provided in Gordon (forthcoming). 
conditioning to one with no air conditioning, as a difference in quality. It is a misuse of the word to employ it to describe a shift in the composition of the capital stock from structures to trucks to computers. That shift is no more or less than a shift to shorter-lived equipment, which must have a higher marginal product to pay for its faster depreciation. And it is positively offensive, not to mention politically incorrect, to describe the 1970s shift in the composition of the labor force toward a greater percentage of females as a shift to lower quality. The preferable word, "composition," which I have used above, is neutral and describes the outcome of a particular weighting scheme, which may itself disguise some debatable issues. One of these is whether the lower average wage of female workers represents nothing more than a lower marginal product, or whether, as is likely, there is a substantial contribution from a history of discrimination and occupational crowding.

Another semantic issue, familiar to readers of Jorgenson over the past thirty-five years, is the emphasis on the unimportance of TFP growth and on how much input growth can explain, particularly when input growth is augmented by the compositional adjustments discussed above. ${ }^{7}$ Thus we read that "input growth is the source of nearly 80 percent of U.S. growth over the last forty years, and TFP has accounted for approximately onefifth." Yet this is quite misleading, because it calculates the percentage contribution of input growth to total output growth, rather than to growth in labor productivity.

Further, this semantic approach appears to minimize the role of technical change in the growth of labor productivity by including in the growth of capital input those "quality" (that is, compositional) changes from structures to trucks to computers that mainly reflect technical change. In fact, much new capital is purchased because technical change has made old capital obsolete, or because technical change has allowed whole new types of capital to be invented (airplanes, motor transport, electric motors, mainframe computers, personal computers). This paper represents an important clarification of Jorgenson's previous work by showing, for example in the paper's table 2, that much of the acceleration in capital input is due to an acceleration in purchases of computers and other high-technology equipment, which the text attributes to an acceleration in technical change.

7. This emphasis is equally evident in Jorgenson and Griliches (1967) and in the paper under discussion. 
Furthermore, the results of the paper show that, far from being unimportant, the deceleration and subsequent acceleration of TFP explain roughly half of the economy's growth slowdown after 1973 and its speedup after 1995. From table 2 we can extract the following growth rates of output per hour (average labor productivity, or ALP) and TFP:

ALP (percent per year)

TFP (percent per year)

\begin{tabular}{ccc}
$1959-73$ & $1973-95$ & $1995-99$ \\
\hline 2.95 & 1.42 & 2.58 \\
1.01 & 0.34 & 0.99
\end{tabular}

Thus the share of the pre-1995 slowdown in ALP contributed by TFP (as contrasted with a slowdown in inputs) is 44 percent, and the share of the post-1995 acceleration in ALP contributed by TFP is 56 percent.

This paper and that of Oliner and Sichel concur in ascribing a major role in the productivity acceleration to the apparent technological acceleration in the manufacture of computer hardware. The indirect evidence of this phenomenon is an acceleration of the annual rate of price decline in the hedonic price deflator for computer hardware and peripherals (in the national income accounts) from 15.8 percent over the period $1972-95$ to 32.0 percent during $1995-99 .{ }^{8}$ The U.S. national accounts develop the price index of computer hardware directly from a hedonic regression and compute the real growth rate of computer hardware by dividing nominal expenditure by the same price index. For this reason, at least part of the American economic miracle is the direct legacy of Griliches' role in introducing hedonic price deflators into the economic mainstream. ${ }^{9}$ By the same token, the failure to adopt hedonic price indexes for computers in most other industrial nations explains at least some part, perhaps half a percentage point per year, of the deceleration of inflation and the acceleration of output and productivity in the U.S. economy compared with these other economies in the late 1990s. However, hedonic price indexes do not distort the evident superiority of U.S. economic performance along the dimensions of lower unemployment and booming stock market valuations over the same period.

A particularly valuable contribution of this paper is its calculation of indexes of output, capital input, ALP, and TFP, under two alternative

8. Data provided by Christian Ehemann, Bureau of Economic Analysis.

9. Griliches (1961). 
assumptions about the price behavior of computer software and of telecommunications equipment. As the paper's table 5 shows, assumptions of much more rapid rates of price decline increase the role of IT capital in explaining the post-1995 acceleration in ALP but do not yield any increase in residual aggregate TFP growth. Indeed, the faster the assumed decline in prices for software and communications equipment, the slower is TFP growth in the aggregate economy, and the stronger is the conclusion that I reach below that there has been no acceleration in the productivity trend outside of durable goods manufacturing.

My major qualification of the results of both this paper and that of Oliner and Sichel involves the treatment of actual productivity growth as a sustainable trend. A substantial literature validates the proposition that when output grows faster than its sustainable trend, so does productivity. There are many reasons to believe that U.S. output grew from 1995 to 1999 at an unsustainably rapid rate. If that is true, it also must be true that some of the actual growth in productivity explained by Jorgenson and Stiroh and by Oliner and Sichel is a temporary, cyclical phenomenon. My analysis of cyclical effects is complementary to theirs, since they remain agnostic about the cyclical component. My analysis simply represents an updating of old research applied to a new situation rather than a new invention to explain away part of the evident acceleration of actual productivity. ${ }^{10} \mathrm{~A}$ second part of my analysis goes beyond the cyclical effect to decompose the productivity acceleration by sector: productivity growth in the durable manufacturing sector (roughly 12 percent of nonfarm private GDP) has been incredibly dynamic, because of computer manufacture and much else, in industries ranging from telecommunications to steel to automobiles. But when productivity in the durable manufacturing sector is deducted from the rest of the private business economy, much less of a productivity revival remains in the official statistics.

Why do we know that output grew faster than its sustainable trend in 1995-99? This growth surge was made possible in part by an unsustainable recourse to two "safety valves" (in Alan Greenspan's phrase): a decline in the unemployment rate from 5.6 percent to 4.2 percent, and an increase in the current account deficit from 1.5 percent to 3.7 percent of GDP. The most optimistic observers have boosted their estimates of poten- 
tial (trend) real GDP growth to 3.75 to 4.0 percent, yet in the second half of 1999 real GDP growth reached an annual rate of 6.4 percent, much faster than anyone's estimate of its potential. ${ }^{11}$ Despite uncertainty about the sustainable rate of real GDP growth and its corollary, the lowest sustainable rate of unemployment, a wide range of estimates on these issues still yields the conclusion that productivity growth in 1995-99 surged well past any sustainable trend growth rate.

My own more extensive cyclical analysis, based on quarterly BLS data for output and hours, decomposes growth in labor productivity $(y-h)$ into trend and cyclical components separately for the nonfarm private business (NFPB) sector and for that sector excluding durable manufacturing (nonfarm nondurables, or NFND). ${ }^{12}$ The idea that productivity varies procyclically dates back to Thor Hultgren as well as to Okun's law and was first interpreted by Oi, who described labor as a "quasi-fixed factor" that adjusts only partially during cyclical swings of output. ${ }^{13}$ In my econometric specification, the change in the growth of actual hours worked relative to the hours trend $\left(h-h^{*}\right)$ is explained by changes in its own lagged values and by changes in the growth of output relative to trend $\left(y-y^{*}\right)$. Hours growth lags behind output growth and eventually responds by roughly three-quarters of the output change. Thus growth in output per hour $(y-h)$ exhibits a temporary acceleration when hours are lagging behind output changes, and in addition increases by roughly one-quarter of any excess in output growth relative to trend.

The recent productivity acceleration is decomposed into cycle and trend by specifying a value for the hours growth trend $\left(h^{*}\right)$ and then conducting a grid search to find the output growth trend $\left(y^{*}\right)$ that optimizes the fit of the equation explaining the relation of $h-h^{*}$ to $y-y^{*} .{ }^{14}$ The results, displayed in table 1 below, allow us to assess the direct and spillover effects

11. The most optimistic current estimate of potential GDP growth, 4.0 percent per year, is that of Chase Securities. Other estimates, for example that of the Congressional Budget Office, are as low as 3.25 percent per year.

12. Gordon (2000b).

13. Hultgren (1960); Okun (1962); Oi (1962).

14. It is assumed that actual output and trend output were equal in 1954:1, 1963:3, 1972:2, 1978:2, 1987:3, and 1995:4. The task is to determine the optimal output trend after 1995:4. The regression equation is estimated for the period from 1954:1 to 1999:4, and growth in trend output is varied to minimize the root-mean-squared error over the period from 1996:1 to 1999:4. The hours trend growth rate of 1.56 percent per year is set at a rate consistent with a NAIRU in 1999:4 of 5.0 percent. 
Table 1. Decomposition of Growth in Output Per Hour, 1995:4-1999:4, into Contributions of Cyclical Effects and Structural Change in Trend Growth

Percent per year

\begin{tabular}{|c|c|c|c|}
\hline Item & $N F P B$ & $\begin{array}{c}\text { NFPB } \\
\text { excluding } \\
\text { computer hardware } \\
\text { manufacturing }\end{array}$ & $\begin{array}{c}\text { NFPB } \\
\text { excluding } \\
\text { durable } \\
\text { manufacturing }\end{array}$ \\
\hline 1. Actual growth & 2.82 & 2.42 & 2.05 \\
\hline 2. Contribution of cyclical effect & 0.54 & 0.55 & 0.62 \\
\hline $\begin{array}{l}\text { 3. Growth in trend } \\
\text { (line } 1 \text { minus line } 2 \text { ) }\end{array}$ & 2.28 & 1.87 & 1.43 \\
\hline 4. Trend, $1972: 2$ to $1995: 4$ & 1.47 & 1.25 & 1.19 \\
\hline $\begin{array}{l}\text { 5. Acceleration of trend } \\
\text { (line } 3 \text { minus line } 4 \text { ) }\end{array}$ & 0.81 & 0.62 & 0.24 \\
\hline $\begin{array}{l}\text { 6. Contribution of change in price } \\
\text { measurement }\end{array}$ & 0.14 & 0.14 & 0.14 \\
\hline $\begin{array}{l}\text { 7. Contribution of labor } \\
\text { composition effect }\end{array}$ & 0.05 & 0.05 & 0.05 \\
\hline $\begin{array}{l}\text { 8. Structural acceleration in labor } \\
\text { productivity (line } 5 \text { minus } \\
\text { lines } 6 \text { and } 7 \text { ) }\end{array}$ & 0.62 & 0.43 & 0.05 \\
\hline $\begin{array}{l}\text { 9. Contribution of capital } \\
\text { deepening }\end{array}$ & 0.33 & 0.33 & 0.33 \\
\hline $\begin{array}{l}\text { 10. Contribution of MFP growth in } \\
\text { computer and computer-related } \\
\text { semiconductor manufacturing }\end{array}$ & 0.29 & 0.19 & - \\
\hline $\begin{array}{l}\text { 11. Structural acceleration in MFP } \\
\text { (line } 7 \text { minus lines } 8 \text { through 10) }\end{array}$ & 0.00 & -0.09 & -0.28 \\
\hline
\end{tabular}

Sources: Gordon (2000b); lines 7, 9, and 10 are based on Oliner and Sichel (2000, tables 2 and 4).

of computers on output per hour and multifactor productivity growth during the period between the fourth quarter of 1995 (1995:4) and 1999:4. The first column refers to the aggregate economy, that is, the NFPB sector including computers. Of the actual 2.82 percent annual growth of output per hour, 0.54 percentage point is attributed to a cyclical effect and the remaining 2.28 percentage points to trend growth; the latter is 0.81 percentage point faster than the 1972-95 trend.

How can this acceleration be explained? A small part, shown in lines 6 and 7 of the table, is attributed to changes in price measurement methods and to a slight acceleration in the labor composition effect. ${ }^{15}$ The

15. The price measurement effect consists of two components. Whereas most changes in price measurement methods in the consumer price index have been backcast in the national accounts to 1978, one remaining change - the 1993-94 shift in medical care deflation from 
remaining 0.62 percentage point can be directly attributed to computers. The capital-deepening effect of faster growth in capital relative to labor in the aggregate economy accounts for 0.33 percentage point of the acceleration (all due to computers), and an acceleration of MFP in computer and computer-related semiconductor manufacturing accounts for all of the rest. ${ }^{16}$ Nothing is left for a structural acceleration in MFP outside of the computer-producing sector. This conclusion is surprisingly insensitive to alternative assumptions about the trend growth of hours, which in the results here takes the decline in unemployment from 5.6 percent in 1995:4 to 4.1 percent in 1999:4 and assigns 0.6 percentage point of the decline to a permanent effect and the remaining 0.9 percentage point to a temporary, cyclical effect. If the entire decline in unemployment is assumed to be cyclical, the cyclical productivity effect becomes 0.10 percentage point per year larger than in table 1 , whereas if the entire decline is assumed to be permanent, the cyclical productivity effect becomes 0.12 percentage point per year smaller.

The second column of table 1 presents a different way of assessing the role of computers. Here we subtract output and hours in computer manufacturing from the NFPB economy and find that the structural acceleration of labor productivity in line 8 is 0.43 percentage point, compared with 0.62 percentage point for the total NFPB economy. Line 11 indicates a small structural deceleration in MFP of 0.09 percentage point. ${ }^{17}$ From the analysis thus far we can conclude that capital deepening has created a genuine revival in growth in output per hour (ALP) in the noncomputer

the consumer price index to the slower-growing producer price index-creates a measurement discontinuity of 0.09 percent. The fact that other measurement changes were carried back to 1978 rather than 1972 creates a further discontinuity of 0.05 percent when the full 1972-95 period is compared with 1995-99. The acceleration in the labor composition effect is based on the official BLS estimates through 1997, linked to the estimates of Oliner and Sichel (2000) for 1997-99.

16. In the Oliner-Sichel decomposition on which line 9 is based, computers account for all of the acceleration in the capital-deepening effect, and the additional acceleration attributable to semiconductors and telecommunications is exactly canceled out by a deceleration of capital deepening for all other types of equipment and structures. (See Oliner and Sichel, 2000, table 2, lines 2 through 7.)

17. The main explanation of the difference between the first two columns for line 11 is that the first column subtracts out MFP growth in computers and computer-related semiconductors, whereas the second column subtracts out computers but not computer-related semiconductors. This inconsistency is imposed by the data available in the source (Oliner and Sichel, 2000). 
economy, but that spillover effects on MFP in the noncomputer economy are absent (the first column) or slightly negative (the second column).

However, this conclusion is far too optimistic regarding the effect of computers outside of durable manufacturing (that is, the NFND sector examined in the final column of table 1). Starting from a much lower actual growth rate of 2.05 percent, a slightly larger cyclical effect is subtracted, leaving an acceleration in trend in line 5 of only 0.24 percentage point. ${ }^{18}$ Almost all of this can be explained by price measurement and labor composition effects, leaving a structural acceleration in output per hour of only 0.05 percentage point, far less than is accounted for by capital deepening (line 9). As a result, line 11 shows that there has been a substantial structural deceleration in MFP in the NFND sector. This surprising finding can be interpreted either as a literal deceleration in MFP compared with the 1972-95 period or as suggesting that the acceleration of computer investment has had a negligible payoff, implying a near-zero rate of return for computer investment outside of durable manufacturing.

How could there be such a low payoff to computer investment in most of the economy where the vast majority of computers are located? ${ }^{19}$ In this sense the Solow paradox, that we see the computer age everywhere but in the productivity statistics, survives intact for most of the economy. ${ }^{20}$

Overall, this paper provides a rich new source of data on the role of IT in the post-1995 acceleration in productivity, and it applies the time-tested Jorgenson methodology to sorting out the roles of changes in input quan-

18. There is no cyclical effect in durable or nondurable manufacturing; this is the corollary of the absence of any increase in the capacity utilization rate in manufacturing and of the absence of any acceleration in hours growth in manufacturing between 1995 and 1999. Thus the cyclical effect occurs entirely outside of manufacturing, accounting for the higher cyclical effect when durables are stripped out in the third column.

19. McGuckin and Stiroh (1998, table 1) show that 88.5 percent of computers are used in eight of the thirty-four industries in their database for the U.S. private economy. Three industries-trade; finance, insurance, and real estate; and other services-use 76.6 percent of all computers, 11.9 percent are used in five computer-intensive industries within manufacturing, and only 11.5 percent are used in the remaining twenty-seven industries.

20. The 1999 version of my research on cyclical productivity effects (Gordon 1999a), as quoted in the paper under discussion, found no acceleration in the productivity trend outside of computer manufacturing. Extensive data revisions in the U.S. national accounts, released in October 1999, account for the slightly less pessimistic conclusion of my current research that there has been no acceleration in the productivity trend outside of durable manufacturing. Data revisions substantially increased the trend productivity acceleration in the noncomputer part of durable manufacturing, with nothing left over for the nondurable part of the economy. 
tity and composition in aggregate productivity behavior. My own research on cyclical effects does not alter any of the paper's decomposition of input growth into the relative contributions of IT capital, non-IT capital, labor hours, and labor composition. Instead my research suggests that some fraction of the paper's estimate of the post-1995 TFP acceleration is likely to be transitory rather than permanent.

Daniel E. Sichel: Productivity growth has been a frequent subject of Brookings Panels in the past, and this paper makes an important contribution to that line of work. The particular subject of this paper, the role of information technology in the recent productivity resurgence, has received considerable press attention recently and increasing interest in the research community. At a time in the not-so-distant past, many researchers saw a relatively small role for IT in growth because its share in the capital stock was quite small. This position contrasted sharply with the view in the popular press, perhaps best exemplified by the nearly annual proclamations in Business Week that the new economy had that year finally arrived.

Now a growing body of evidence is emerging that, in the second half of the 1990s, IT was an important factor in the economy's favorable performance. The growth-accounting calculations in Dale Jorgenson and Kevin Stiroh's paper are carefully done, and they bolster that body of evidence, telling the same broad story as that in work by Karl Whelan and by Stephen Oliner and me. ${ }^{1}$ Therefore I do not come with dramatic comments on the paper. Rather, I would like to compare this paper's answers with those of other researchers to the big questions wrapped up in these issues.

One of those questions is whether IT is the source of the economy's recent favorable performance. The first part of the paper uses the wellknown Jorgenson growth-accounting framework to examine that performance and to assess the role that investment in information technology has played in it. Tables 1 and 2 below summarize the paper's results in terms of labor productivity and compare them with results obtained by Oliner and Sichel and by Robert Gordon. As the first line of table 1 shows, Jorgenson and Stiroh's estimates yield about a 1-percentage-point acceleration in labor productivity in the second half of the 1990s. Of this 
Table 1. Alternative Estimates of the Sources of Acceleration in Labor Productivity in the Second Half of the 1990s

(percentage points per year) ${ }^{\mathrm{a}}$

\begin{tabular}{lcc}
\hline & $\begin{array}{c}\text { Jorgenson and } \\
\text { Stiroh }\end{array}$ & (this paper) \\
\hline Labor productivity & 1.0 & Oliner and Sichel (2000) \\
Capital deepening & 0.5 & 1.0 \\
Information technology & $0.3^{\mathrm{b}}$ & 0.5 \\
Other & 0.2 & 0.5 \\
Labor quality & -0.1 & 0.0 \\
Multifactor productivity & 0.6 & -0.1 \\
Production of IT & 0.2 & 0.7 \\
Other & 0.4 & 0.3 \\
\hline
\end{tabular}

Source: Jorgenson and Stiroh (this volume); Oliner and Sichel (2000).

a. Figures are contributions to the annual increase in labor productivity between 1990-95 and either 1995-98 (Jorgenson and Stiroh) or 1995-99 (Oliner and Sichel). Numbers may not sum to totals because of rounding.

b. Derived from tables 3,4 , and B3 of the paper.

c. In calculating the contribution from the production of IT, Jorgenson and Stiroh include computer hardware, software, and communications equipment, whereas Oliner and Sichel focus on the production of computers and computer-related semiconductors.

acceleration, capital deepening accounted for 0.5 percentage point, and IT accounted for a considerable portion of this pickup in capital deepening. Multifactor productivity (MFP) accounted for the remainder of the acceleration.

Oliner and I have just completed a paper that also used a neoclassical framework to address this issue, and we obtained numbers that tell a broadly similar story, as can be seen by comparing the columns in table 1 .

Table 2. Gordon's Estimates of the Sources of Acceleration in Labor Productivity ${ }^{\mathrm{a}}$ $\underline{\text { (percentage points per year) }}$

Contribution to

productivity

increase

\begin{tabular}{ll}
\hline Actual acceleration in labor productivity, 1972-95 to 1995-99 & 1.4 \\
Trend acceleration (including CPI adjustment) & 0.7 \\
Contribution from: & \\
$\quad$ Capital deepening & 0.3 \\
Labor quality improvement & 0.1 \\
Multifactor productivity & 0.3 \\
$\quad$ Production of IT & 0.3 \\
$\quad$ Other sources & 0.0 \\
\hline
\end{tabular}

Source: Gordon (2000).

a. Figures are based on Robert Gordon's tables dated April 25, 2000, which incorporate the comprehensive October 1999 revision of the national income and product accounts.

b. Calculated using the same definition as in Oliner and Sichel (2000). 
Because there are some differences in our measurement frameworks, it is reassuring that the basic story told is similar. One key place where a difference does emerge, however, is in our estimates of the contribution of IT to growth. As the table shows, we found a larger contribution of hightechnology capital to the acceleration in labor productivity than did Jorgenson and Stiroh.

Because the contribution of IT is central to this debate, this difference warrants further exploration. Aside from the obvious difference that our results include an estimate for the contribution of IT to productivity growth in 1999—a very big year-one other difference in methodology is important. Jorgenson and Stiroh use different measurement conventions than does the Bureau of Labor Statistics or do we. In particular, Jorgenson and Stiroh employ broader concepts of output and input. They include imputed service flows from owner-occupied housing and consumer durables (and the associated inputs), which are excluded from the framework used in the official published productivity data. ${ }^{2}$ With these additions to output, the income share attributed to business IT falls, all else equal. Business-owned IT is simply a smaller part of the economy that they choose to measure. There is no right or wrong position on this issue; however, it is important to understand what output concept is being used when evaluating a particular set of results.

Jorgenson and Stiroh also emphasize the contribution of the production of IT capital to MFP growth. As they put it, Moore's law-the doubling of the capacity of new microchips every eighteen months or so-boosts labor productivity growth in two ways. First, technological advances in semiconductors boost MFP growth in that sector, and second, the faster and lower-priced computers produced with these semiconductors boost labor productivity elsewhere in the economy through capital deepening, as firms put this equipment to use. The last three lines of the top panel of table 1 show a split of MFP growth into the portion arising from production of IT capital and the portion coming from other sources. The two sets of estimates are very close. Again, it is reassuring that different researchers have generated broadly similar estimates of the contribution of the production of IT capital to growth in MFP.

2. Because the stock of consumer durables accelerated in the late 1990s, their measure of the contribution of "other" capital deepening (the fourth line in table 1) to the acceleration in productivity is larger than ours, which includes business capital only. 
Gordon's work has also made an important contribution in this area, and his recent results are summarized in table $2 .{ }^{3}$ The primary difference between Gordon's paper and the others is that he focuses on a decomposition of trend productivity, whereas the other papers focus on actual productivity. Gordon's focus on trends leads to some differences in interpretation. However, as the decomposition in the table shows, Gordon's numbers for the contribution of IT to growth line up closely with those in the other papers. In fact, his numbers for capital deepening-which includes the contribution from the use of IT-and for the boost to MFP growth from the production of computers are taken from our paper. Because Gordon considers a different time period, his numbers do not exactly match those in the upper panel, but his underlying story for the contribution of IT to growth is, by construction, the same as in our paper.

Where does this leave us on the question of whether IT is driving the economy's recent performance? Jorgenson and Stiroh clearly answer that it is, reflecting both the production and the use of computers and other high-technology capital. Oliner and I found a somewhat larger effect, reflecting differences in measurement methodology, and Whelan has found an even larger contribution of computers. ${ }^{4}$ Although Gordon has emphasized the production of computers and has focused on growth in trend rather than actual productivity, his numbers on the contribution of IT to the resurgence in actual labor productivity tell the same story as the other papers. Thus, on this question, I judge that a consensus largely has emerged: IT was a key driver of the acceleration in actual labor productivity in the late 1990s.

Is the recent productivity resurgence permanent or temporary? Jorgenson and Stiroh address this issue by evaluating a long-run forecast from the Congressional Budget Office. As they report, the CBO projects growth of output per hour in the nonfarm business sector of 2.3 percent per year during 1999-2010. In light of their estimates of the sources of growth, Jorgenson and Stiroh propose a few downward adjustments to the CBO numbers that imply a reduction in the $\mathrm{CBO}$ projection for productivity growth

3. Gordon (1999b) first developed this decomposition prior to the October 1999 comprehensive revision of the national income and product accounts. Before that revision, the data showed less of an acceleration in labor productivity, and therefore, according to Gordon's estimates, the growth contribution from the production of computers fully accounted for the pickup in trend productivity.

4. Whelan (2000). 
to 2.15 percent per year. Nonetheless, they find that the $\mathrm{CBO}$ projection is broadly consistent with their own analysis of recent trends.

Jorgenson and Stiroh do, however, tend to highlight potential downside risks to the growth projection. In particular, exceptionally rapid declines in prices of computers and semiconductors in the past few years have boosted productivity growth through the direct MFP channel and by spurring additional capital deepening. As the authors point out, if the recent pace of efficiency gains in semiconductor production reflects transitory factors, then the contribution of this important source of productivity growth would drop back in coming years. More generally, the authors note that "caution is warranted until productivity patterns have been observed for a longer time period." Such caution seems reasonable enough, particularly when forecasting ten years ahead. As for the big question on the table, note that Jorgenson and Stiroh's projection of trend productivity growth of 2.15 percent per year is somewhat below the average pace of about $2 \frac{1}{2}$ percent that has prevailed since 1995 , and well below the nearly 3 percent average pace of 1998 and 1999. Thus this paper's analysis suggests that some, but certainly not all, of the recent pickup in labor productivity growth is permanent.

Jorgenson and Stiroh's analysis of the economy's speed limit provides critical insights into the factors that will affect long-run growth. Perhaps more important, it highlights the risks and uncertainties associated with long-term projections. The authors are cautious and tend to emphasize the downside risks, but there also are upside risks. "New economy" stories related to the Internet and the convergence of computer and communications technologies raise the possibility of a continued boost to growth for some time to come. Also, there are upside risks on the measurement side. The authors' results-along with those in the other papers-are based on a product-side measure of output, which reflects spending on goods and services. Alternatively, output could be measured from the income side as the sum of payments to capital and labor. Although the growth rates of the two measures differed only slightly on average through the mid-1990s, a sizable gap has emerged in recent years, with the income-side measure of real output growing about $1 / 2$ percentage point faster (at an annual average rate) since 1995. It is unclear whether the product-side or the income-side estimate of real output will ultimately prove more accurate; however, the income-side data raise the tantalizing 
possibility that the growth acceleration seen in recent years is even larger than that indicated by the typically used product-side measure of real output.

Finally, any assessment of the economy's long-run speed limit requires a decomposition of recent growth into trend and cycle. Making such a split is particularly challenging at the present time, when the economy remains in the midst of an economic expansion that has not followed usual cyclical norms, with productivity accelerating in the mature phase of the expansion. It may well be that we will not know how much of the recent favorable performance is permanent and how much is cyclical until after the next recession. In any case, I judge that a consensus has not emerged on the question of how much of the productivity resurgence is permanent.

Two other pieces of analysis in the paper also warrant comment. First, the detailed industry decomposition of productivity in the paper is well done and adds to the work done by others in that area. Unfortunately, however, the data only extend to 1996 and so are of limited use for answering questions about the source of the productivity resurgence in the latter part of the 1990s. Second, the authors raise legitimate concerns that prices of software and communications equipment in the national accounts might be mismeasured. In particular, they present serious arguments that these prices might not fall rapidly enough in the national accounts. The counterfactual cases they present very succinctly highlight some potential implications of such possible mismeasurement.

Finally, to come back to where I started, I liked the paper very much; the authors are to be commended for their excellent work.

General discussion: Panel discussion focused on the role of IT in increasing productivity and on the sustainability of recent rapid productivity growth. Dale Jorgenson observed that the doubling time for the number of transistors that can be placed on a microchip has fallen since about 1995. Therefore Moore's law is an important source of the growth acceleration that has taken place, and the current rapid rate of improvement is likely to continue. However, Olivier Blanchard wondered how much weight one should place on the law as the explanation of the computer industry's contribution to productivity growth, noting that there have been rapid declines in the prices of computer hardware of all types, not just of microchips. Robert Gordon pointed to the dramatic growth in size and the decline in 
price of both hard- and removable-disk drives since the early 1980s as examples of such non-chip-driven improvements. However, he suggested that something corresponding to Moore's law could be taken to apply to basic high-technology products other than microchips. Gordon took no position on whether the IT component of the growth increase was transitory, saying economists had no way of judging whether effects like those of Moore's law will continue at recent rates or, if so, for how long.

Jack Triplett reported his own finding that most of the productivity growth had occurred in semiconductors more broadly, with computer microchips as one important example. The significance of the finding is that technological change in semiconductors has an impact throughout the economy, rather than just in the narrow computer sector. Triplett noted that, in the authors' model, investments in IT simply raise the capital-labor ratio, pushing up labor productivity and growth but not total factor productivity. He agreed with that view. However, if IT has special characteristics that make it possible to do things in new ways, as the "new economy" view holds, then the paper's measure of capital deepening may not adequately capture these effects. William Brainard noted that IT undoubtedly had played a major role in the profound changes in the distribution system we have observed, and that some have suggested that business-tobusiness trading is going to replace a significant fraction of the traditional trade sector in the future. Jorgenson agreed that some long-standing participants in the trade sector, like Wal-Mart, had adjusted to and benefited from IT, but he noted that these effects could be seen as the benefits of capital deepening. Gordon saw business-to-business trading as part of a continuum of progress that has made the distribution system more efficient, rather than as a one-time level change; many computer-related productive innovations occurred before the 1990s. Triplett noted that the authors had aggregated across service industries in which IT played quite different roles than it did in their services aggregate, and that there are many puzzling negative productivity numbers, particularly for services industries that are intensive users of computers.

Jason Cummins observed that the "new economy" explanation of the recent rapid productivity growth is hard to support or contradict, since it appeals to a kind of capital that the authors may not have adequately measured. However, he noted that, in the paper's table $8, R \& D$ intensity does seem to be correlated with rapid productivity growth across industries, consistent with the new economy view of the sources of recent growth. 
Gordon, on the other hand, reported that when he decomposed the sources of acceleration in labor productivity, he found that almost all of it occurred in durable goods manufacturing. This finding weakened the new economy argument, according to which IT had raised productivity in the rest of the economy.

William Nordhaus noted that the shortening of the microchip cycle should be associated with more rapid obsolescence, making short-lived capital goods a growing fraction of investment. Such a shift of investment to shorter-lived assets with the same net rate of return will increase gross domestic product relative to net national product. This would make increases in gross output productivity a misleading indicator of welfare improvements, and it highlights the desirability of paying more attention to net output measures. Jorgenson responded that a shorter production cycle did not necessarily imply that products were less durable. Daniel Sichel reported that previous work of his with Stephen Oliner had explored net output specifications. Based on this work, he speculated that the contribution from IT to the growth rate of productivity would be smaller for net output than for gross output, but that the net output specification would still show a large pickup in the contribution of IT to productivity growth in the second half of the 1990s.

Gordon and Jorgenson agreed that the data probably understated recent growth in labor productivity. Jorgenson believed that moderate to large declines in IT prices had occurred, and he cited as an example the decline in communications equipment prices. He believed that the future would bring fast productivity growth, concentrated in IT and induced capital formation. Therefore the $\mathrm{CBO}$ and other agencies that rely on productivity projections are probably underestimating the future trend growth rate. Sichel speculated that a significant portion of the pickup in IT's contribution will prove permanent, but he emphasized the large uncertainties here. Because of these uncertainties, his research with Oliner had not provided a precise breakdown between permanent and cyclical components of the productivity surge. Gordon remarked that only a few years ago the consensus was that potential GDP was growing at a $2 \frac{1}{4}$ percent annual rate. Now the debate is whether that rate is $3 \frac{1}{2}$ or $3 \frac{3}{4}$ percent, and actual growth in the last three years has been over 4 percent. His estimates suggested that about half a percentage point of the recent growth was cyclical, which still left room for a significant upward revision of the potential growth rate. 


\section{References}

Baily, Martin Neil, and Robert J. Gordon. 1988. "The Productivity Slowdown, Measurement Issues, and the Explosion of Computer Power." BPEA, 2:1988, $347-420$.

Blinder, Alan S. 1997. "The Speed Limit: Fact and Fancy in the Growth Debate." The American Prospect 34(September-October): 57-62.

Brynjolfsson, Erik, and Chris F. Kemerer. 1996. "Network Externalities in Microcomputer Software: An Econometric Analysis of the Spreadsheet Market." Management Science 42(12): 1627-47.

Brynjolfsson, Erik, and Shinkyu Yang. 1996. "Information Technology and Productivity: A Review of the Literature." Advances in Computing 43(February): 179-214.

Bureau of Economic Analysis. 1998a. Fixed Reproducible Tangible Wealth in the United States, 1925-96. NCN-0136 (CD-ROM; May).

-_-_- 1998b. "Fixed Reproducible Tangible Wealth in the United States: Revised Estimates for 1995-97 and Summary Estimates for 1925-97." Survey of Current Business 78(9): 36-46.

_- 1998c. "Investment Estimates of Fixed Reproducible Tangible Wealth, 1925-1997."

Bureau of Labor Statistics. 1983. Trends in Multifactor Productivity, 1948-1981. Bulletin 2178. Government Printing Office (September).

—. 1997. BLS Handbook of Methods. Government Printing Office.

_. 1999. "Multifactor Productivity Trends." USDL 99-36 (February 11).

- 2000 . "Productivity and Costs: Preliminary Fourth Quarter and Annual Averages, 1999." USDL 00-37 (February 8).

Christensen, Laurits R., and Dale W. Jorgenson. 1973. "Measuring Economic Performance in the Private Sector." In The Measurement of Economic and Social Performance, edited by Milton Moss. New York: National Bureau of Economic Research.

Cole, Roseanne, and others. 1986. "Quality-Adjusted Price Indexes for Computer Processors and Selected Peripheral Equipment." Survey of Current Business 66(1): 41-50.

Congressional Budget Office. 1995. "CBO's Method for Estimating Potential Output." CBO Memorandum (October).

___ 1997. "An Economic Model for Long-Run Budget Simulations." CBO Memorandum (July).

- 1999a. The Economic and Budget Outlook: Fiscal Years 2000-2009. Government Printing Office (January). (July). 
2000. The Budget and Economic Outlook: Fiscal Years 2001-2010. Government Printing Office (January).

Corrado, Carol, and Lawrence Slifman. 1999. "Decomposition of Productivity and Unit Costs." American Economic Review, Papers and Proceedings 89(2): 328-32.

Council of Economic Advisers. 2000. Economic Report of the President 2000. Government Printing Office.

Dean, Edwin R. 1999. "The Accuracy of the BLS Productivity Measures." Monthly Labor Review 122(2): 24-34.

Denison, Edward F. 1962. "The Sources of Economic Growth in the United States and the Alternatives Before Us." Supplementary paper 13. New York: Committee for Economic Development.

Diewert, W. E. 1980. "Aggregation Problems in the Measurement of Capital." In The Measurement of Capital, edited by Dan Usher. University of Chicago Press.

Domar, Evsey. 1961. "On the Measurement of Technological Change." Economic Journal 71(December): 709-29.

Federal Reserve Board. 1995. "Balance Sheets for the U.S. Economy, 1945-94." Release C.9 (June).

—. 1997. "Flow of Funds Accounts of the United States." Release Z.1.

Fisher, Franklin M. 1992. Aggregation: Aggregate Production Functions and Related Topics. New York: Harvester Wheatsheaf.

Flamm, Kenneth. 1993. "Measurement of DRAM Prices: Technology and Market Structure." In Price Measurements and Their Uses, edited by Murray F. Foss, Marilyn E. Manser, and Allan H. Young. University of Chicago Press.

Fraumeni, Barbara. 1997. "The Measurement of Depreciation in the U.S. National Income and Product Accounts." Survey of Current Business 77(7): 7-23.

Gandal, Neil. 1994. "Hedonic Price Indexes for Spreadsheets and an Empirical Test for Network Externalities." RAND Journal of Economics 25(1): 160-70.

General Accounting Office. 1995. "The Deficit and the Economy: An Update of Long-Term Simulations.” GAO/AIMD/OCE-95-119 (April).

— 1996. "Budget Issues: Deficit Reduction and the Long Term." Statement of Paul L. Posner before the House Committee on the Budget. GAO/T-AIMD96-66.

Gordon, Robert J. 1979. “The 'End-of-Expansion' Phenomenon in Short-Run Productivity Behavior." BPEA 2:1979, 447-61.

- 1990. The Measurement of Durable Goods Prices. University of Chicago Press.

. 1993. "The Jobless Recovery: Does It Signal a New Era of ProductivityLed Growth?” BPEA, 1:1993, 271-316.

_. 1999a. "U.S. Economic Growth Since 1870: One Big Wave?" American Economic Review, Papers and Proceedings 89(2): 123-28. 
1999b. “Has the 'New Economy' Rendered the Productivity Slowdown Obsolete?" Unpublished paper. Northwestern University (June 14).

___ 2000a. "Does the 'New Economy' Measure Up to the Great Inventions of the Past?" Journal of Economic Perspectives (forthcoming).

_. 2000b. "Has the 'New Economy' Rendered the Productivity Slowdown Obsolete?" Unpublished paper. Northwestern University.

- Forthcoming. "Interpreting the 'One Big Wave' in U.S. Long-Term Productivity Growth.” In Productivity, Technology, and Economic Growth, edited by Bart van Ark, Simon Kuipers, and Gerard Kuper. Kluwer.

Greenwood, Jeremy, Zvi Hercowitz, and Per Krusell. 1997. "Long-Run Implications of Investment-Specific Technological Change." American Economic Review 87(3): 342-62.

Griliches, Zvi. 1961. "Hedonic Price Indexes for Automobiles: An Econometric Analysis of Quality Change." In The Price Statistics of the Federal Government, General Series 73. New York: National Bureau of Economic Research.

__ 1992. “The Search for R\&D Spillovers.” Scandinavian Journal of Economics 94(Supplement): S29-S47.

—. 1994. "Productivity, R\&D, and the Data Constraint." American Economic Review 84(1): 1-23.

Grimm, Bruce T. 1997. "Quality Adjusted Price Indexes for Digital Telephone Switches.” Unpublished memorandum. Bureau of Economic Analysis (May 20).

Gullickson, William, and Michael J. Harper. 1999. "Possible Measurement Bias in Aggregate Productivity Growth.” Monthly Labor Review 122(2): 47-67.

Haimowitz, Joseph H. 1998. "Has the Surge in Computer Spending Fundamentally Changed the Economy?" Economic Review, Federal Reserve Bank of Kansas City 83(2): 27-42.

Hercowitz, Zvi. 1998. “The 'Embodiment' Controversy: A Review Essay.” Journal of Monetary Economics 41(1): 217-24.

Ho, Mun Sing, and Dale W. Jorgenson. 1999. "The Quality of the U.S. Workforce, 1948-95." Unpublished manuscript. Harvard University.

Ho, Mun Sing, Dale W. Jorgenson, and Kevin J. Stiroh. 1999. "U.S. High-Tech Investment and the Pervasive Slowdown in the Growth of Capital Services." Unpublished manuscript. Harvard University.

Hulten, Charles R. 2000. “Total Factor Productivity: A Short Biography.” Working Paper 7471. Cambridge, Mass.: National Bureau of Economic Research (January).

Hultgren, Thor. 1960. "Changes in Labor Cost During Cycles in Production and Business.” Occasional Paper 74. New York: National Bureau of Economic Research.

Jorgenson, Dale W. 1966. "The Embodiment Hypothesis.” Journal of Political Economy 74(1): 1-17. 
1990. "Productivity and Economic Growth." In Fifty Years of Economic Measurement, edited by Ernst Berndt and Jack Triplett. University of Chicago Press. $24-42$.

Jorgenson, Dale, Frank Gollop, and Barbara Fraumeni. 1987. Productivity and U.S. Economic Growth. Harvard University Press.

Jorgenson, Dale W., and Zvi Griliches. 1967. "The Explanation of Productivity Change." Review of Economic Studies 34(3): 249-83.

Jorgenson, Dale W., and Kevin J. Stiroh. 1995. "Computers and Growth.” Economics of Innovation and New Technology 3(3-4): 295-316.

-----. 1999. "Information Technology and Growth." American Economic Review, Papers and Proceedings 89(2): 109-15.

-_-_ 2000. "U.S. Economic Growth at the Industry Level." American Economic Review, Papers and Proceedings 90(2): 161-67.

Jorgenson, Dale W., and Kun-Young Yun. 1991. Tax Reform and the Cost of Capital. Oxford University Press.

Katz, Arnold J., and Shelby W. Herman. 1997. "Improved Estimates of Fixed Reproducible Tangible Wealth, 1929-95." Survey of Current Business 77(5): 69-92.

Katz, Lawrence F., and Alan B. Krueger. 1999. "The High-Pressure U.S. Labor Market of the 1990s." BPEA, 1:1999, 1-65.

Kiley, Michael T. 1999. "Computers and Growth with Costs of Adjustment: Will the Future Look Like the Past?" Finance and Economics Discussion Paper 1993-36. Federal Reserve Board (July).

Krugman, Paul. 1990. The Age of Diminished Expectations: U.S. Economic Policy in the 1990s. MIT Press.

-_-_. 1997. "How Fast Can the U.S. Economy Grow?" Harvard Business Review 75(July-August): 123-29.

Lum, Sherlene K. S., and Robert E. Yuskavage. 1997. "Gross Product by Industry, 1947-96." Survey of Current Business 77(11): 20-34.

McGuckin, Robert H., and Kevin J. Stiroh. 1998. "Computers Can Accelerate Productivity Growth." Issues in Science and Technology (Summer): 41-48.

- Forthcoming. "Do Computers Make Output Harder to Measure?" Journal of Technology Transfer.

Moulton, Brent R., Robert P. Parker, and Eugene P. Seskin. 1999. “A Preview of the 1999 Comprehensive Revision of the National Income and Product Accounts: Definitional and Classification Changes." Survey of Current Business 79(8): 7-19.

Office of Management and Budget. 1997. Analytical Perspectives, Budget of the United States Government, Fiscal Year 1998. Government Printing Office. 
2000. Analytical Perspectives, Budget of the United States Government, Fiscal Year 2001. Government Printing Office.

Oi, Walter Y. 1962. "Labor as a Quasi-Fixed Factor." Journal of Political Economy 70(6): 538-55.

Okun, Arthur M. 1962. "The Gap between Actual and Potential Output." Proceedings of the American Statistical Association. Reprinted in Problems of the Modern Economy, edited by Edmund S. Phelps. Norton, 1965.

Oliner, Stephen D. 1993. "Constant-Quality Price Change, Depreciation, and Retirement of Mainframe Computers." In Price Measurements and Their Uses, edited by Murray F. Foss, Marilyn E. Manser, and Allan H. Young. University of Chicago Press.

1994. "Measuring Stocks of Computer Peripheral Equipment: Theory and Application." Board of Governors of the Federal Reserve System (May).

Oliner, Stephen D., and Daniel E. Sichel. 1994. "Computers and Output Growth Revisited: How Big Is the Puzzle?” BPEA 2:1994, 273-334.

2000. "The Resurgence of Growth in the Late 1990s: Is Information Technology the Story?" Journal of Economic Perspectives (forthcoming).

Parker, Robert, and Bruce Grimm. 2000. "Software Prices and Real Output: Recent Developments at the Bureau of Economic Analysis." Paper presented at the NBER Program on Technological Change and Productivity Measurement. National Bureau of Economic Research, Cambridge, Mass., March 17.

Sichel, Daniel E. 1997. The Computer Revolution: An Economic Perspective. Brookings.

-_-_. 1999. "Computers and Aggregate Economic Growth.” Business Economics 34(2): 18-24.

Social Security Administration. 1992. "Economic Projections for OASDHI Cost and Income Estimates, 1992.” Actuarial Study No. 108, SSA Pub. No. 1111551 (December).

- 1996. 1996 Annual Report of the Board of Trustees of the Federal OldAge and Survivors Insurance and Disability Insurance Trust Funds. Government Printing Office.

Solow, Robert M. 1957. "Technical Change and the Aggregate Production Function." Review of Economics and Statistics 39(3): 312-20.

. 1960. "Investment and Technical Progress." In Mathematical Methods in the Social Sciences, 1959, edited by Kenneth J. Arrow, Samuel Karlin, and Patrick Suppes. Stanford University Press.

Stiroh, Kevin J. 1998a. “Computers, Productivity, and Input Substitution.” Economic Inquiry 36(2): 175-91.

-_-_-_. 1998b. "Long-Run Growth Projections and the Aggregate Production Function: A Survey of Models Used by the U.S. Government." Contemporary Economic Policy 16(4): 467-79. . 1999. "Is There a New Economy?" Challenge 42(4): 82-101. 
Tevlin, Stacey, and Karl Whelan. 2000. "Explaining the Investment Boom of the 1990s." Finance and Economics Discussion Series 2000-11. Federal Reserve Board (February).

Triplett, Jack E. 1986. “The Economic Interpretation of Hedonic Methods.” Survey of Current Business 66(1): 36-40.

- 1989. "Price and Technological Change in a Capital Good: A Survey of Research on Computers." In Technology and Capital Formation, edited by Dale W. Jorgenson and Ralph Landau. MIT Press.

- 1996. "High-Tech Industry Productivity and Hedonic Price Indices." In OECD Proceedings: Industry Productivity, International Comparison and Measurement Issues. OECD Workshop. Paris.

-----. 1999. "Economic Statistics, the New Economy and the Productivity Slowdown." Business Economics 34(2): 13-17.

Triplett, Jack, and Barry Bosworth. 2000. "Productivity in the Service Sector." Unpublished paper. Brookings (January 5).

U.S. Department of Commerce. 1999. The Emerging Digital Economy II (June).

Whelan, Karl. 2000. "Computers, Obsolescence, and Productivity." Finance and Economics Discussion Series 2000-6. Federal Reserve Board (January). 
